\title{
Characteristics and Development Report for the MC4169 Double- Layer Capacitor Assembly
}

\author{
Nancy H. Clark and Wes E. Baca \\ Storage Batteries Department \\ Sandia National Laboratories \\ Albuquerque, NM 87185-5800
}

\begin{abstract}
The MC4169 Double-Layer Capacitor Assembly was developed in response to a request from the $B 61$ Systems organization to provide interim power for the B61 Common JTA Development. The project has been successfully completed, and Lot 1 has been built by MMSC/GEND. Development testing showed that this assembly met all design requirements. This report describes the design configuration, environmental testing, and aging, reliability, and safety studies done to ensure that the design requirements were met.
\end{abstract}




\section{Contents}

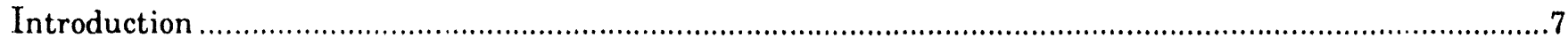

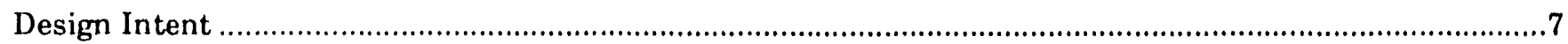

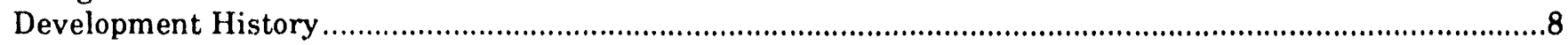

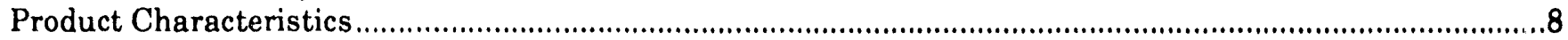

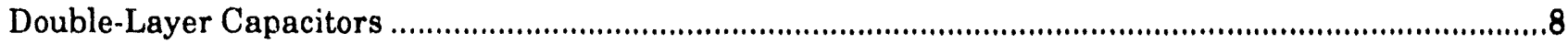

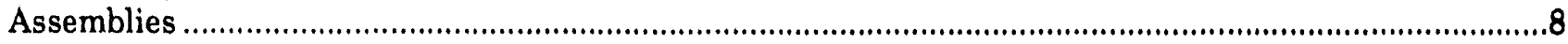

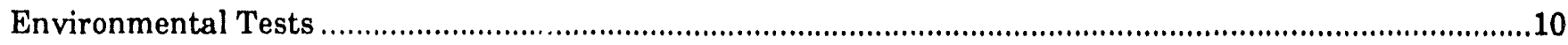

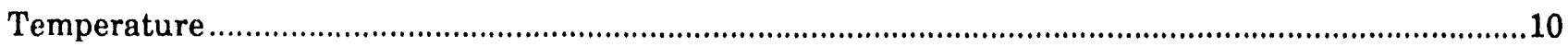

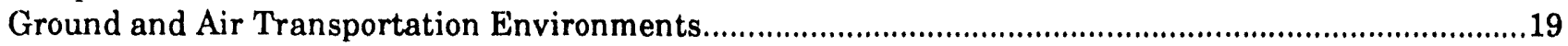

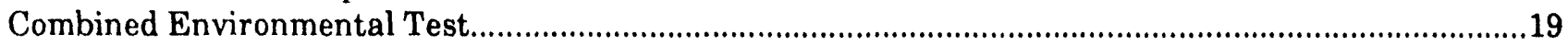

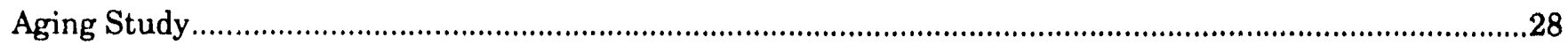

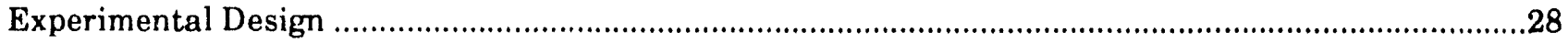

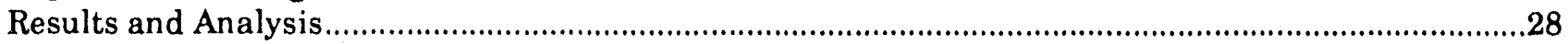

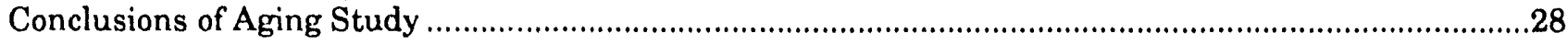

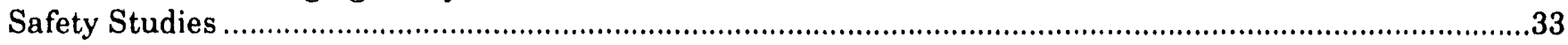

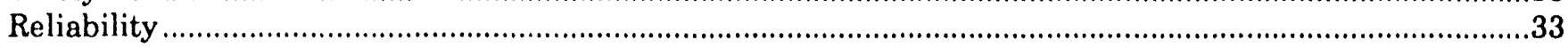

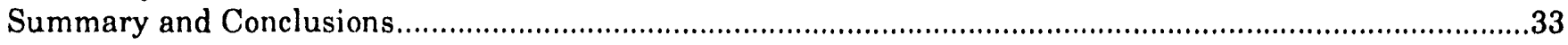

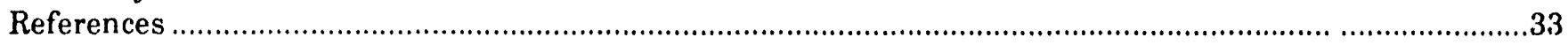

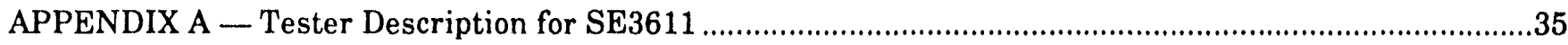

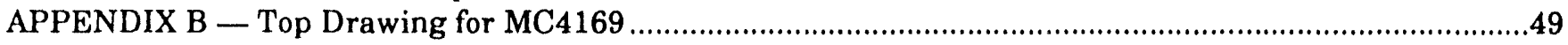

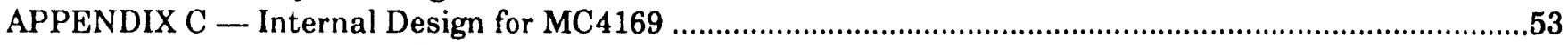

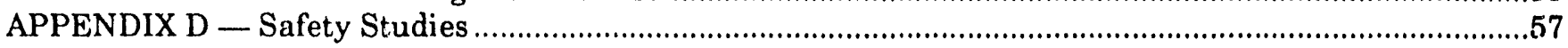

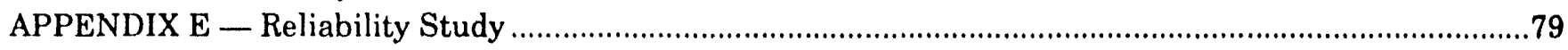

\section{Figures}

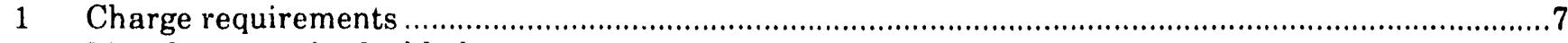

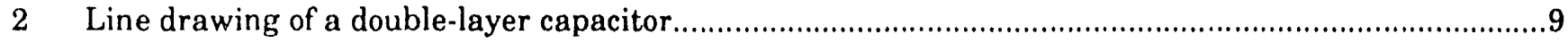

3 Voltage response of individual cells when charged in series .....................................................10

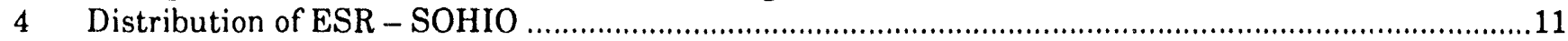

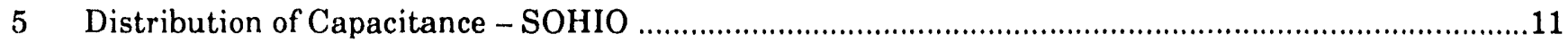

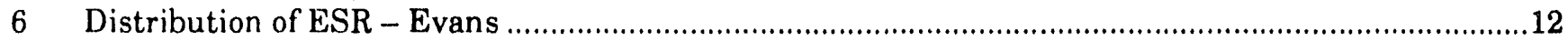

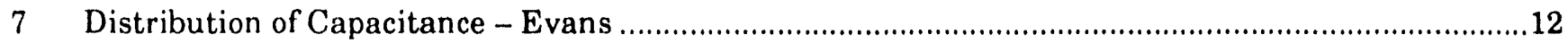

8 Comparison of ESR - Opened SOHIO, Closed Evans...................................................................13

9 Comparison of Capacitance - Opened SOHIO, Closed Evans ......................................................13

10 Comparison of Capacitance - SNL and Evans data showing 5\% error bars ..................................14

11 Comparison of ESR - SNL and Evans data showing 5\% error bars ..........................................14

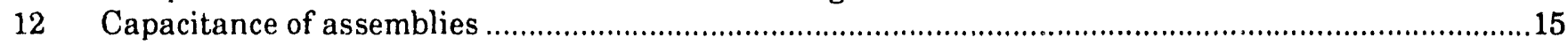

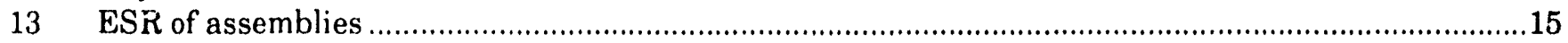

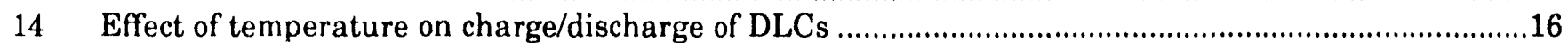

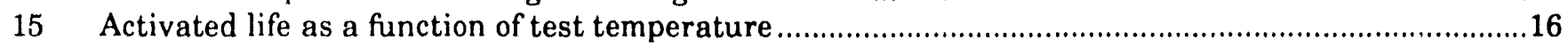

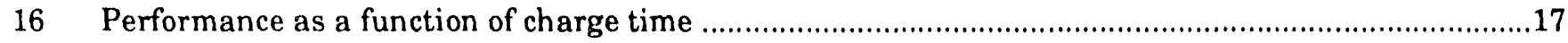

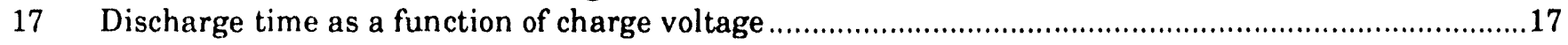

18 Activated life as a function of temperature and location of measurement ...................................18

19 Predicted vs. measured time for constant current discharge ............................................................18

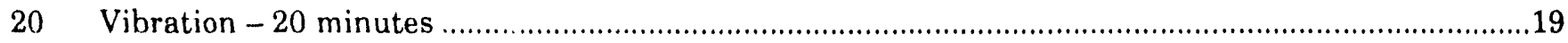

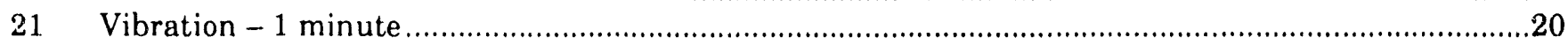




\section{Figures (continued)}

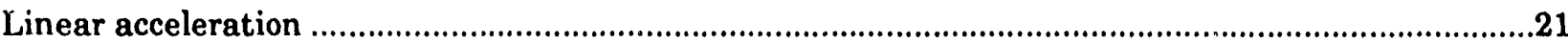

Activated life measured before and after environments at $-30^{\circ} \mathrm{C},+23^{\circ} \mathrm{C}$, and $+73^{\circ} \mathrm{C}$.

Activated life measured at $-30^{\circ} \mathrm{C},+23^{\circ} \mathrm{C}$, and $+73^{\circ} \mathrm{C}$ before and after environments -

tested 4 times.

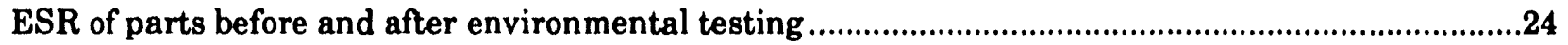

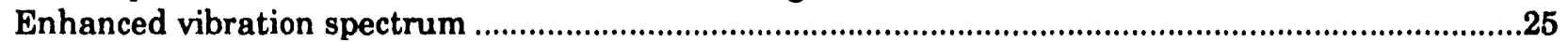

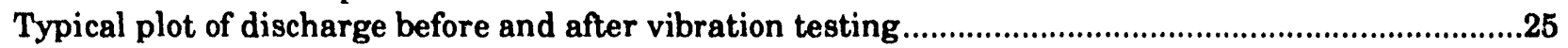

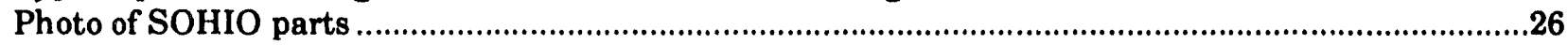

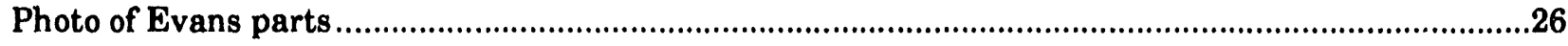

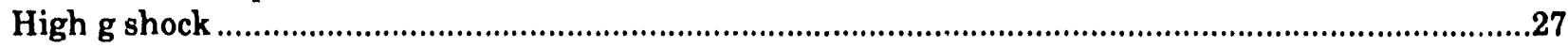

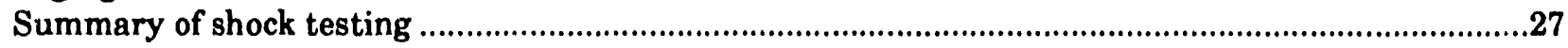

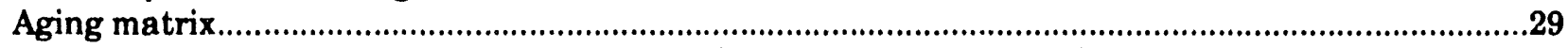

Percent change in Capacitance as a function of time, temperature, and voltage at $25^{\circ} \mathrm{C}$

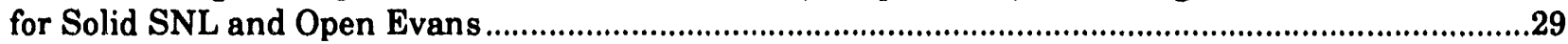

Percent change in Capacitance as a function of time, temperature, and voltage at $-30^{\circ} \mathrm{C}$.

Percent change in ESR as a function of time, temperature, and voltage at $25^{\circ} \mathrm{C}$ for Solid SNL and

Open Evans

Percent change in ESR as a function of time, temperature, and voltage at $-30^{\circ} \mathrm{C}$

30 Percent change in Activated Life as a function of time, temperature, and voltage .............................32

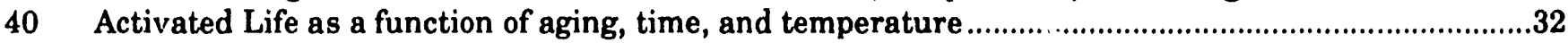

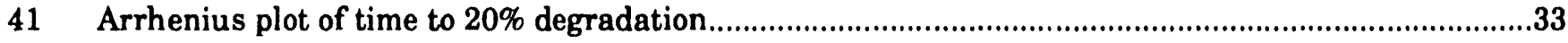




\section{Characteristics and Deveiopment Report for the MC4169 Double- Layer Capacitor Assembly}

\section{Introduction}

The MC4169 Double-Layer Capacitor $\Lambda$ ssembly was developed as a power source to supply keep-alive electrical energy to the MC4130 data recorder in the telemetry system for the B61 common JTA system. Without this keep-alive power, data acquired immediately after release of the system would not be stored in the nonvolatile memory. The system would be without power until the thermal battery achieved full power 0.85 second after release. The request to develop this assembly was formalized in a memo from $\mathrm{H}$. W. Schmitt (5100) to D. B. Hayes (2500, Acting) dated January $11,1988$.

The power sources used in the MC4169 are double-layer capacitors (DLCs)-specifically, three Evans model RE110474, 0.47-farad, 11-voit Capatteries, connected in series. (Capatteries are the Evans trade name for double-layer capacitors.) These DLCs are then encapsulated in urethane foam in a machined 7075 aluminum case.

DLCs were chosen for this application because of several desirable attributes:

- They are chargeable by aircraft power.

- They have none of the safety problems associated with lithium batteries, which are used in some systems.

- Unlike thermal batteries that can only discharge once, they can be charged and discharged many times.

- Large amounts of energy can be stored in a small volume.

Early development work is documer ted by Miller and Street [1] and Dvorack [2].

\section{Design Intent}

A summary of requirements critical to the design intent of the MC4169 is given below.

- Electrical Requirements

1. Charge in 1 minute using the voltage/ current profile shown in Figure 1.

2. Discharge through a 7-watt constant power load such that the discharge voltage is at least 17.5 volts after 0.85 second at temperatures ranging from $+85^{\circ} \mathrm{C}$ to $-30^{\circ} \mathrm{C}$.

- Environmental Requirements

1. Survive all the usual ground and air transportation environments of vibration, shock, and linear acceleration. (Specifics are given in testing section.)

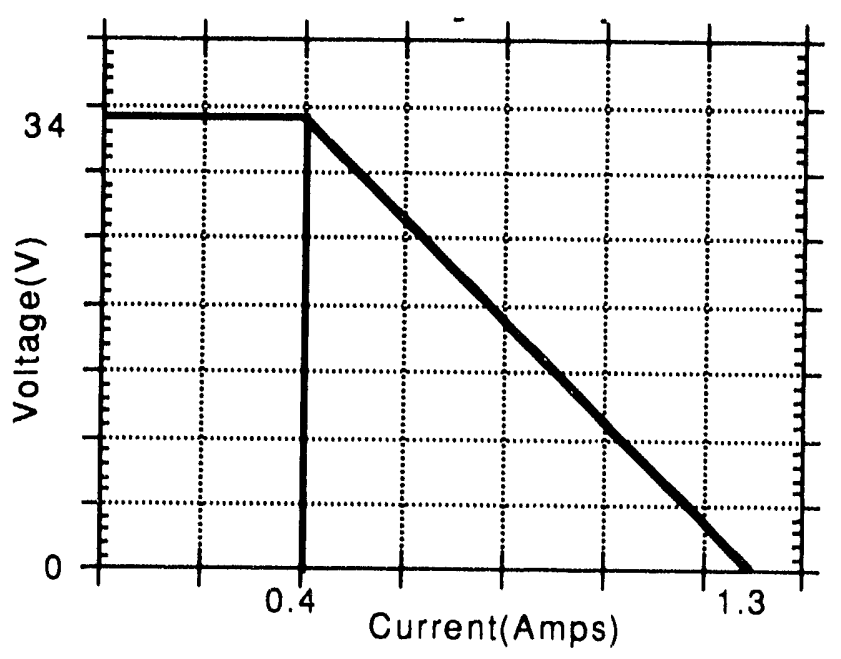

Figure 1. Charge requirements 
2. Perform in temperature range of $-30^{\circ} \mathrm{C}$ to $+85^{\circ} \mathrm{C}$.

3. Perform at pressures ranging from 0.57 to 15.8 psia.

- Lifetime - Storage at room temperature for 7 years.

- Reliability - 0.995 over life of the program.

\section{Development History}

In 1986 Sandia became interested in developing a long-life power supply that would provide power to volatile memory devices for short periods of time. Double-layer capacitors appeared to be ideal devices for this purpose, but the construction methods allowed the electrolytes to evaporate and thus limit their lifetimes. A program began in 1986 with SOHIO Company to develop a hermetically sealed device that was expected to have a 20-year life. That development was completed in 1988.

In 1988 , the request that resulted in the development of the MC4169 was received, and the hermetic devices developed as a result of the SOHiO contact were proposed. These were later replaced by Evans DLCs for environmental stability, as will be discussed later in this report.

\section{Product Characteristics}

Because this was the first time DLCs had been used in a weapons application, the performance characteristics of both the DLCs and assemblies were measured extensively. The electrical measurements for the DLCs and assemblies were:

1. Equivalent Series Resistance (ESR)

2. Capacitance-One time constant for charging capacitance

3. Activated Life-For Assembly, above $\mathbf{1 7 . 5}$ volts after being charged for 60 seconds to 34 volts and discharged through a 7-watt load. For DLC, above 5.83 volts after being charged for 60 seconds to 11.3 volts and discharged through a 7/3-watt load.

The ESR and Capacitance were measured using a tester built by W. E. Baca. This new tester, SE3611, allowed 16 parts to be tested at one time; it is described in detail in Appendix A. The Activated Life was measured using an existing thermal battery tester (PT3392), modified for this requirement.

These measurements were used to (1) assess variability in DLCs and assemblies, and (2) assess changes in performance during and after the development testing

\section{Double-Layer Capacitors}

Double-layer capacitors are energy storage devices that share characteristics of capacitors and batteries. They are similar to capacitors in that energy is stored in large surface areas and no chemical reactions take place. They are similar to batteries in that ions are charged particles and the performance of the device depends on mass transport of ions. Figure 2 shows a line drawing of a DLC. Detailed descriptions of the principles of DLCs are given in the two reports referenced above.

DLCs from SOHIO and Evans are similarly constructed internally, and were used in the development of the MC4169. Their differences are as follows:

- SOHIO used adhesive bonds between cells; Evans used vulcanization (a chemical reaction) to form the bond.

- SOHIO used hermetically sealed cans; Evans used a perm-selective valve on the cans.

In the conceptual design phase, SOHIO DLCs were used. However, in a series of vibration tests with prototype assemblies, most assemblies had a failure of at least one DLC. The failures were at the bond line. Details of these tests are in the section on Environmental Tests. At about that time Evans DLCs became available and, with vulcanized joints, it was expected that they would be more stable environmentally. The patented perm-selective valve was also expected to reduce the pressure in the cells because it allows $\mathrm{CO}_{2}$ to vent without the loss of electrolyte. (This was tested and will be reported in the aging study section of this report.) Evans DLCs replaced the SOHIO DLCs; to date, no vibrational test failures have occurred.

\section{Assemblies}

The original external mechanical design called for the MC4169 to be mounted with a bracket on the spin rocket of the $\mathrm{B} 61$. The part fit nicely on the B61-7; unfortunately, connections could not be made on the $B 61-3,4$, cable. A redesign was done such that the assembly mounts to the skin of the 
weapon. A concern about the strength of the aluminum led to the use of 7075 alloy in the new design. The redesign was tested and fit all B61 MODs. That design is shown in Appendix B. It is the 4111797 (MC4169) Double-Layer Capacitor Assembly. The internal design is shown in Appendix C. Basically it consists of a foam holder for the DLCs that is bonded to the bottom of the assembly. The bottom of the assembly has a connector to which the leads of the DLCs are soldered. The bottom is then screwed to the top of the assembly, which is tall enough to cover the series-connected DLC. As a final step, the DLCs are overpotted with urethane foam.
The original electrical design had three 11-volt, 0.5 -farad DLCs connected in series with 10.5 -volt Zener diodes for over-voltage protection for each DLC. A simplification of the design was to omit the Zeners. They were found to be necessary only if the DLCs were charged for days instead of the hours required for this application. This was tested in a series of charge/discharge cycles. Figure 3 shows the results of both the 30-minute and 5-hour cycles. The 30-minute cycle showed the worst voltage aifference between DLCs 1,2 , and 3 from 8 to 12 volts. Tests of the DLCs after these cycles showed no change in baseline performance. Thus, the fingl design is three DLCs connected in series.

Characterization of these parts is reported in the following section, "Environmental Tests."

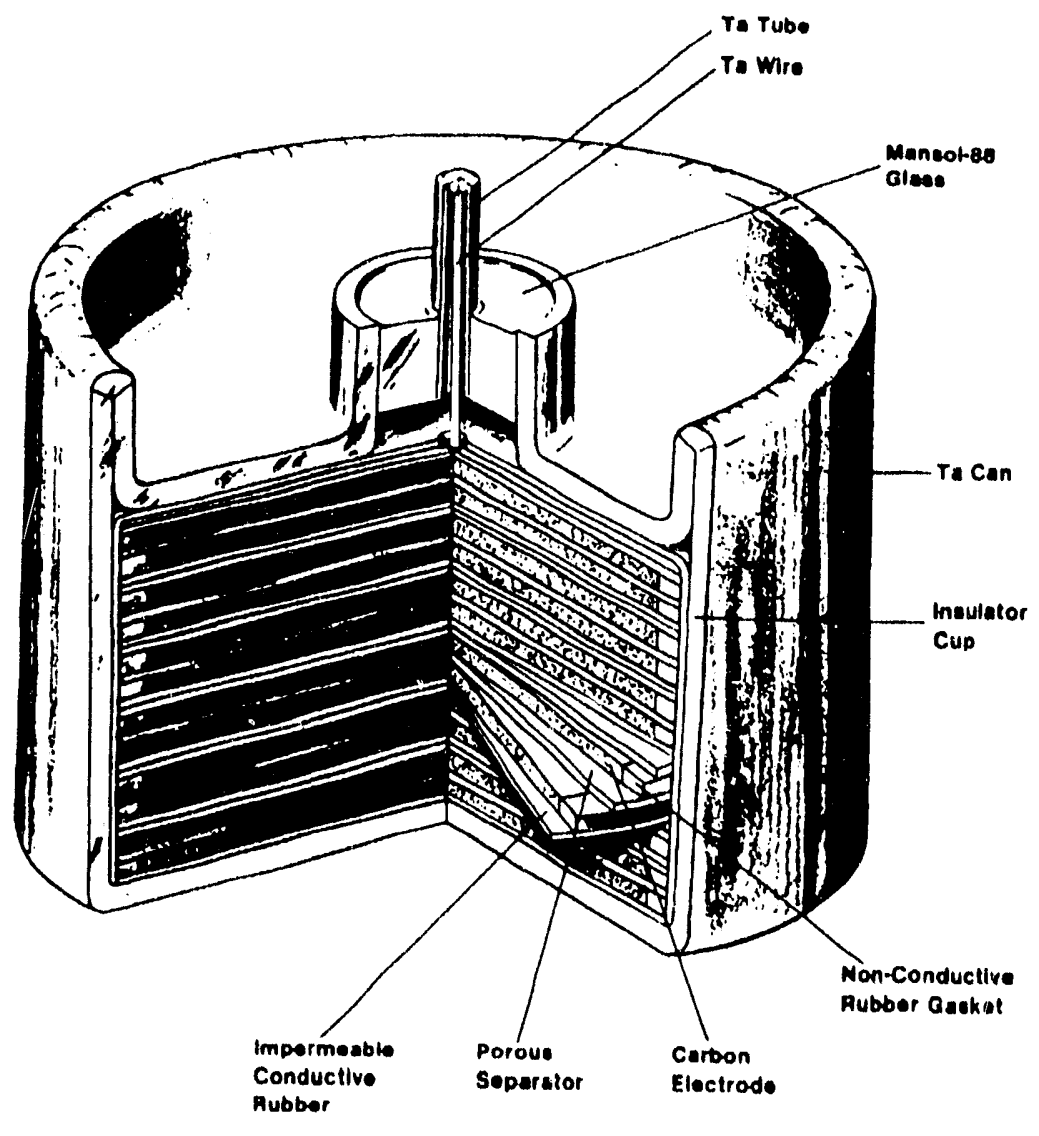

Figure 2. Line drawing of a double-layer capacitor 


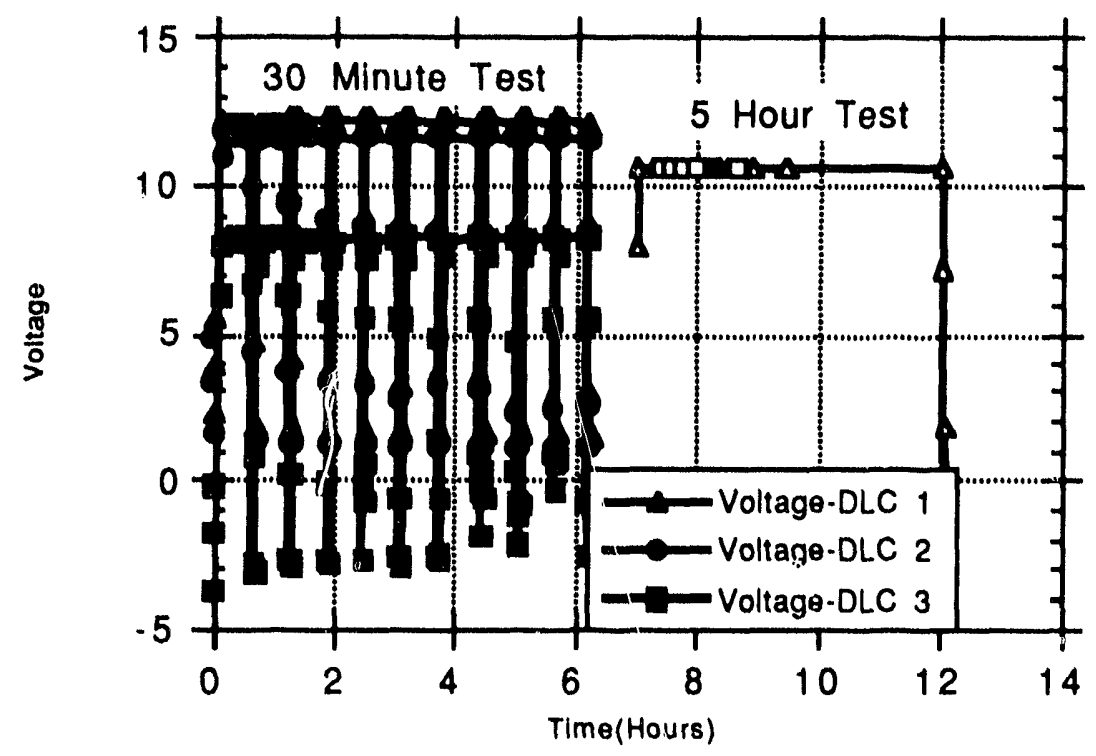

Figure 3. Voltage response of individual cells when charged in series

\section{Environmental Tests}

\section{Temperature}

The performance of assemblies and DLCs was measured at $-30^{\circ} \mathrm{C},+25^{\circ} \mathrm{C}$, and $+74^{\circ} \mathrm{C}$. All parts received by Sandia had been measured for ESR and capacitance by the manufacturer before shipment. These two measurements are typical of the measuremerits done by the capacitor industry. On many parts, these measurements were repeated by Sandia or GEND. Figures 4 and 5 show the distributions of ESR and capacitance measured by SOHIO; Figures 6 and 7 show those measured by Evans.

The values are clearly temperature dependent. Figures 8 and 9 compare data from Evans and SOHIO. Figures 10 and 11 (which are typical of other comparisons made) show that measurements made at two locations were generally within $5 \%$ of one another. Figures 12 and 13 show the variation measured in capacitance and ESR for assemblies.

For this application the measurement of interest is the charging and discharging characteristic. Figure 14 shows the charge and discharge of typical DLCs as a function of temperature using the requirements stated in the design intent. Figure 15 shows the discharge portion as a function of temperature. Measurements were also made to show performance as a function of charging time (Figure 16) and charging voltage (Figure 17). These results are shown only for $-30^{\circ} \mathrm{C}$, the region in which performance does not greatly exceed the specification. Performance shown as a function of temperature (Figure 15) shows that below $-30^{\circ} \mathrm{C}$, the design intent is not met.

Activated Life is a measurement that shows if a given assembly or DLC meets its design intent of delivering constant power for 0.85 second, and is a way of summarizing the charge/discharge data. Figure 18 shows variation in Activated Life for a number of assemblies and the variability of test data between GEND and SNL.

Not only does temperature affect performance in these parts, but at very low temperatures, predictions of performance using classical electrical models to predict performances yield very poor results. Figure 19 shows results based on current load. These figures show that even at room temperature not all of the predicted energy is available. It is explained in part by the fact that these devices depend on mass transport of ions instead of electrons and that at low temperature the conductivity of the electrolyte in combination with mass transport controls the performance. 


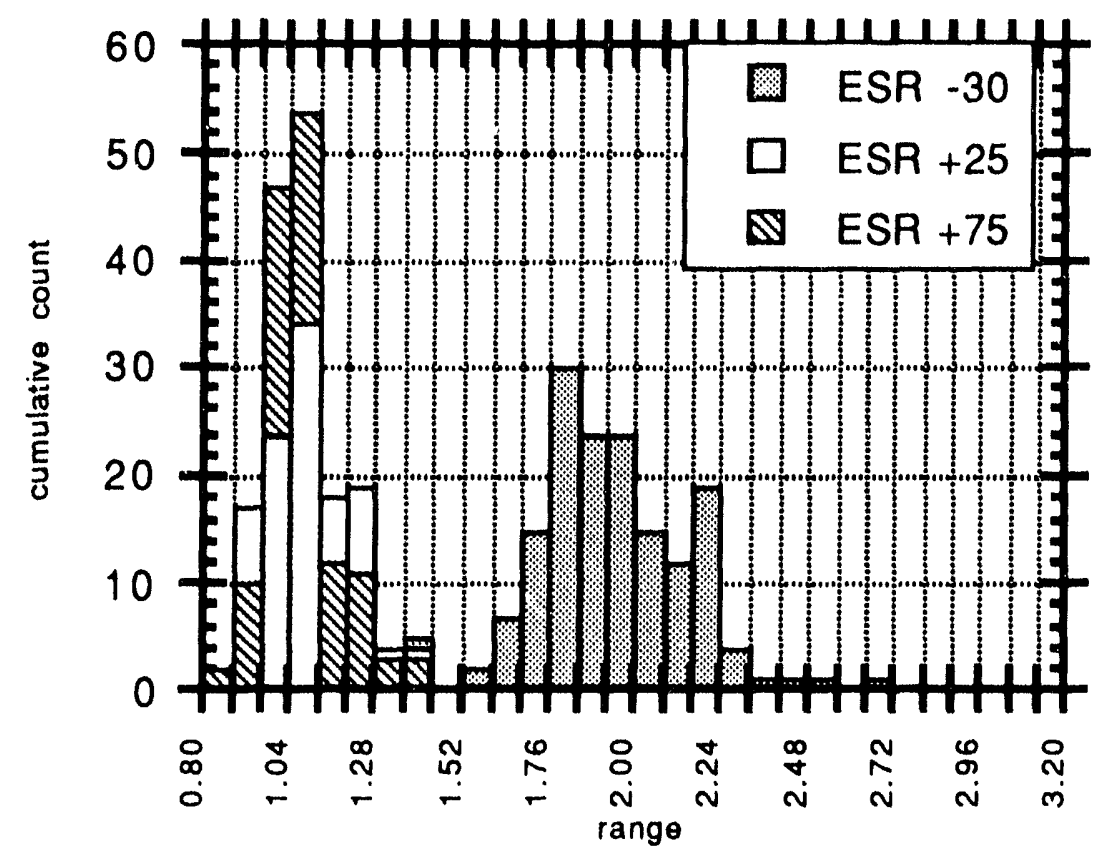

(Resistance in ohms)

FIgure 4. Distribution of ESR - SOHIO

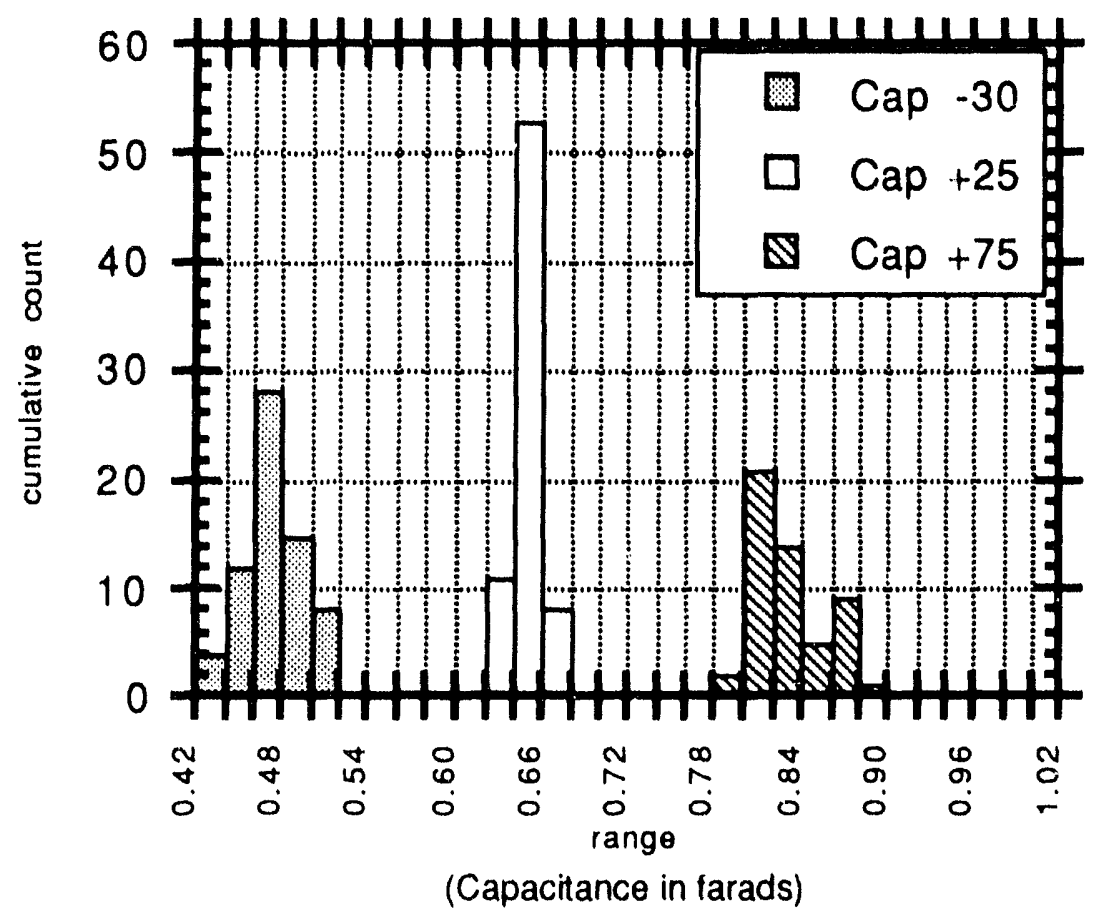

FIgure 5. Distribution of Capacitance-SOHIO 


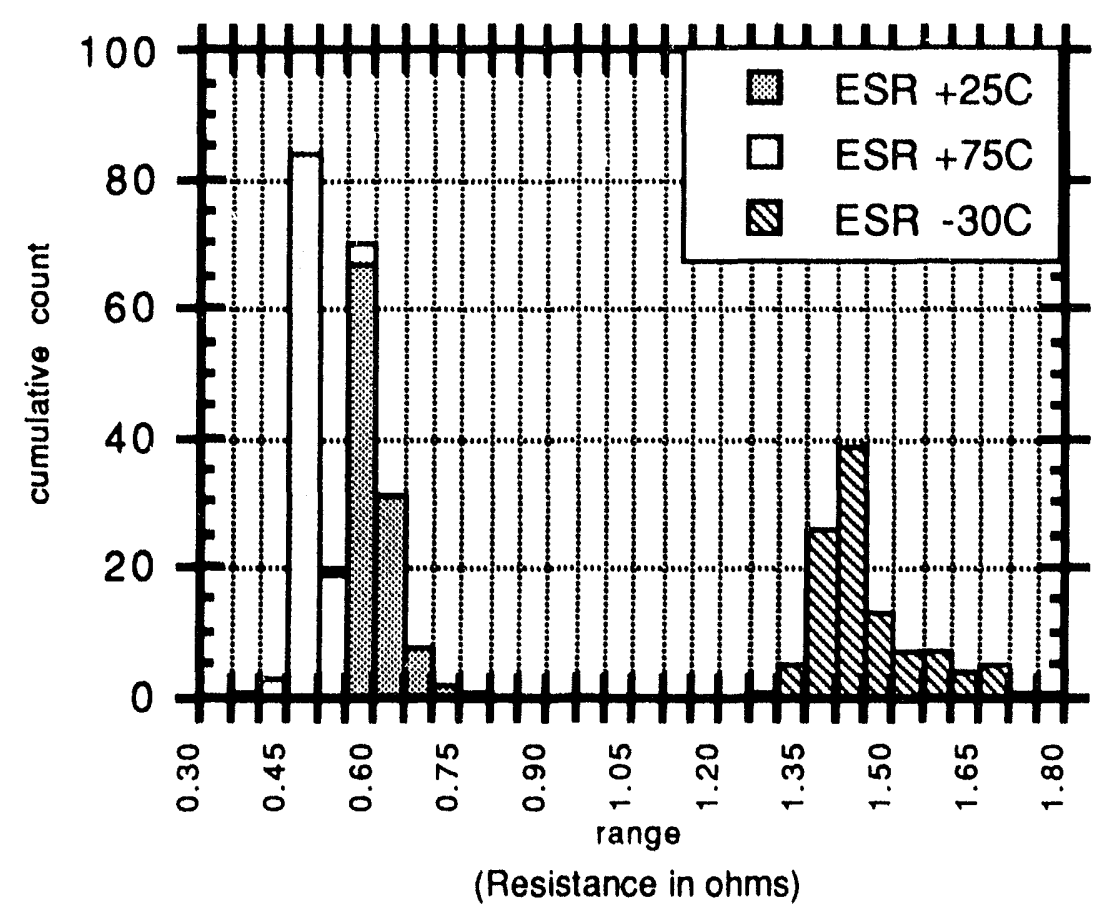

FIgure 6. Distribution of ESR - Evans

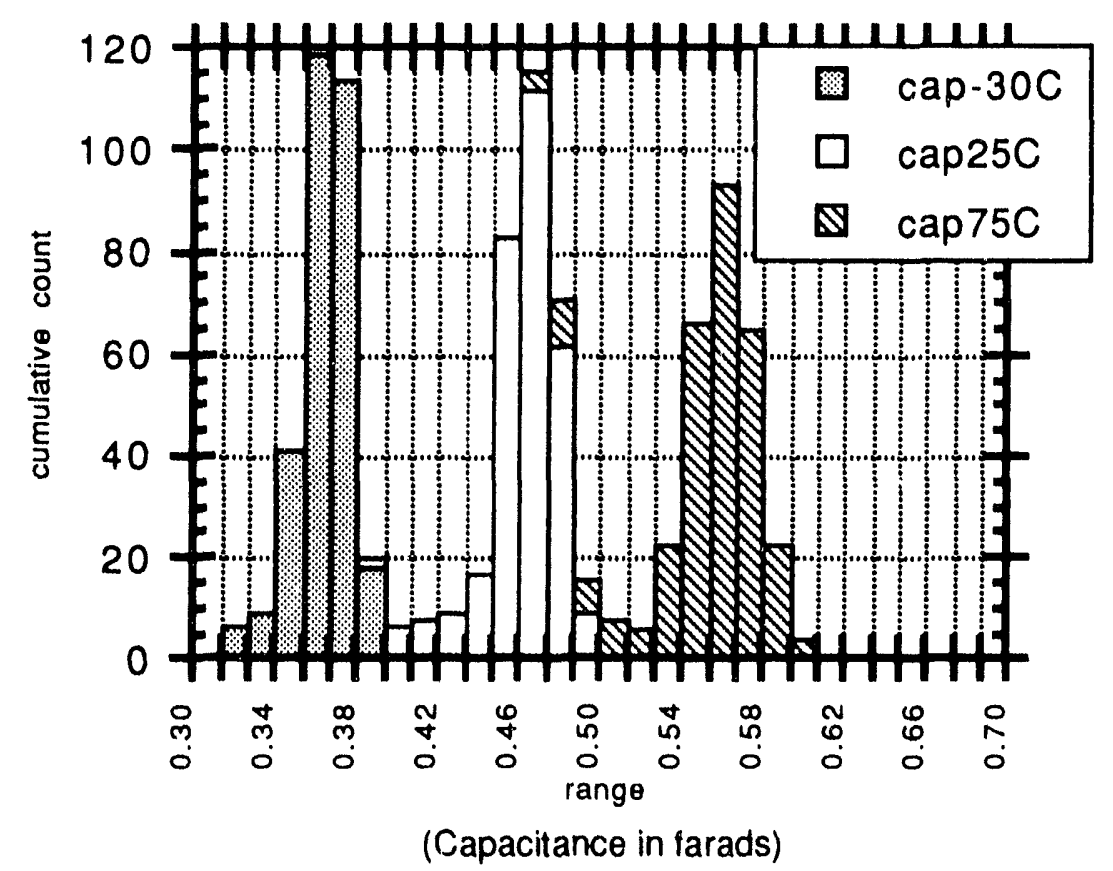

FIgure 7. Distribution of Capacitance-Evans 


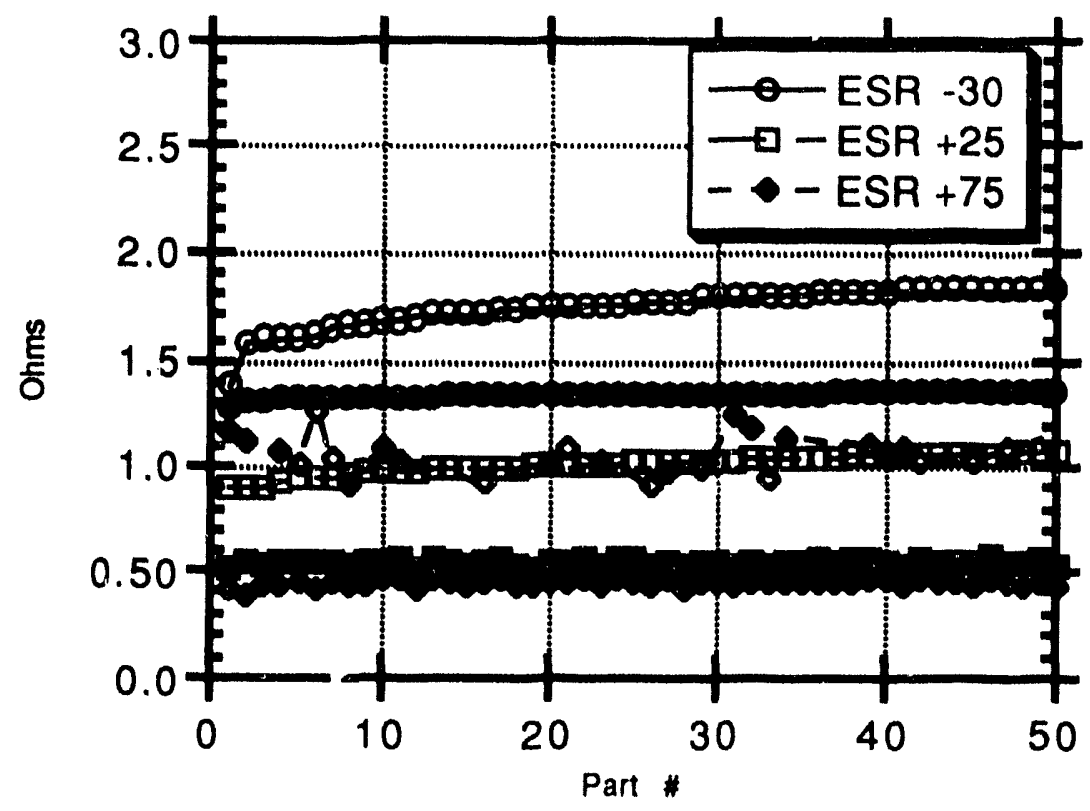

FIgure 8. Comparison of ESR - Opened SOHIO, Closed Evans

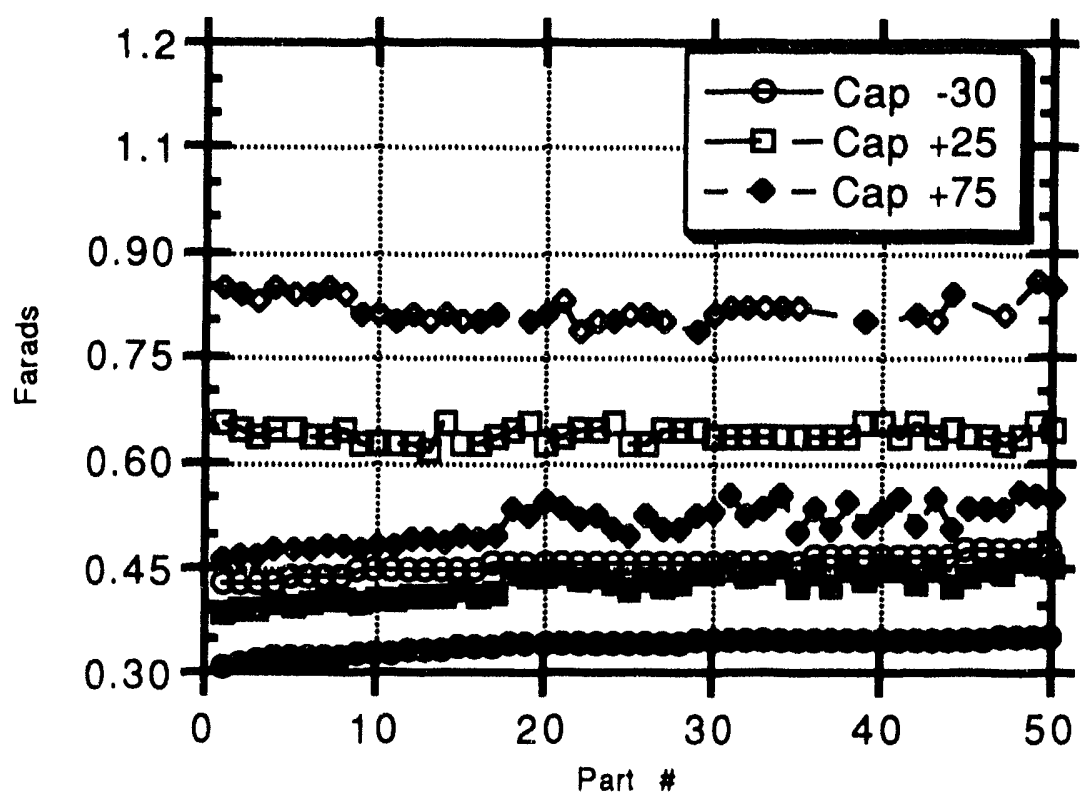

Figure 9. Comparison of Capacitance - Opened SOHIO, Closed Evans 


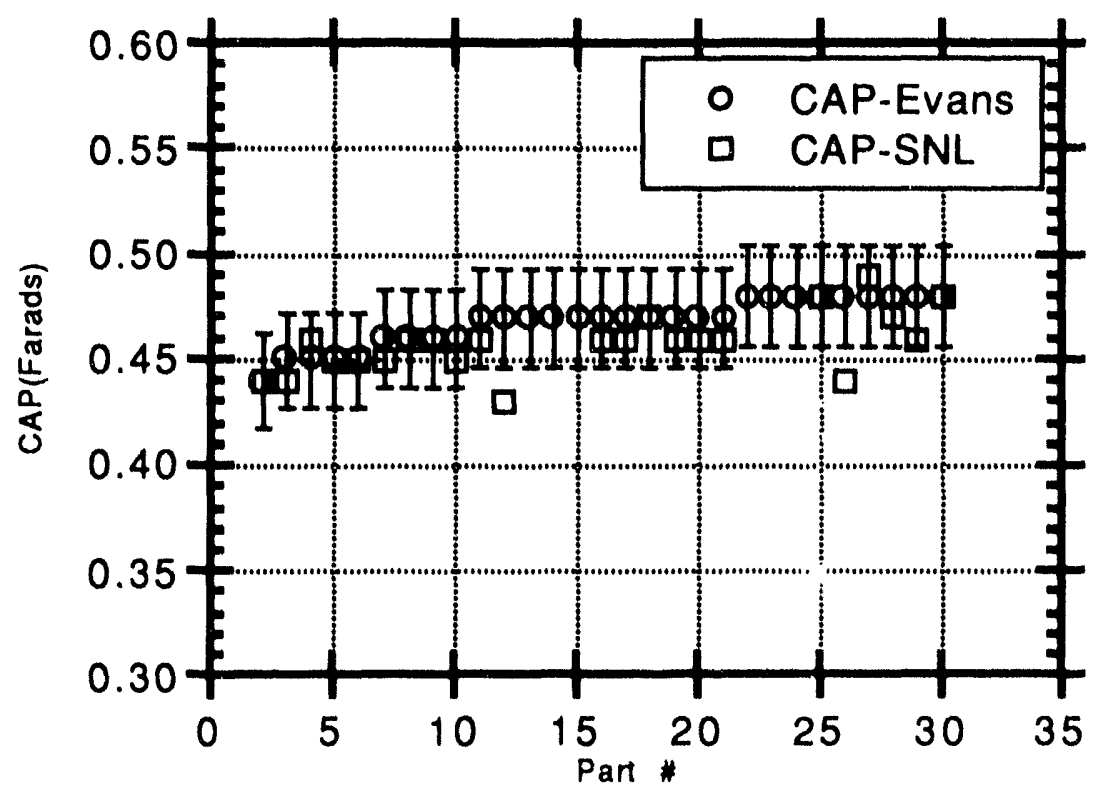

FIgure 10. Comparison of Capacitance - SNL and Evans data showing $5 \%$ error bars

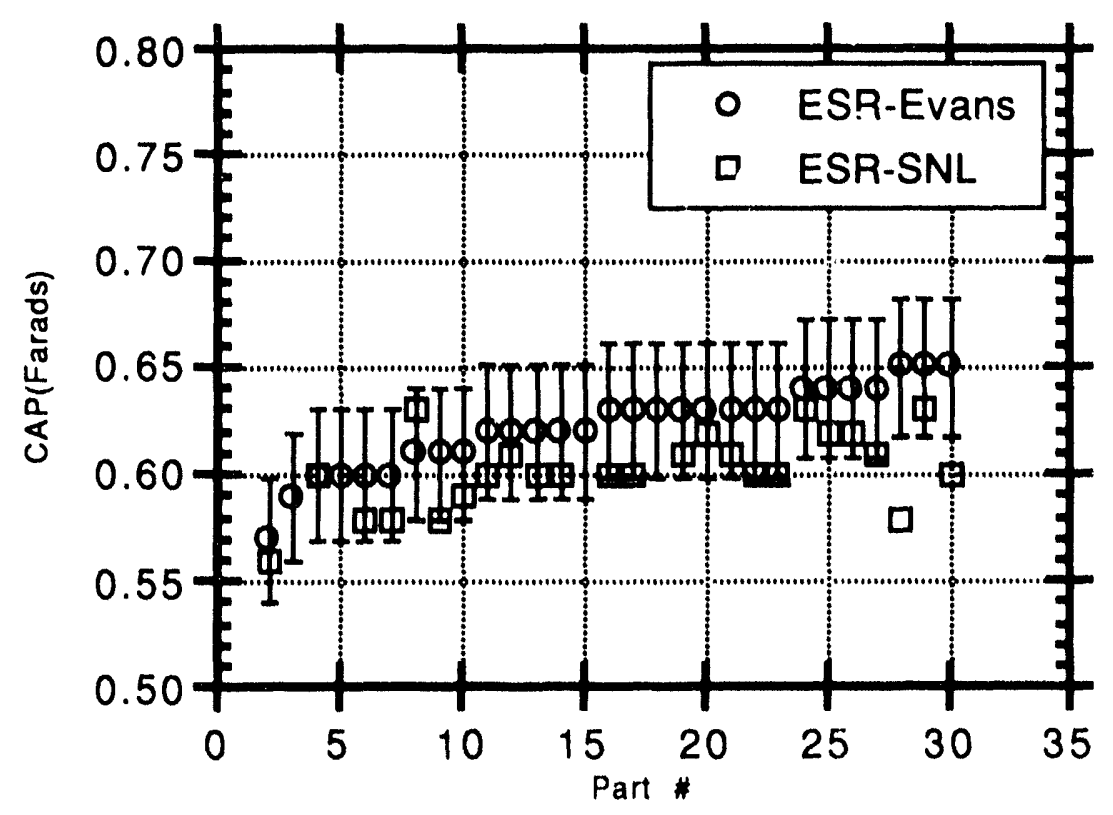

FIgure 11. Comparison of ESR - SNL and Evans data showing $5 \%$ error bars 


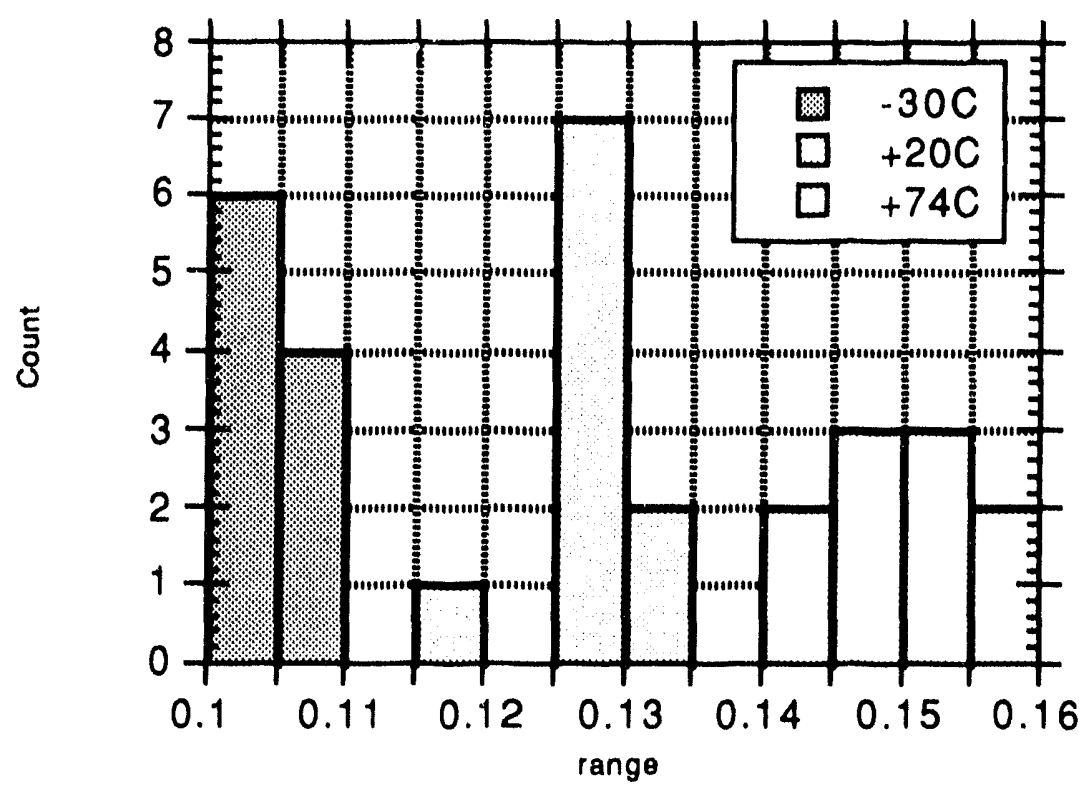

(Capacitance in farads)

FIgure 12. Capacitance of assemblies

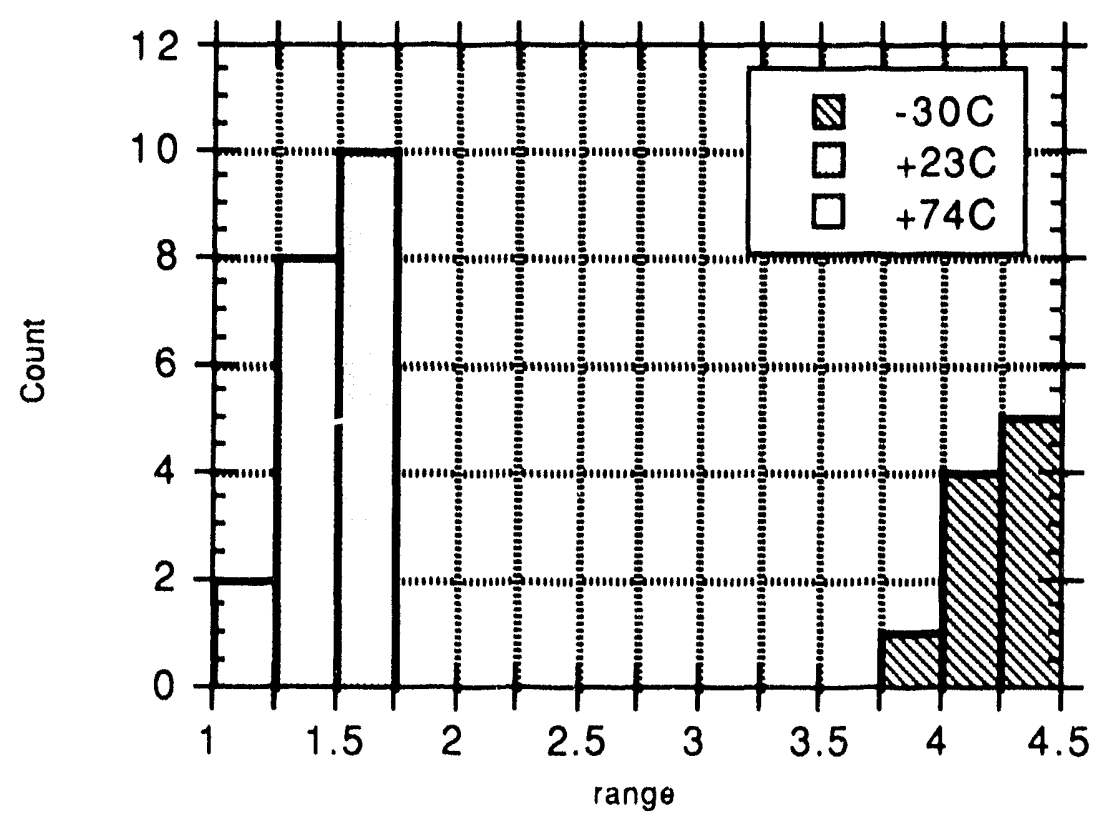

(Resistance in ohms)

FIgure 13. ESR of assemblies 


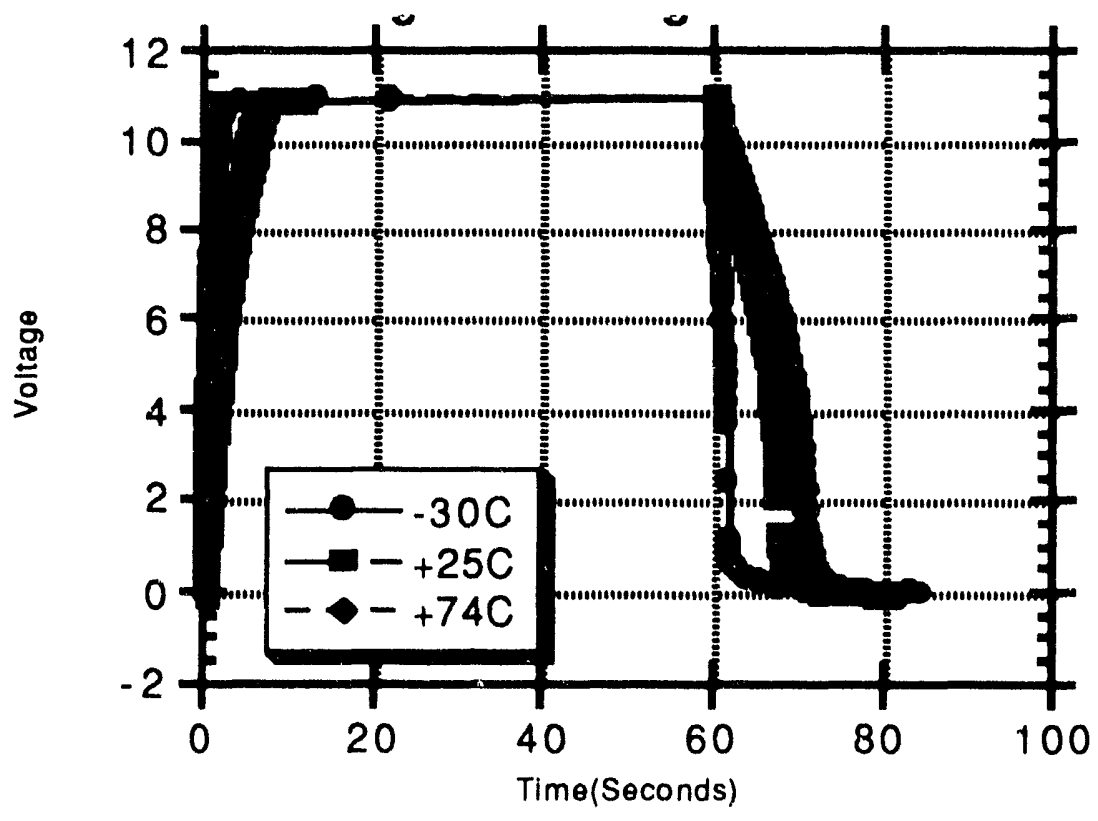

Figure 14. Effect of temperature on charge/discharge of DLCs

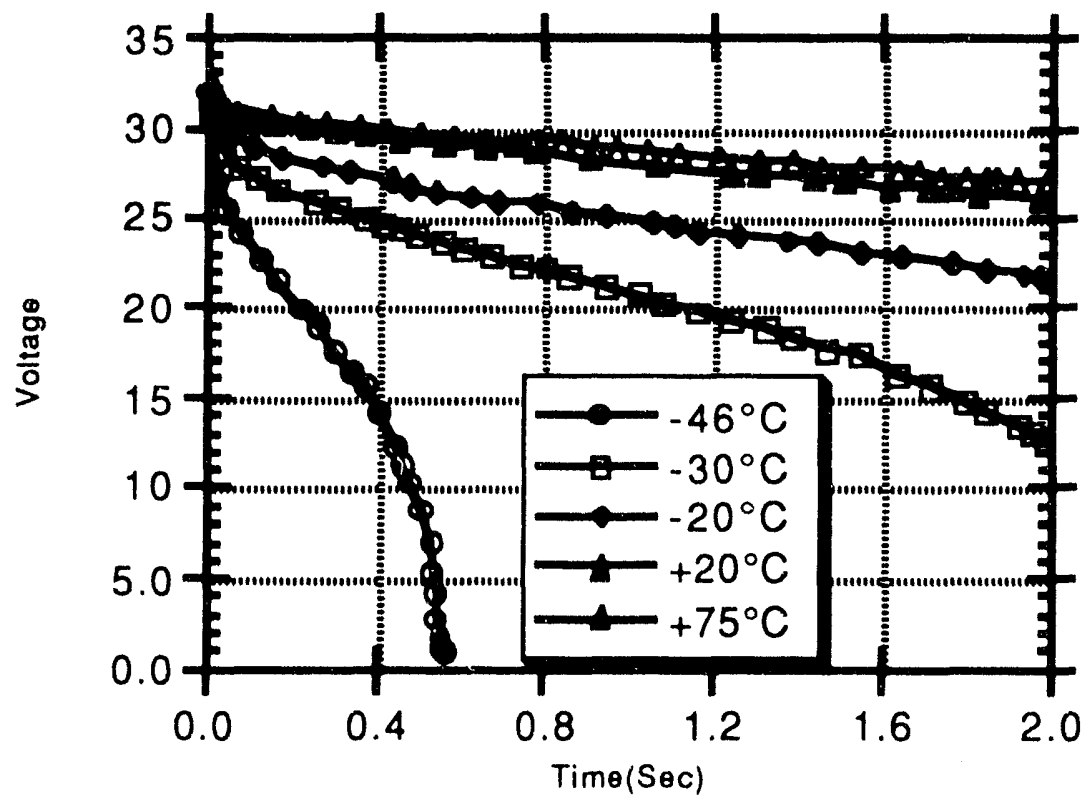

FIgure 15. Activated life as a function of test temperature 


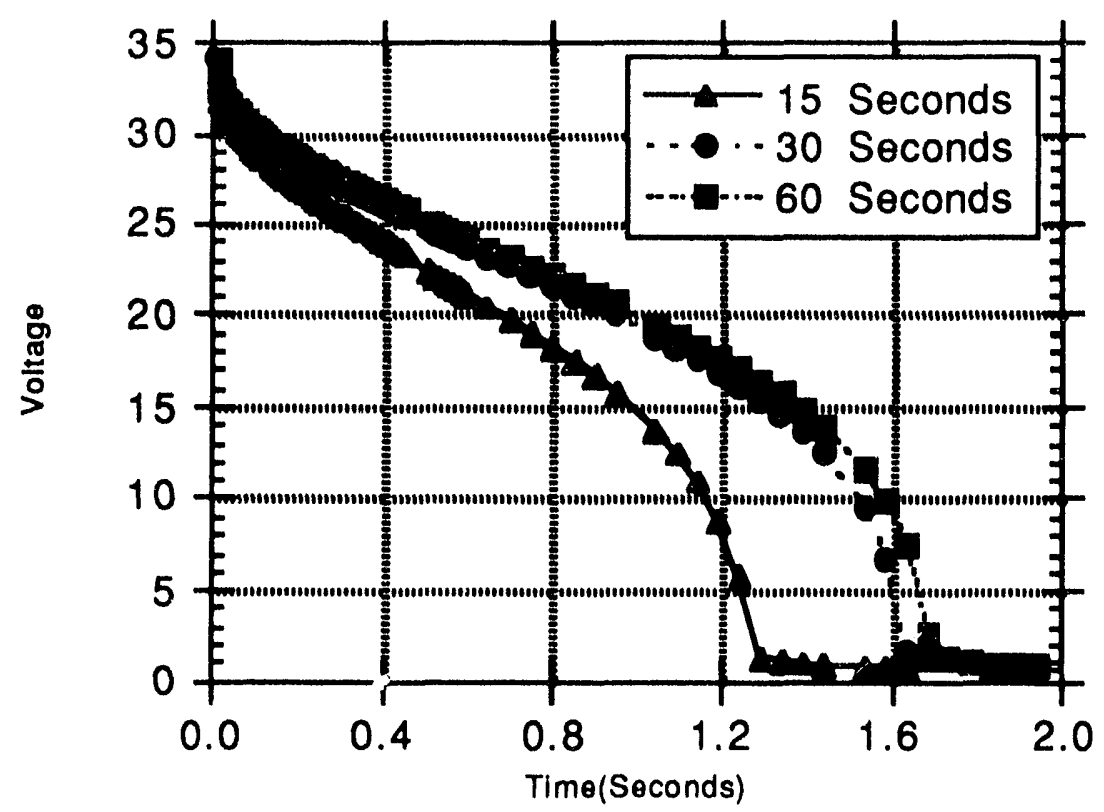

FIgure 16. Performance as a function of charge time

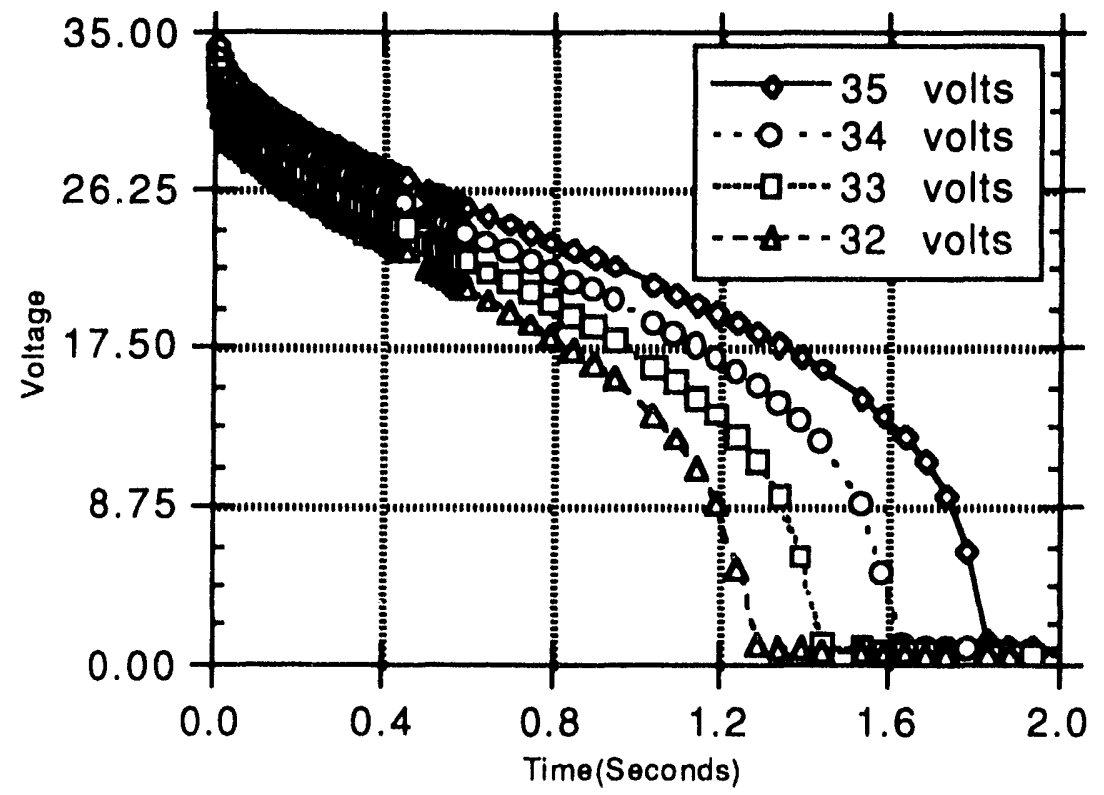

Figure 17. Discharge time as a function of charge voltage 


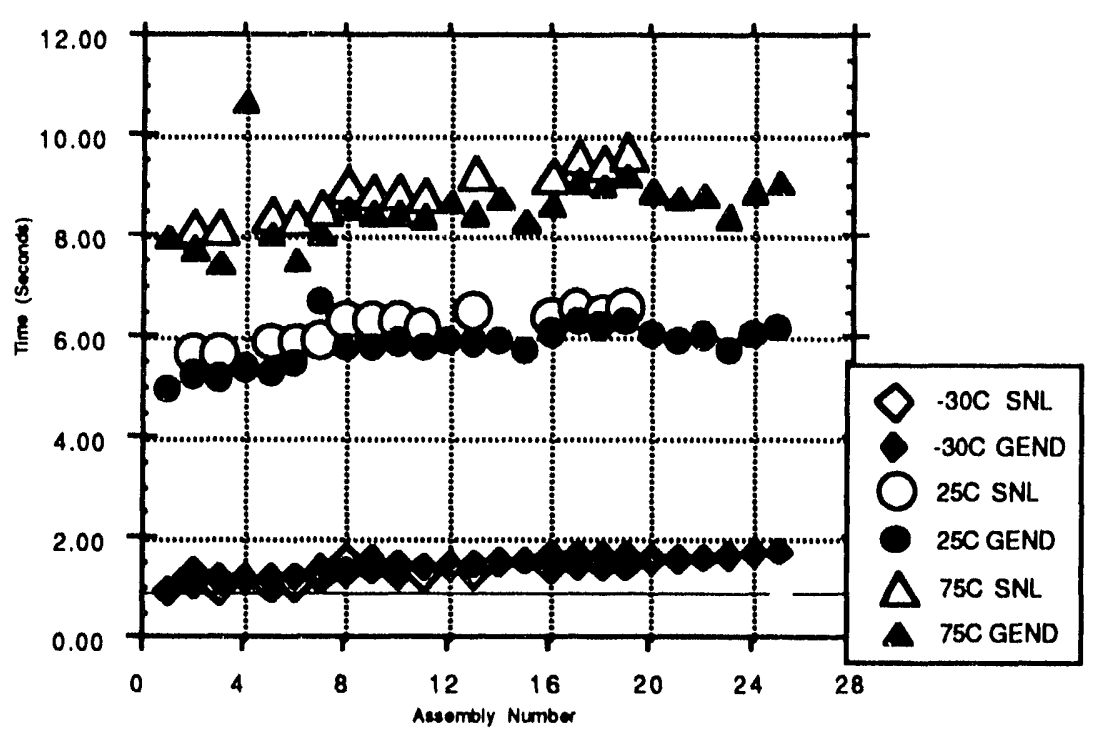

FIgure 18. Activated life as a function of temperature and location of measurement

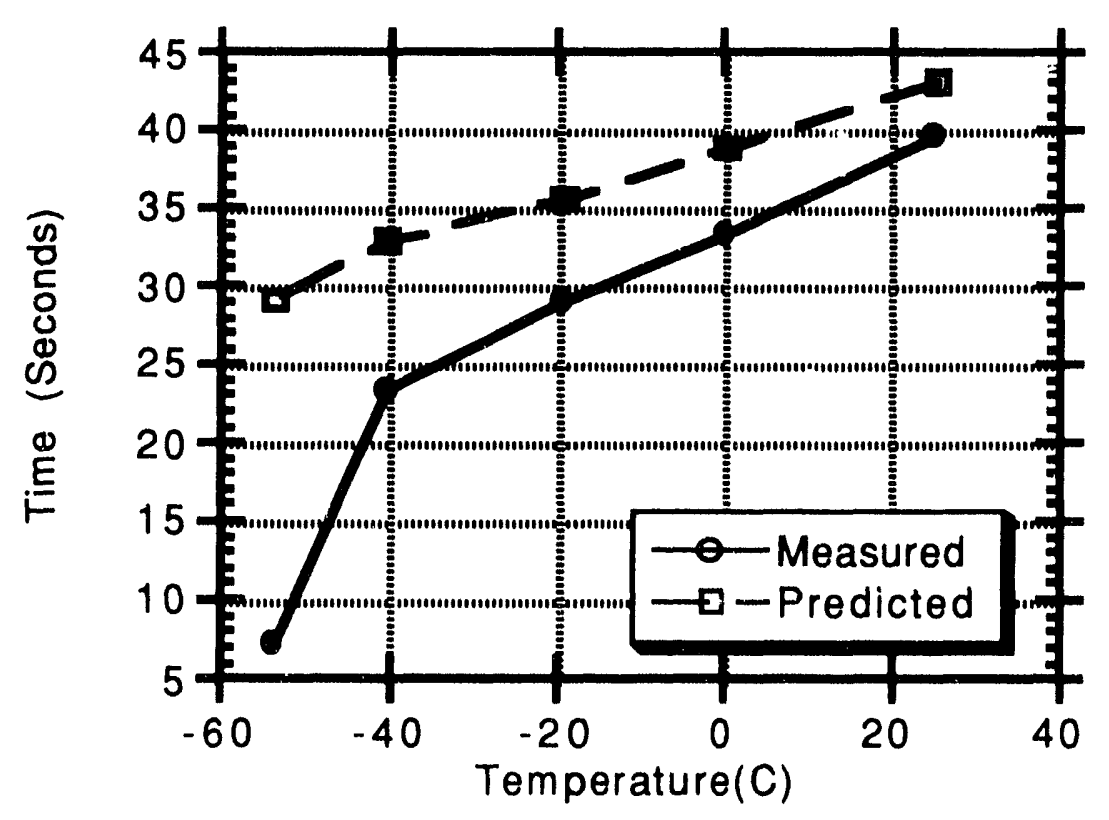

Figure 19. Predicted vs. measured time for constant current discharge 


\section{Ground and Air Transportation}

\section{Environments}

A series of environmental tests was run on assemblies and DLCs. Performance of parts before and after environmental tests was measured in three ways:

1. Equivalent Series Resistance (ESR)

2. Capacitance

3. Activated Life

\section{Combined Environmental Test}

The combined environmental test series was designed to envelop all of the usual ground and air transportation environment. The test series consisted of vibration, shock, and linear acceleration. The two vibration spectra used are shown in Figures 20 and 21 , shock spectra are shown in Figure 22, and linear acceleration spectra in Figure 23. Tests were run at $75^{\circ} \mathrm{C}$ and $-30^{\circ} \mathrm{C}$.

Twenty parts were subjected to the combined environment. Although there is some variability in the measured parameters of Equivalent Series Resistance, Capacitance, and Activated Life, no significant degradation in any property was seen. An example of the before and after Activated Life data is shown in Figure 24.

To further test the limits of the parts, these combined environments were run five times on five parts. Again no significant degradation was seen (Figure 25).

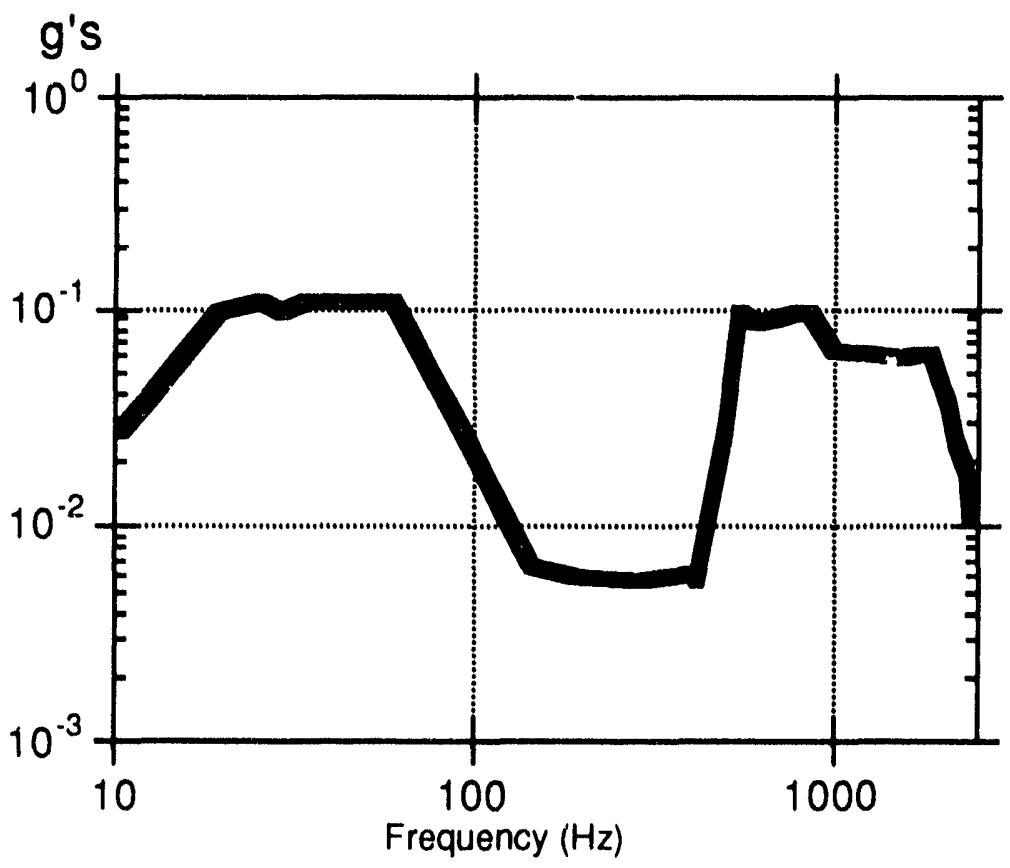

FIgure 20. Vibration -20 minutes 


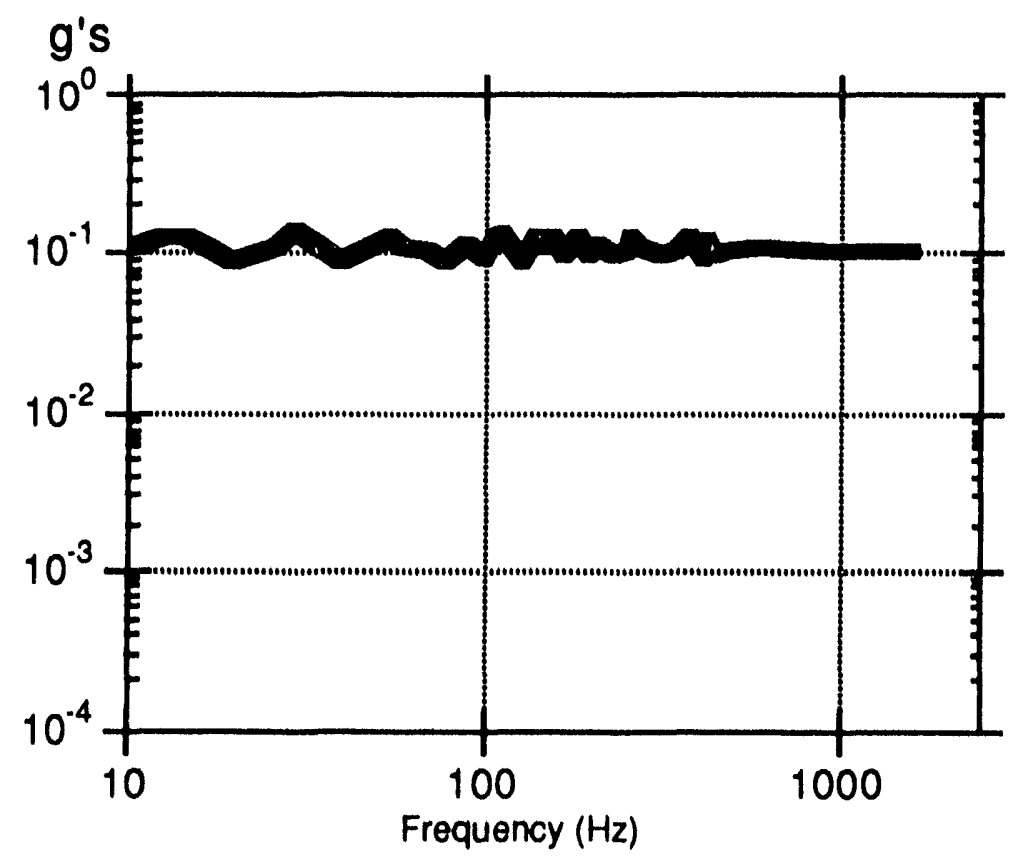

FIgure 21. Vibration - 1 minute

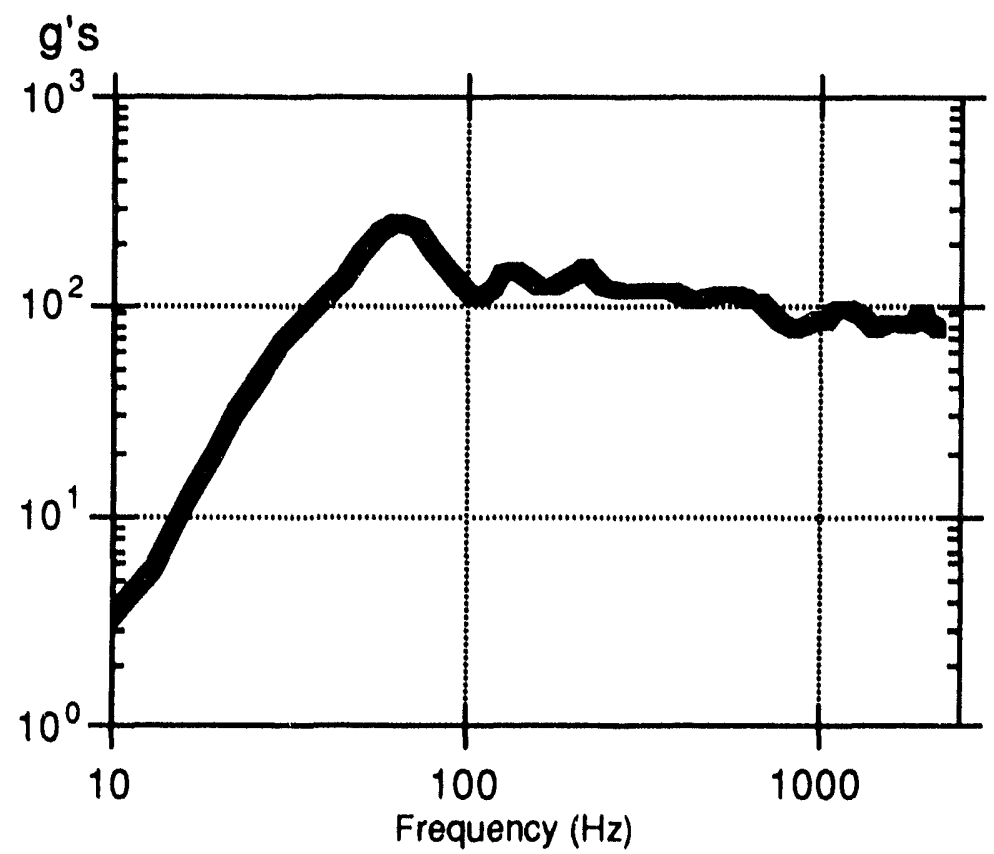

FIgure 22. Shock -30 seconds 


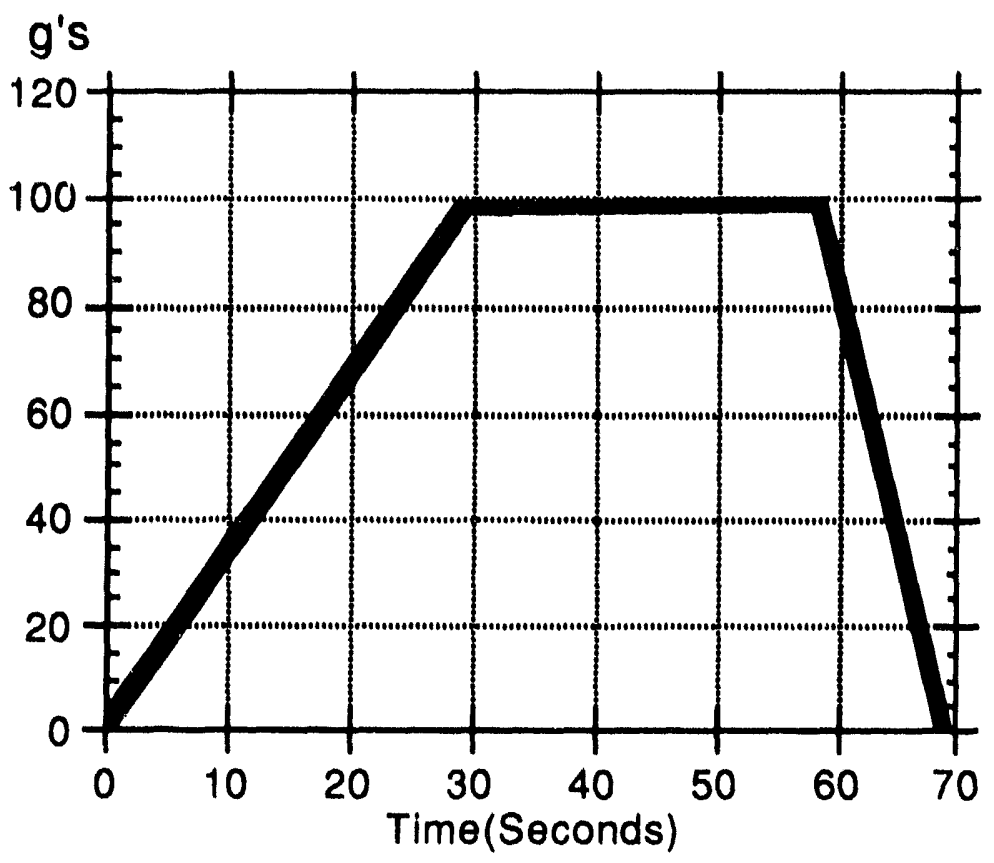

FIgure 23. Linear acceleration

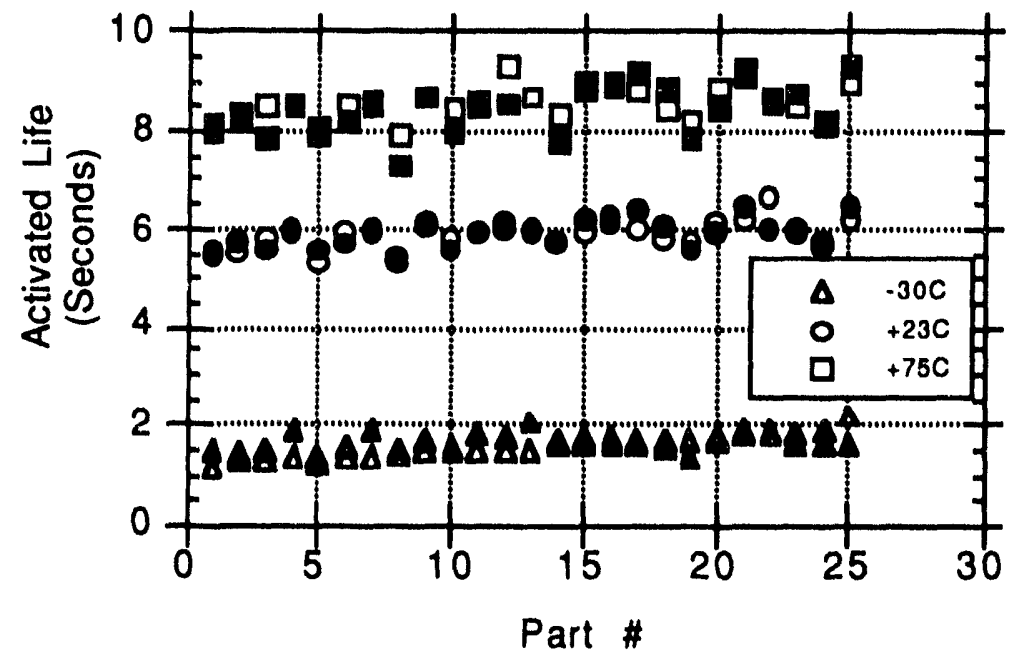

FIgure 24. Activated life measured before and after environments at $-30^{\circ} \mathrm{C},+23^{\circ} \mathrm{C}$, and $+73^{\circ} \mathrm{C}$ (Open-Before, Solid-After) 


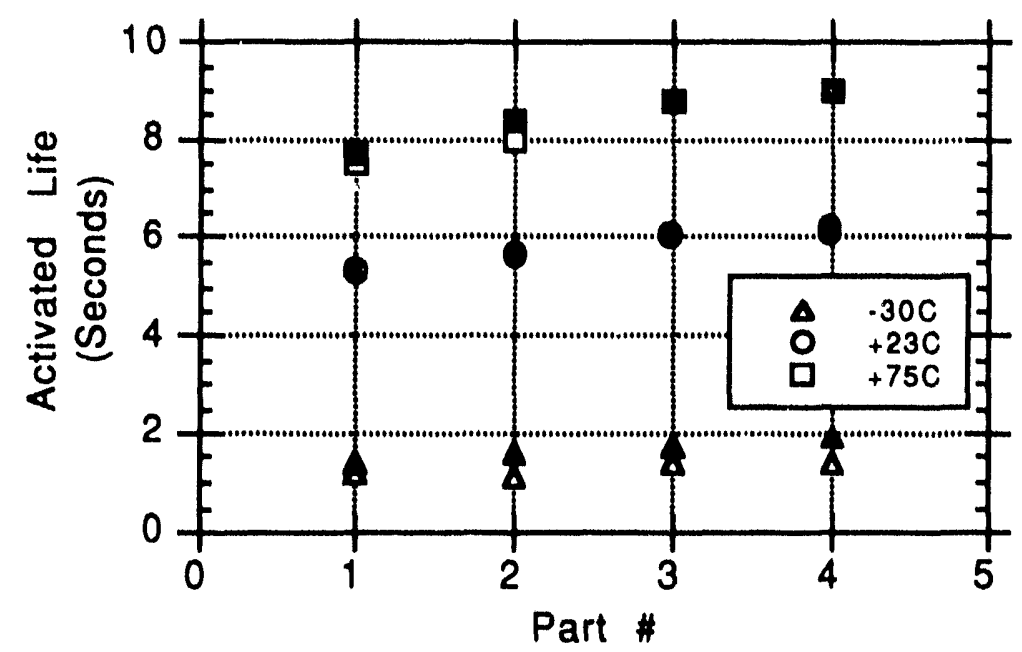

FIgure 25. Activated life measured at $-30^{\circ} \mathrm{C},+23^{\circ} \mathrm{C}$, and $+73^{\circ} \mathrm{C}$ before and after environments-tested 4 times (OpenBefore, Solid-After)

\section{Vibration Only:}

Vibration spectra as in Figures 20 and 21 were run on a series of parts and assemblies. A summary of DLC tests is shown in the following table. Figure 26 shows that individual DLC performance was not affected by these tests.

Assembly tests showed that the way the MC4169 assembly was fixtured resulted in 6 to 100 times more the energy input into the part than expected at frequencies above $2000 \mathrm{~Hz}$. Figure 27 shows a typical vibration spectrum with this enhancement. This result simply means that assemblies were subjected to and survived a significantly harsher environment than expected. (All parts in the combined environmental test were subjected to this effect.)

Six assemblies using SOHIO parts were subjected to vibration spectra in Figures 20 and 21. Five of the six parts showed significant degradation. The ESR showed a significant increase. During disassembly of the DLCs in these assemblies, bubbling could be observed on at least one joint in the cell stack. The bubbling was most likely sulfuric acid and $\mathrm{CO}_{2}, \mathrm{O}_{2}$, or $\mathrm{H}_{2}$ gas. The increase in ESR could then be explained by the fact that sulfuric acid leaked from one cell to adjacent cells, causing a short. This short resulted in overvoltage in the cell, which resulted in gas production. The gas production caused the conductive layer to separate, and thus increased the resistance. Three assemblies using the Evans double-layer capacitors showed no significant degradation in this environment on tests at Sandia (Figure 28); the parts tested at GEND reported above in the combined environment also showed no degradation. Figures 29 and 30 are enlarged photos of the Evans and SOHIO parts, respectively. The possibility for cracking in the bond lines is evident in the SOHIO parts.

\section{High g Shock Only:}

High g shock tests were run to assess the design limits and the feasibility of using the Evans double-layer capacitors in penetrator environ. ments. SNL has tested four Evans parts. Figure 31 shows a typical spectrum. Two standard Evans parts may have had a voltage dropout for a few microseconds at $4500 \mathrm{~g} / 2$ millisecond, but further tests need to be done to verify that this is the limit of these parts. After the suspected dropout in these parts, two with special features for shock environments were tested and performed at $9000 \mathrm{~g}$ forces. In addition, tests have been run on the shock table at shorter durations to assess design limits. A summary of all tests run thus far is shown in Figure 32 as a function of peak g's and duration. All times greater than 1.5 milliseconds are from penetrator testing through concrete. The data are for one direction only and, usually in these tests, there is also high $g$ stress in other directions. Thus, the stress on the part was even higher than reported. The only problem found in all of these tests was the possible dropout in the penetrator tests. 


\section{Summary of DLC Tests}

\section{EVANS CARB}

SERIES 1

\begin{tabular}{llllllllllll}
6 & 7 & 8 & 63 & 73 & 41 & 70 & 37 & 38 & 44 & 66 & 76 \\
\hline
\end{tabular}

\section{$T E M P=74$}

$X$ SHOCK

20 MIN VIB

30 SEC VIB

Y SHOCK

20 MIN VIB

30 SEC VIB

$Z$ SHOCK

$20 M I N$ VIB

30 SEC VIB

TEMP $=-30$

$X$ SHOCK

20 MIN VIB

30 SEC VIB

$Y$ SHOCK

20 MIN VIB

30 SEC VIB

$Z$ SHOCK

20 MIN VIB

30 SEC VIB

C.1

C-1 ESR

C-1

C.1

C-I ESR

C-1

C.1

C.1 ESR

c. 1

C.1

C-1

c. -1

C-1

C. -1

C. -1

C.1

c. 1

c.1
ESR

ESR

ESR
ESR ESR ESR

ESR ESR ESR

ESR ESR ESR

ESR ESR ESR

ESR ESR ESR

ESR ESR ESR $\begin{array}{llll}0.1 & 0.1 & 0.1 & 0.1\end{array}$

$\begin{array}{llll}c .1 & 0.1 & 0.1 & 0.1\end{array}$

$\begin{array}{llll}c .1 & 0.1 & 0.1 & 0.1\end{array}$

$\begin{array}{llll}c .1 & c-1 & 0.1 & c-1\end{array}$

$\begin{array}{llll}c-1 & c-1 & c-1 & c-1\end{array}$

$\begin{array}{llll}c-1 & 0.1 & 0.1 & 0.1\end{array}$

$\begin{array}{llll}0-1 & 0.1 & 0.1 & 0.1\end{array}$

$\begin{array}{llll}c-1 & 0.1 & 0.1 & 0.1\end{array}$

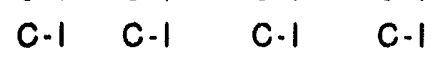

$\begin{array}{cccc}0.1 & 0.1 & 0.1 & 0.1\end{array}$

c.1 $\quad$ c.1 $\quad$ c.1 $\quad$ c.1

c.1 $\quad$ c.1 $\quad$ C.1 $\quad$ c.1

$\begin{array}{llll}c .1 & 0.1 & c .1 & c .1\end{array}$

$\begin{array}{llll}c .1 & 0.1 & 0.1 & 0.1\end{array}$

c.1 c.1 c.1 c.1

c.1 $\quad 0.1 \quad 0.1 \quad 0.1$

$\begin{array}{llll}c-1 & c-1 & c-1 & c-1\end{array}$

c.1 $\quad$ C.1 $\quad$ C.1 $\quad$ C.1

\section{SERIES 2}

\begin{tabular}{|c|c|c|c|c|c|c|c|c|c|}
\hline \multicolumn{10}{|l|}{$T E M P=74$} \\
\hline$X \cdot 20 \mathrm{MIN} V I B$ & $C \cdot S$ & C.S & C.S & C.S & C.S & C.S & C.S & C-S & C.S \\
\hline 30 SEC VIB & C.S & C.S & C.S & C.S & C.S & C.S & C.S & C-S & C.S \\
\hline$Y \cdot 20 \mathrm{MIN} V I B$ & C.S & $\mathrm{C} \cdot \mathrm{S}$ & C.S & C.S & C.S & C.S & C.S & C.S & C.S \\
\hline 30 SEC VIB & C.S & c.s & C.S & C.S & C.S & C.S & C.S & C.S & C.S \\
\hline$Z-20$ MIN VIB & C.S & C.S & C.S & C.S & C.S & C.S & C.S & C.S & C.S \\
\hline 30 SEC VIB & $\mathrm{C} \cdot \mathrm{S}$ & c.s & C.S & C.S & C.S & C.S & C.S & C.S & C.S \\
\hline \multicolumn{10}{|l|}{$T E M P=-30$} \\
\hline$X-20$ MIN VIB & C.S & C.S & C.S & C.S & C.S & C.S & C.S & C.S & C.S \\
\hline 30 SEC VIB & C.S & C.S & C.S & C.S & C.S & C.S & C.S & C.S & C.S \\
\hline$Y-20$ MIN VIB & C-S & C.S & C.S & C.S & C.S & C.S & C.S & C.S & C.S \\
\hline 30 SEC VIB & C.S & c.s & C.S & C.S & C.S & C.S & C.S & C.S & C.S \\
\hline$Z .20 \mathrm{MIN} V I B$ & C.S & C.S & C.S & C.S & C.S & C.S & C.S & C.S & C.S \\
\hline 30 SEC VIB & C.S & C.S & C.S & C.S & C.S & C.S & C.S & C.S & C.S \\
\hline
\end{tabular}




\section{Summary of DLC Tests (concluded)}

\begin{tabular}{|c|c|c|c|c|c|c|c|c|c|c|c|c|}
\hline & \multicolumn{3}{|c|}{ EVANS } & \multicolumn{2}{|c|}{ CARB } & \multirow[b]{2}{*}{41} & \multirow[b]{2}{*}{70} & \multirow[b]{2}{*}{37} & \multirow[b]{2}{*}{38} & \multirow[b]{2}{*}{44} & \multirow[b]{2}{*}{66} & \multirow[b]{2}{*}{76} \\
\hline & 6 & 7 & 8 & 63 & 73 & & & & & & & \\
\hline \multicolumn{13}{|l|}{ SERIES 3} \\
\hline \multicolumn{13}{|l|}{$T E M P=-30$} \\
\hline$Z-20$ MIN VIB & & & & & & C.S & C.S & C.S & C.S & & C.S & C.S \\
\hline 30 SEC VIB & & & & & & C.S & C.S & C.S & C.S & & C.S & C.S \\
\hline \multicolumn{13}{|l|}{$T E M P=74$} \\
\hline$Y-20 M I N$ VIB & & & & & & C.S & C.S & C.S & C.S & & C.S & C.S \\
\hline 30 SEC VIB & & & & & & C.S & C.S & C.S & C.S & & C.S & C.S \\
\hline$Z \cdot 20$ MIN VIB & & & & & & c.s & C.S & C.S & C.S & & C.S & C.S \\
\hline 30 SEC VIB & & & & & & C.S & C.S & C.S & C.S & & C.S & C.S \\
\hline
\end{tabular}

C.I $=11$ Volt Charge, C.S -3 in Series to 33 Volts, Blank $=$ Not Charged, ESR Continuous, and NT - Not Tested

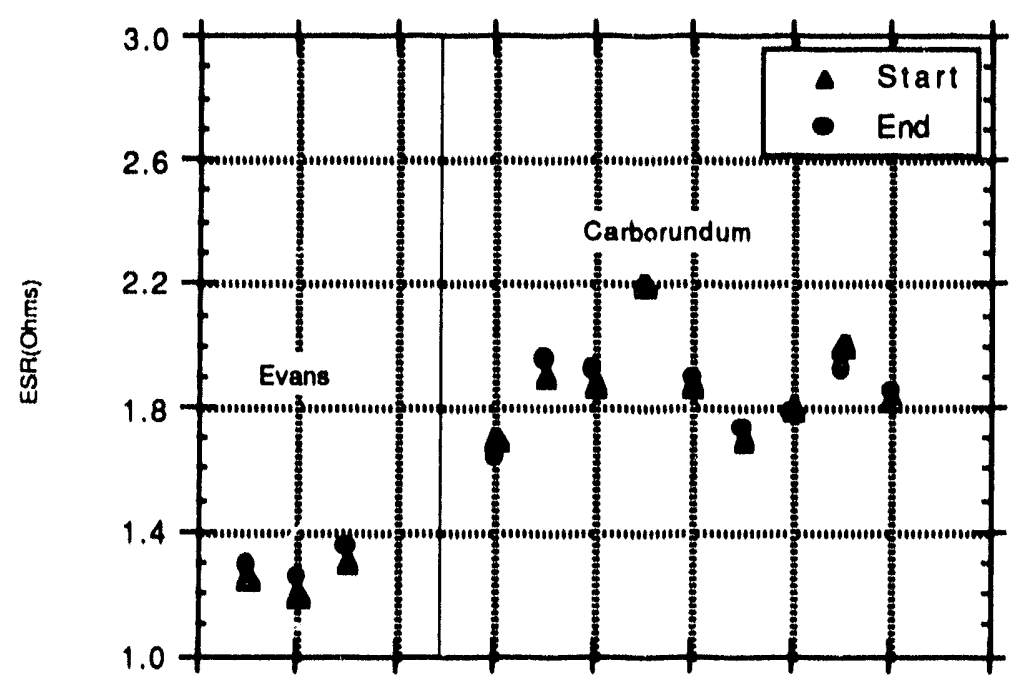

FIgure 26. ESR of parts before and after environmental testing 


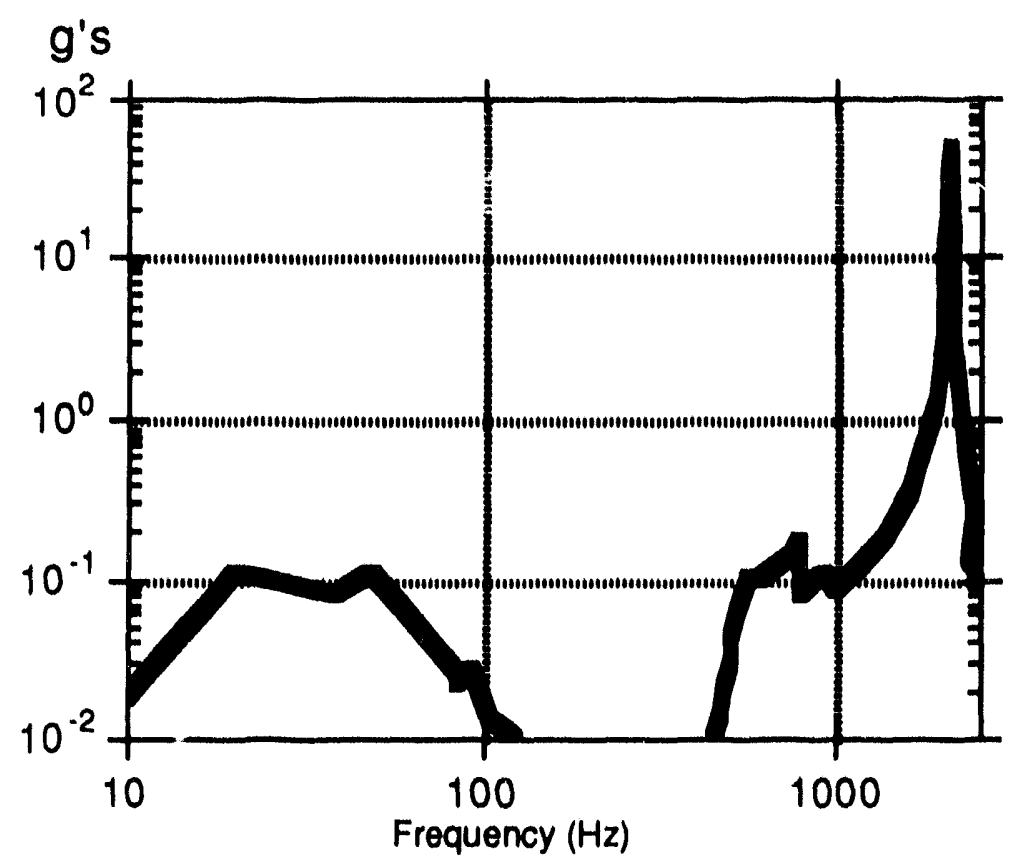

FIgure 27. Enhanced vibration spectrum

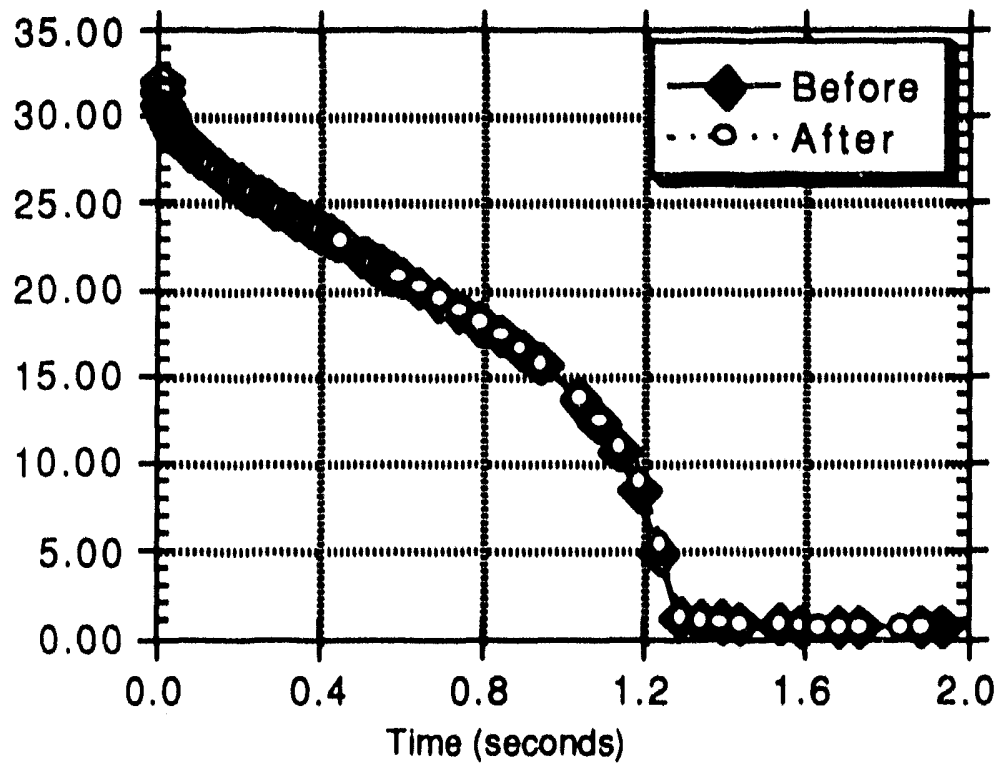

FIgure 28. Typical plot of discharge before and after vibration testing 

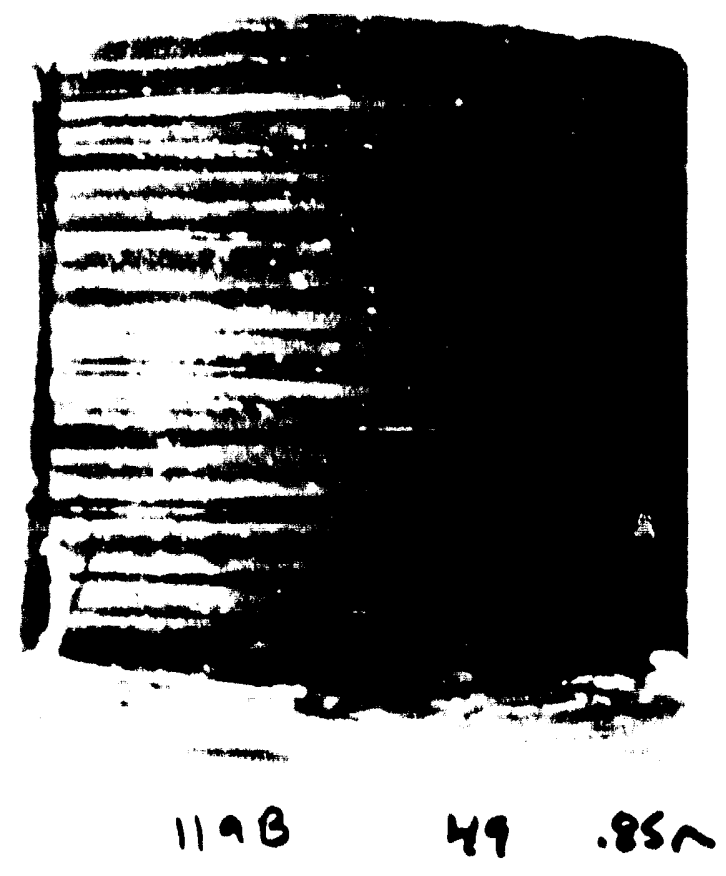

FIgure 29. Photo of SOHIO parts

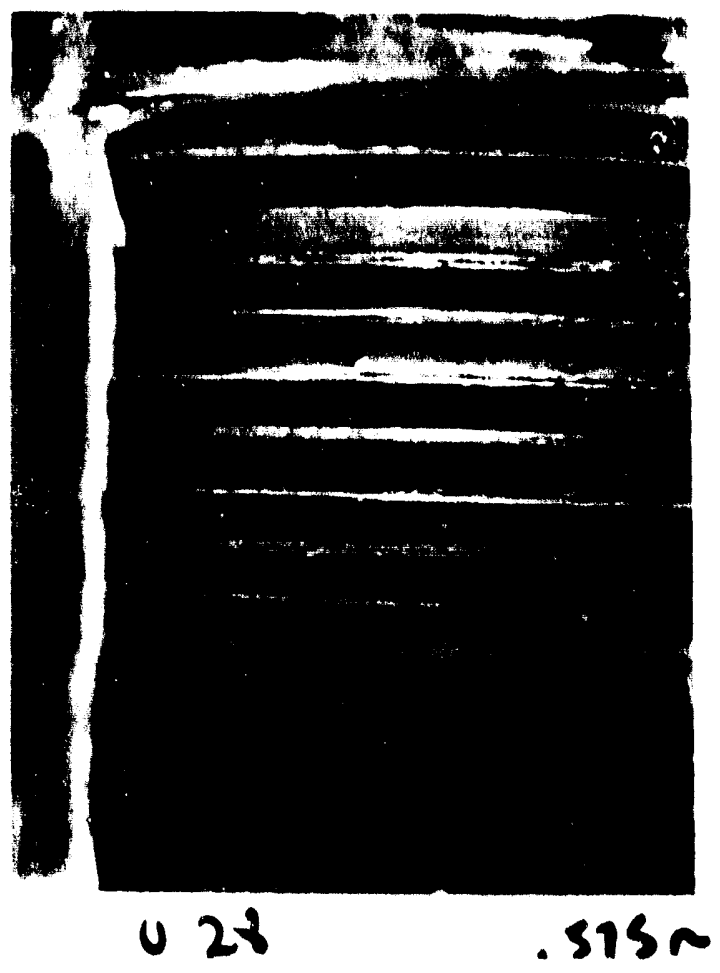

FIgure 30. Photo of Evans parts 


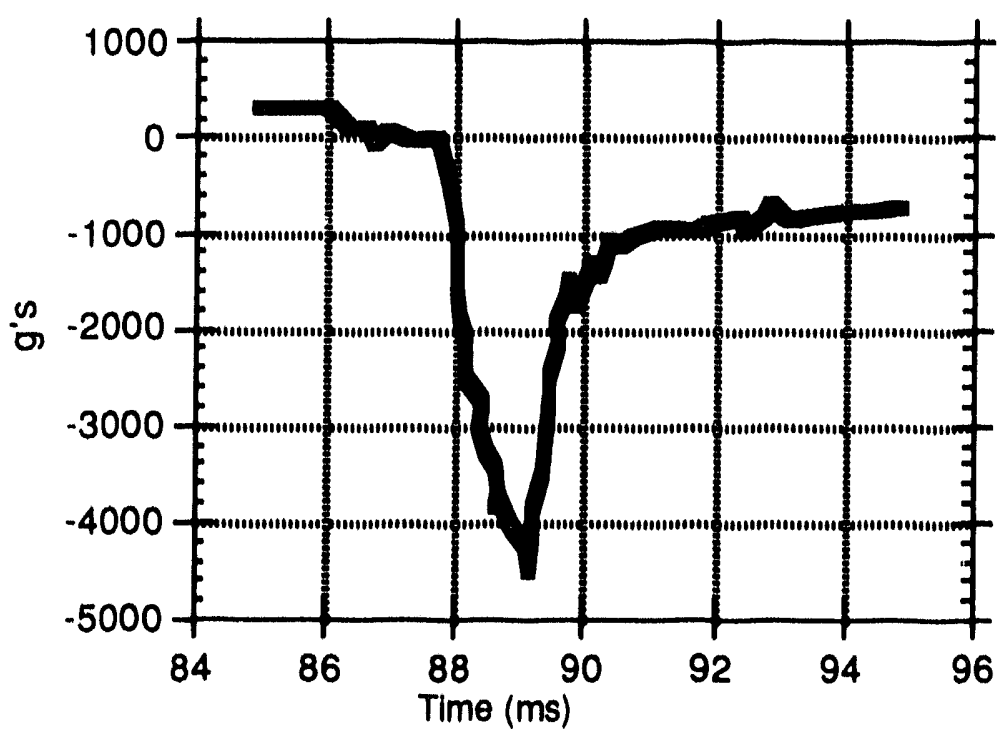

FIgure 31. High g shock

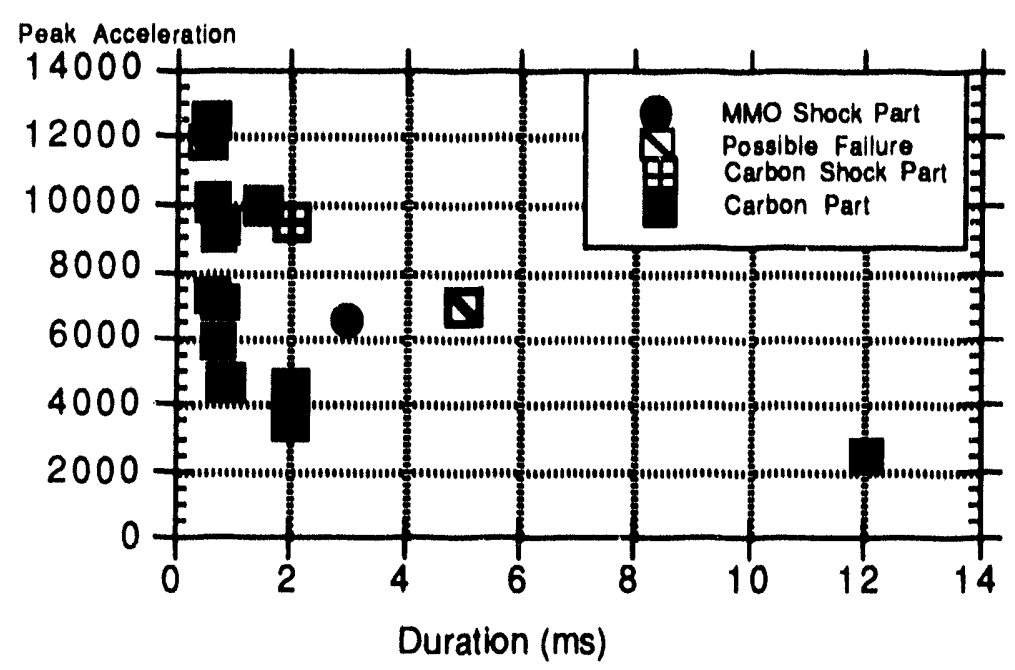

Figure 32. Summary of shock testing 


\section{Pressure Effect:}

The effects of low pressure were tested on assemblies using a vacuum chamber that was mumped down to 0.5 psi. Charge and discharge tests were performed. The Activated Lifetimes were unaffected at all temperatures.

\section{Aging Study}

Since this component was the first application of this design for both Evans and the DOE complex, a joint aging and compatibility study was undertaken. Both individual DLCs and MC4169s were studied. This was necessary because the permeation-selective valve allows the DLCs to interact with the urethane potting and other materials used in the assembly of the MC4169.

\section{Experimental Design}

Previous studies of similar components, including capacitors and batteries, have shown that temperature, state of charge (voltage), and time are the most common causes of performance degradation. Thus, a study was designed using these stress factors. The performance measurements used were capacitance (Cap), Equivalent Series Resistance (ESR), and Activated Life (time for the voltage to drop from 11.3 volts to 5.83 volts under a 2.33-watt load). The Activated Life response is the major electrical requirement for the MC4169. The others were chosen because they are the usual measurements used to characterize capacitors.

To maximize the information obtained in this study, the central composite experimental design was chosen. This design allows for analysis of data with interactions using polynomials, exponential, and/or linear models. The sample space investigated in the study is shown in Figure 33. A maximum temperature of $95^{\circ} \mathrm{C}$ was chosen since a preliminary study done by Evans had shown no abnormal hehavior in parts at that temperature. The maximum voltage was chosen to be below the voltage per cell that would cause irreversible electrochemical degradation of the electrolyte. The time for the study would be determined by failure of the parts.

Following each aging period, the components were removed from the aging condition. The Capacitance, ESR, and the Activated Life were measured at $25^{\circ} \mathrm{C}$ for DLCs and MC4169s.
Measurements of the same properties were made at $-30^{\circ} \mathrm{C}$ on the MC4169s.

\section{Results and Analysis}

Figures 34 through 39 show the average change in Capacitance, ESR, and Activated Life versus aging time for both the MC4169s and the DLCs. Figure 40 compares the changes in Activated Life for measurements made at $25^{\circ} \mathrm{C}$ and $-30^{\circ} \mathrm{C}$. From these plots, it can be seen that the largest changes are in Capacitance and Activated Life. The data also show that the change in Capacitance is independent of voltage. For this application, the Activated Life is the response of importance; therefore, it was used to develop empirical models that then could be used for lifetime predictions. Figure 40 shows that changes in the Activated Life measured at $-30^{\circ} \mathrm{C}$ are much less than those at $25^{\circ} \mathrm{C}$, so no further analysis was done on the measurements made at $-30^{\circ} \mathrm{C}$. The reasons for these differences are not obvinus.

Several methods of analysis were used on Activated Life data. Polynomial fits were tried first [3]. Unfortunately, they resulted in bowl-shaped predictions. From a physical point of view, we know that these parts will not get better with time. Next an Arrhenius fit was used. Data from $60^{\circ} \mathrm{C} / 6.44$ volts, $85^{\circ} \mathrm{C} / 11$ volts, and $95^{\circ} \mathrm{C} / 6.44$ volts were used to represent the worst-case combination of useful data. The $60^{\circ} \mathrm{C} / 12.89$ volt data were not used because the ESR response was unique in that condition and was expected to affect the Activated Life data. Failure was defined as the loss of $20 \%$ of Activated Life. The Arrhenius plot generated is shown in Figure 41. This plot predicts a lifetime of 180 years at $25^{\circ} \mathrm{C}$. Given that the data used were worst-case data, the 7-year required shelf life should easily be met.

\section{Conclusions of Aging Study}

This study suggests that:

- The aging performance of MC4169s can be modeled using Arrhenius models to predict long-term performance at room temperature tests.

- Different mechanisms determine performance at $25^{\circ} \mathrm{C}$ and $-30^{\circ} \mathrm{C}$.

- Additional work needs to be done to understand the mechanisms.

- This new component to the stockpile should function as required after 7 years of storage. 


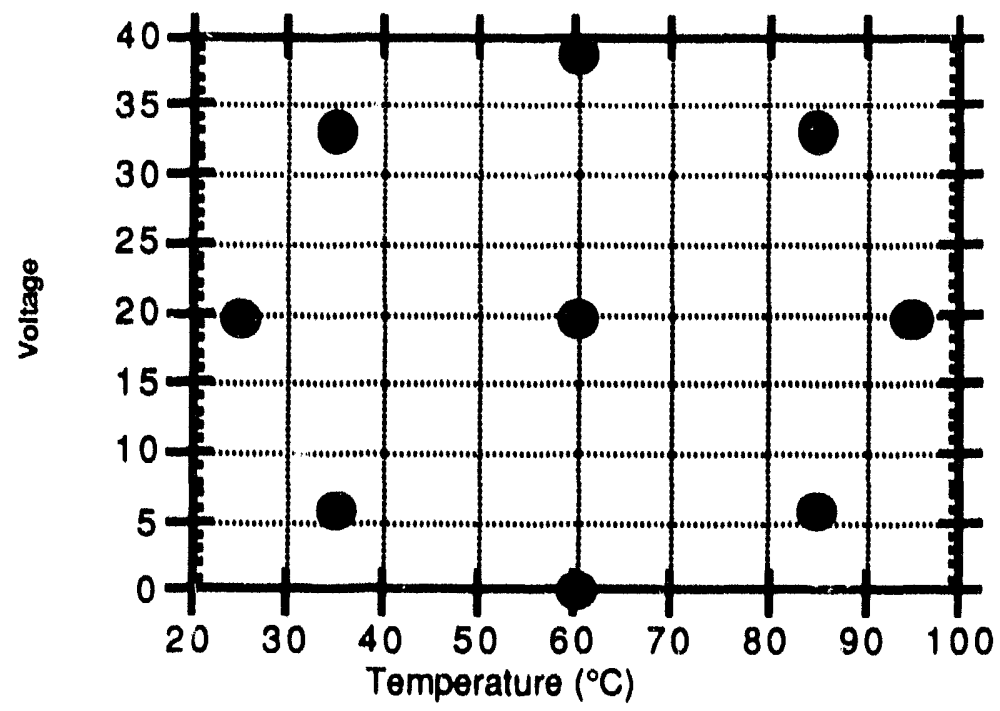

FIgure 33. Aging matrix

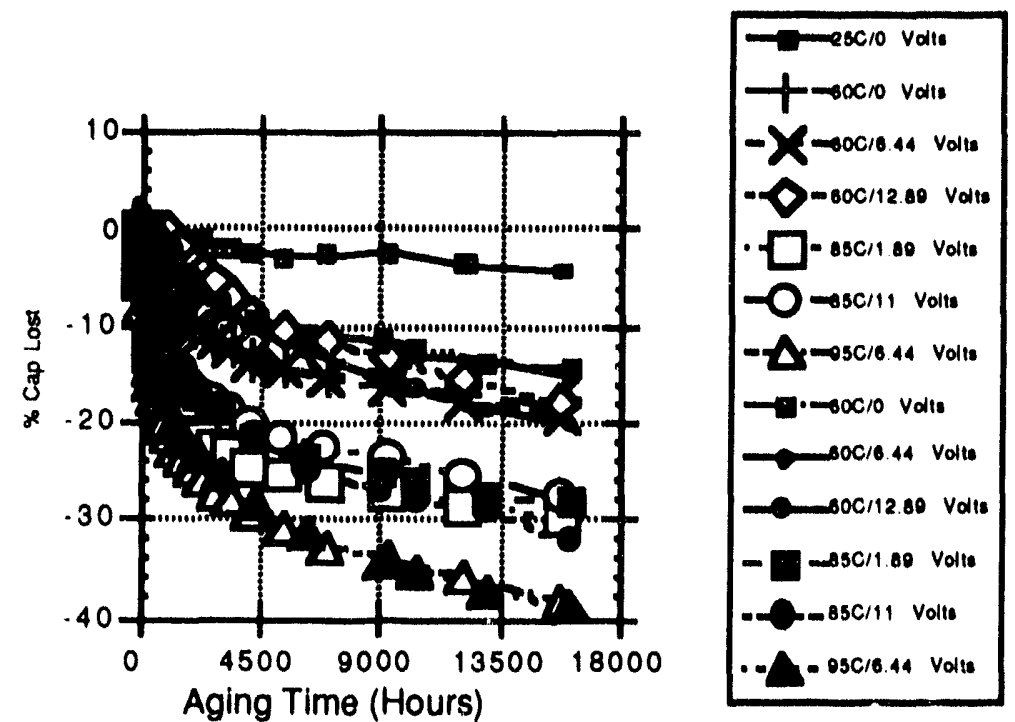

Figure 34. Percent change in Capacitance as a function of time, temperature, and voltage at $25^{\circ} \mathrm{C}$ for Solid SNL and Open Evans 


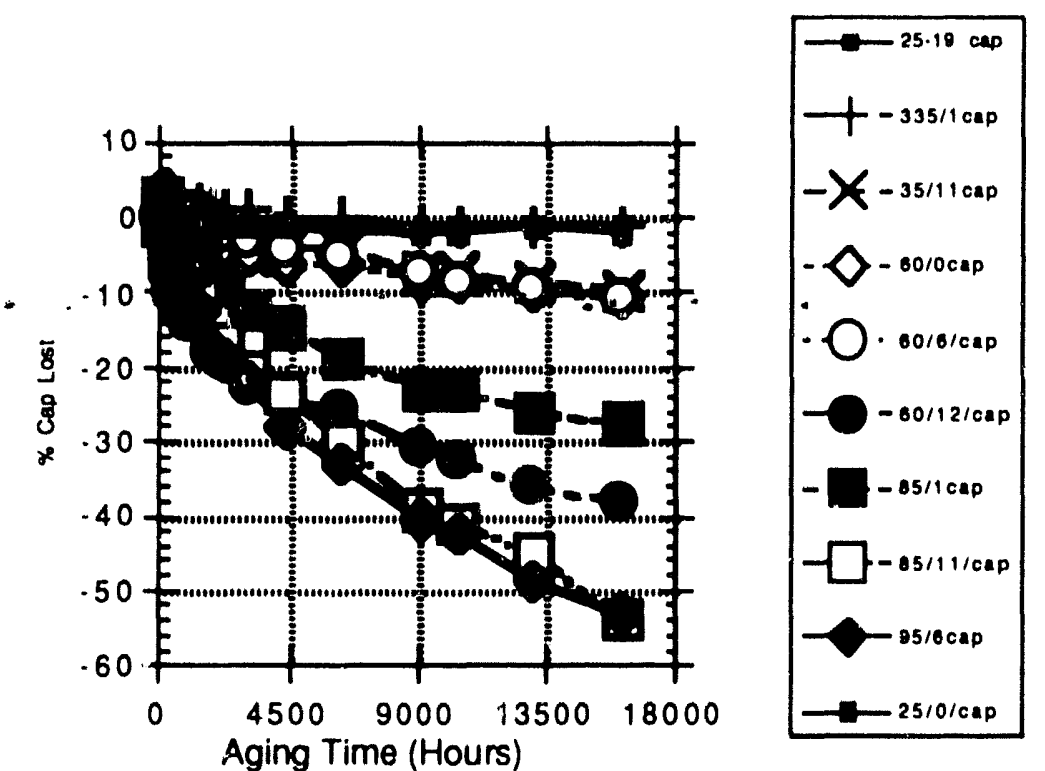

Flgure 35. Percent change in Capacitance as a function of time, temperature, and voltage at $-30^{\circ} \mathrm{C}$

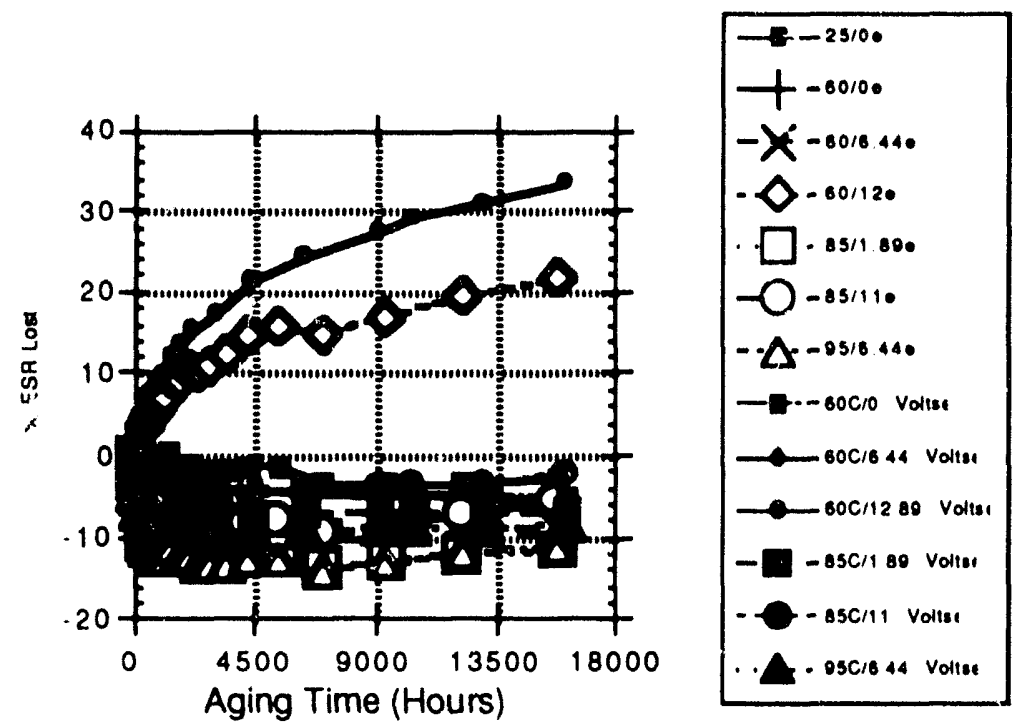

Figure 36. Percent change in ESR as a function of time, temperature, and voltage at $25^{\circ} \mathrm{C}$ for Solid SNL and Open Evans 


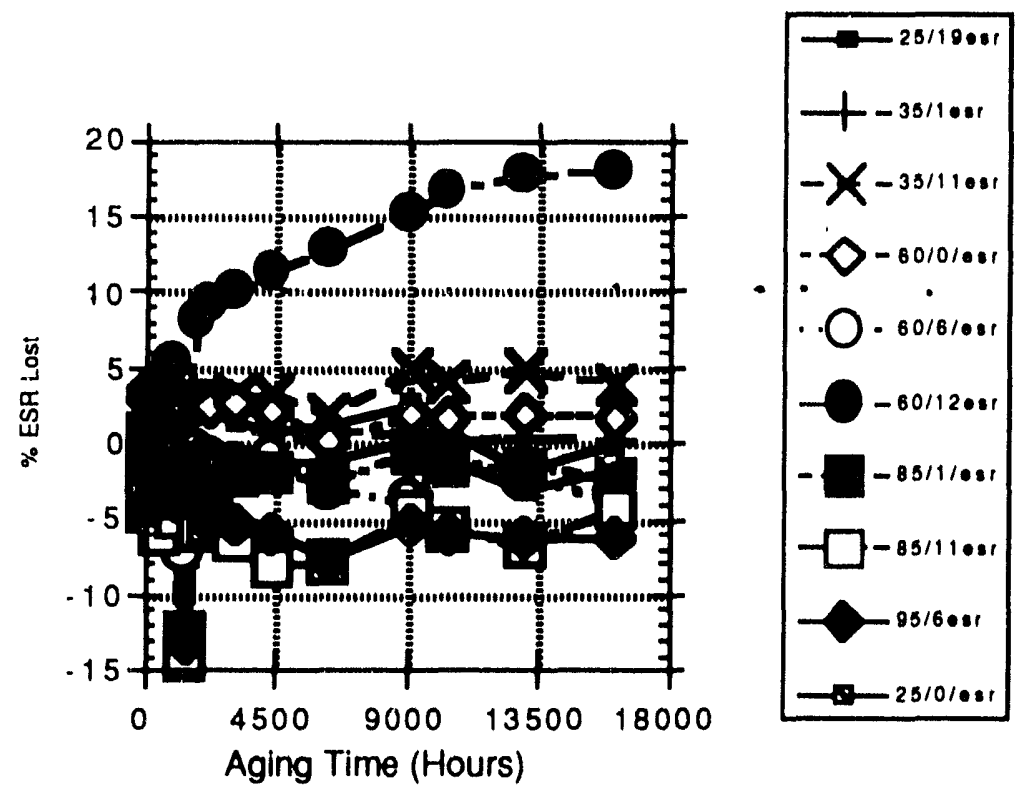

Figure 37. Percent change in ESR as a function of time, temperature, and voltage at $-30^{\circ} \mathrm{C}$

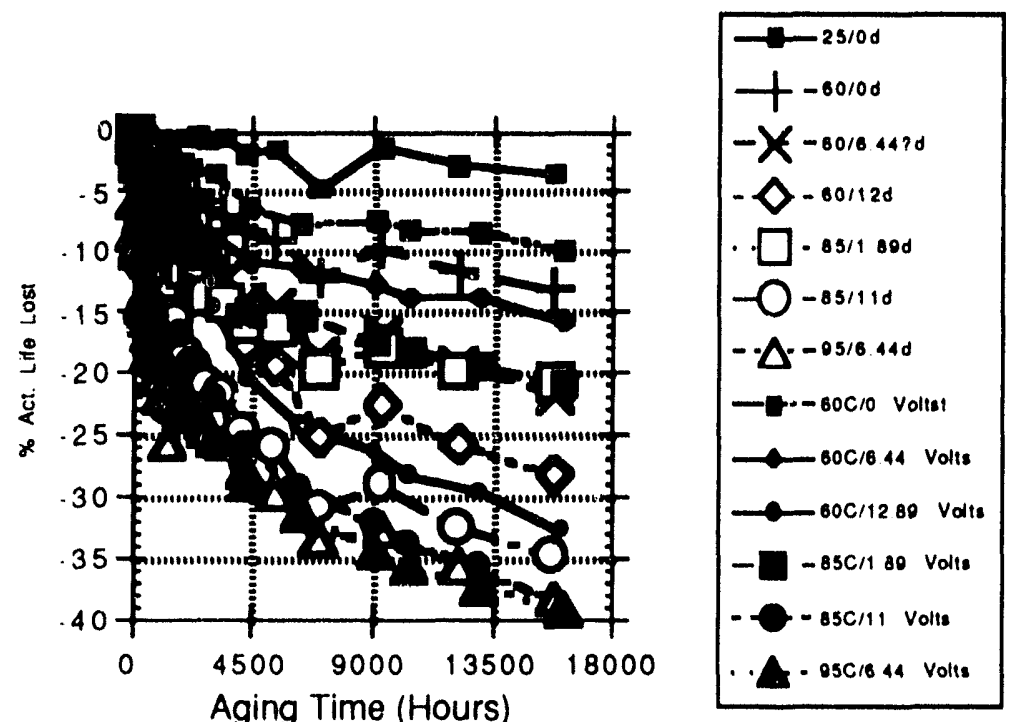

Figure 38 . Percent change in Activated Life as a function of time, temperature, and voltage at $25^{\circ} \mathrm{C}$ for Solid SNL and Open Evans 


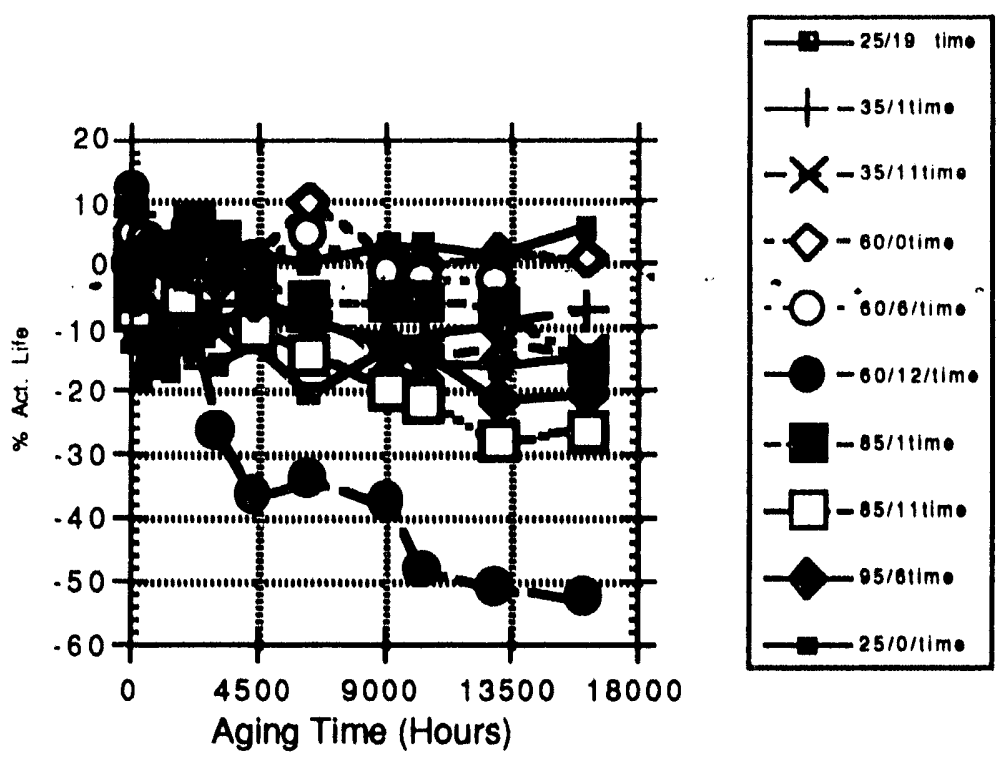

FIgure 39. Percent change in Activated Life as a function of time, temperature, and voltage

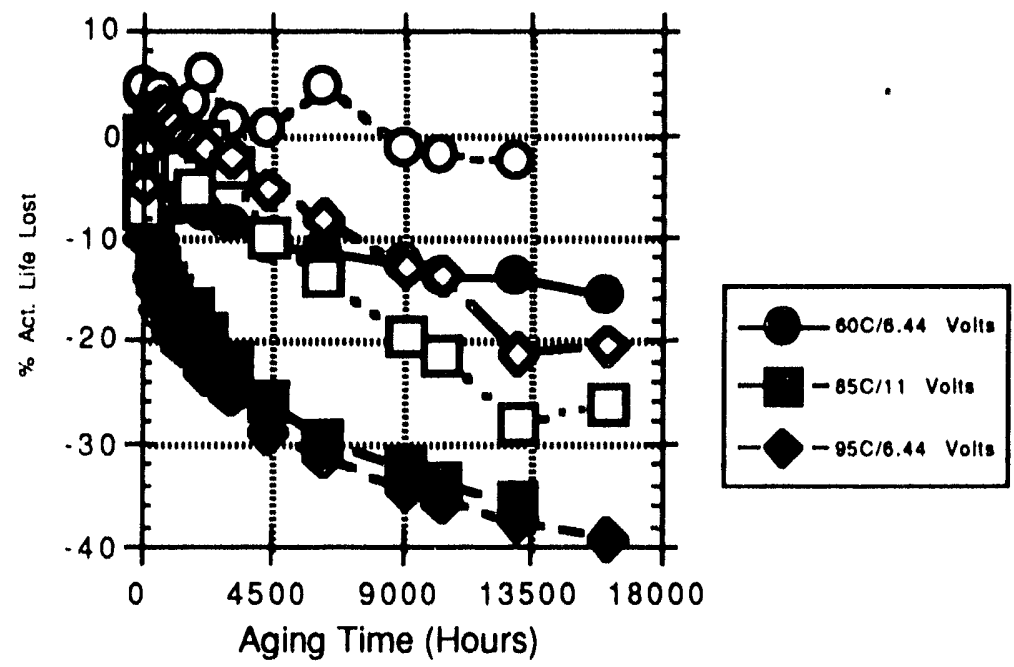

Figure 40. Activated Life as a function of aging, time, and temperature (Solid $+25^{\circ} \mathrm{C}$ and Open $-30^{\circ} \mathrm{C}$ ) 


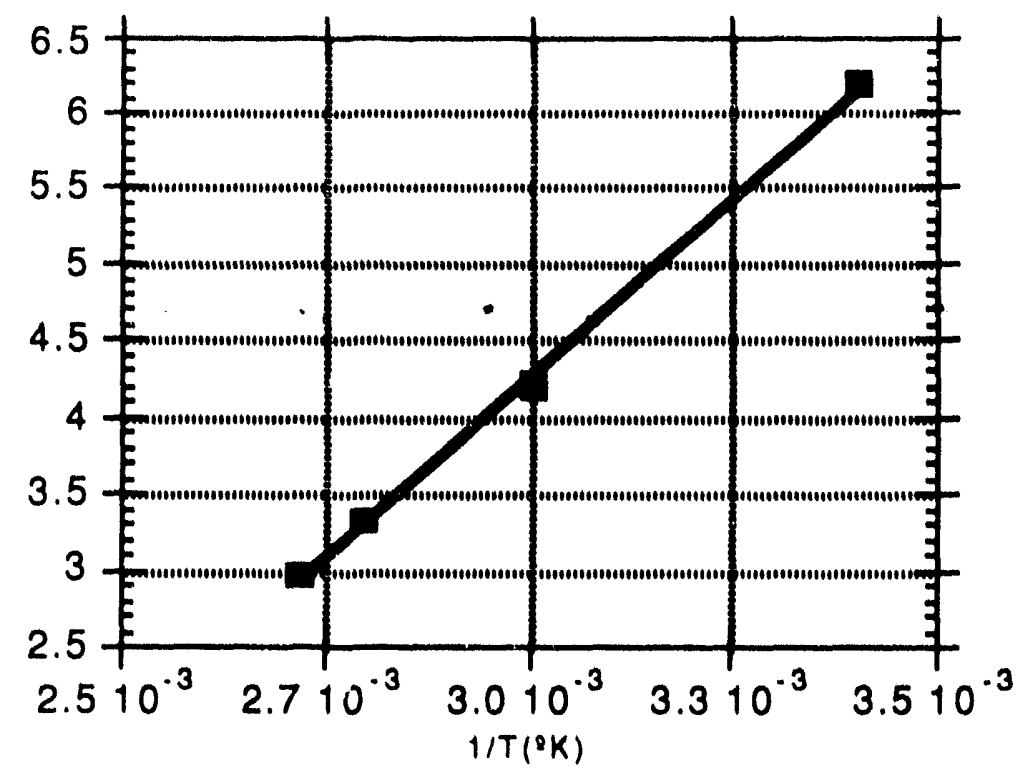

FIgure 41. Arrhenius plot of time to $20 \%$ degradation

\section{Safety Studies}

The safety issues of both the DLCs and the assembly have been assessed by the DLC manufacturer and the Pinellas Plant, which manufactured the assembly. Those reports are included in Appendix D.

\section{Reliability}

To assess the reliability over the life of the program, Don Wright (Org. 335) did statistical calculations using the assumption that 125 units will either be environmentally tested or used in surveillance testing. His report, included as Appendix $\mathrm{E}$, shows that the goal of 0.995 will be met over the life of the program.

\section{Summary and Conclusions}

The MC4169 has been shown to meet the design requirement. The margin testing in the environments shows the product to be robust. The aging study, along with reliability study, indicates that the MC4169 will be a reliable product that exceeds the required design life.

\section{References}

1J. R. Miller and H. K. Street, Development of a Hermetically Sealed Double-Layer Capacitor, SAND88. 7003, Sandia National Laboratories.

${ }^{2}$ M. A. Dvorack, Development Status of the MC4169 Double-Layer Capacitor Assembly for the B61 Common JTA, SAND89-2218, Sandia National Laboratories, February 1989.

${ }^{3}$ D. E. Evans et al., "Capattery Double-Layer Capacitor Life Performance," CARTS '91, 11th Capacitor and Resistor Technology Symposium, April 1991. 


\section{APPENDIX A}

\section{Tester Description for SE3611}


September 24,1992

N. H. Clark, 2525

W. E. Baca, 2525

\section{SE3211 Description}

\section{Introduction}

The SE3211 is capable of measuring the equivalent series resistance (ESR) from 1mOHM to $19.99 \mathrm{MOHM}$, capacitance of double layer capacitors (DLC) rated at 60 volts or less, and leakage current of DLC's rated at 50 volts or less. There are 16 available channels. Test measurements can be made on a single channel, all 16 channels (00-15), or any number of consecutive channels (1.e. 08-10). However, all channels used during a test must be at the same voltage. Data are displayed and stored on floppy disc or printed. The following descriptions are very basic in nature and are for information only. This document will refer to opening and closing of relays to aid in explaining the functions of the SE3211. However, most of the SE3211 functions are software controlled and the user will not be required to understand these functions. This document is not intended as an operation or maintenance procedure.

\section{Components}

The SE3211 consists of a Hewlett-Packard $3852 \mathrm{~A}$ data acquisition/control unit with a $3853 \mathrm{~A}$ extender chassis, HP4262A digital LCR meter, HP6228B dual power supply (0$50 \mathrm{~V} / 0-1 \mathrm{~A})$, HP6038A power supply $(0-60 \mathrm{~V} / 0-10 \mathrm{~A}, 200 \mathrm{~W})$, HP150 computer, and an HP9133 disk drive. The data acquisition/control unit and extender chassis contain the following plug-in accessories:

\footnotetext{
1 - 44701A 5 1/2-digit voltmeter

1 - 44705A 20-channel relay multiplexer

1 - 44728A 8-channel relay actuator (300V/5A $\max$ )

5 - 44725A 16-channel general purpose switch (30V/1.5A $\max )$
} 


\section{Relay Nomenclature}

When referring to a specific relay, switch or mux channel the format is SSCC, SS is the HP3852A slot number where the accessory card is located and CC is the channel number of the relay, switch or mux channel. For example relay \#100 is the Lc relay in slot 1 channel 00 (see $\mathrm{fig}:{ }^{\prime}$ ). The HP3852A data acquisition/control unit has 6 slots numbered $0-6$ and the HP3853A extender chassis has 9 slots numbered $10-18$, but only 10 and 11 are used.

\section{Slot I's 1-4 - ICR Neter connections}

The schematic diagram in Fig. 1 shows the configuration of accessories and instruments in the SE3211. A DLC is shown connected to tester channel 00. Channels 01-15 are omitted for simplicity, but would be similar to Channel 00 . The LCR meter is used for measuring ESR only. The LCR meter requires a four-wire connection to accurately measure ESR since cable resistance is significant in most cases. The four-wire connection consists of high potential (Hp), high current (HC), low potential (Lp) and low current (LC). The four wires must be separated until connection to the device being tested is made. At which time the $\mathrm{Hp}$ and $\mathrm{HC}$ leads will be attached to the positive terminal of the DLC and the $L p$ and LC leads will be attached to the negative terminal of the DLC. To accomplish this, and maintain a 16 channel

capability, a separate 16-channel general purpose switch is used on each of the four wires. slot \#1 in the HP3852A is the Le switch, slot \#2 is the Lp switch, slot \#3 is the Hp switch, and slot \#4 is the Hc switch.

\section{Slot 15 - Test Selection Relays}

The 16-channel switch in slot \#5 is used to connect a DLC to one of four possible "tests". For example when relays $500,504,508$ and 512 are closed the LCR meter can be used. By closing relays $501,505,509$ and 513 the HP6038A power supply can be used to charge DLC's on selected channels.

\section{Slot 6 - Relay Multiplexer}

Slot \#6 contains a 20-channel relay multiplexer (MUX). The MUX is used in conjunction with the DVM in slot 0 to read voltages on the 16 DLC channels (mux channels 600-615), one $100 \mathrm{ohm}$ discharge resistor (mux channel 618) and one $100 \mathrm{ohm}$ charge resistor (mux channel 619). MUX channels 616 and 617 are unused. 


\section{Slot 10 - Leakage current CVR's}

In slot \#10 of the HP3853A there is a 16-channel switch that is used when making leakage current measurements. A ten ohm resistor has been installed in each of the 16 channels on the normally open position of the relay so that when the relays are.closed the. 10. ohm resistors.will be in series with the. DLC's on each of the 16 channels. When the relays are left open slot \#10 is part of the HC leg of the circuit. When leakage current measurements are being made relays in slot \#3 must remain open so as not to short out the 10 ohm resistors in slot \#10.

\section{Slot 11 - Power Supply Configuration Relays}

An 8-channel relay actuator is found in slot \#11 of the HP 3853A. These relays are contact protected and are capable of handling higher currents than the 16-channel switches. Therefore when charging or discharging a DLC, the 16-channel switch relays are closed before any of the relays in the 8channel actuator. By closing relay 1100 the HP6038A may be connected through a $100 \mathrm{ohm}$ series resistor to any of the DLC test channels either individually or in parallel. When relay 1101 is closed the 6038A may be connected directly (no sertes resistor) to the DLC test channels. Closing relay 1102 allows use of the HP6228B left supply and closing relays 1103 and 1105 allows use of the right supply. In order to use the left and right supplies in parallel relays 1102,1103 and 1104 must be closed. The right and left supplies may be used in series by closing relays 1102 and 1105 but this also requires a front panel jumper wire from the left minus (-) to the right plus $(+)$.

\section{ESR Measurements}

ESR measurements are made at $1 \mathrm{kHz}$ after all selected channels are checked for voltage and discharged if needed. Relays $500,504,508$, and 512 are closed first and then $1 X X$, $2 \mathrm{XX}, 3 \mathrm{XX}$, and $4 \mathrm{XX}$ are closed. $\mathrm{XX}$ represents the tester channel currently under test. There is a built in pause in the software to allow the reading to stabilize before storing the value. Each selected channel is tested in succession. Figure 2 shows only the relays used for an ESR measurement on tester channel 00. Note that the relays in slot \#10 are in the normal position for this test. (i.e. the $10 \mathrm{ohm} C V R$ 's are not in the circuit). 


\section{Capacitance Measurements}

Voltage on all selected channels is checked and discharged if necessary. The HP6038A power supply is set by the SE3211 to the proper voltage for the specified capacitors (60 volts $\max )$ and current limited to 3 amps. Relays. 5.01,505,509, and 513 are closed to allow use of the HP6038A power supply. Relays $1 X X, 2 X X, 3 X X$, and $4 X X$ are closed ( $X X$ is active channel number). Then relay 1100 is closed and a timer is started. The DLC currently under test is now charging through a $100 \mathrm{ohm}$ serjes resistor and the DLC voltage is constantly monitored. When the voltage reaches a previously specifled level the timer is stopped. The time is divided by 100 ( $100 \mathrm{ohm}$ resistor) and this is the capacitance value that is stored. Each selected channel is tested in succession. Figure 3 shows only the relays used for a capacitance measurement on tester channel \#00. Again slot \#10 is in normal position. Relay mux channel 619 is used to monitor the voltage.

\section{Leakage Current Measurements}

All selected channels are charged in parallel to a previously specified voltage ( 60 volts max) using the HP6038A. The HP6038A power supply is used initially because it is capable of delivering 60 watts. However, the current limit is set to 3 amps maximum because the 8-channel relay actuator is rated at 3 amps per channel and fused at 5 amps per channel. For the selected channels all slot 1-4 relays are closed, then relays $501,505,509$, and 513 are closed to allow use of the HP6038A. Now relay 1100 is closed and all selected channels begin charging through a 100 ohm series resistor. When the power supply current drops below 0.1 amp, relay 1101 is closed shorting the 100 ohm resistor and charging the selected channels without a series resistor. This helps to speed the initial charging of the capacitors without risk of over-loading tester circuits. When the power supply current drops below 0.02 amps relays $502,506,510$, and 514 are closed to allow use of HP6228B power supply. Note: The HP6228B will be used for the leakage current measurements because is has a more stable voltage regulation than the HP6038A. The relays in slot \#10 are closed for selected channels and the relays in slot \#3 are opened to allow use of the 10 ohm current viewing resistors. Relays in slot 11 will be closed according to the voltage requirements of the DLC's under test. The HP6038A is now switched out of the circuit and the DLC's are held at voltage for 30 minutes, after which cvr voltage is measured on each selected channel. The leakage current is calculated and then stored. Figure 4 shows only the relays used for tester channel \#00 during the pre charge of the DLC. Relays in slot \#10 are in normal position at this point and relay 1100 in slot \#11 is closed to use the $100 \mathrm{ohm}$ series resistor. Relay 1101 will close when the 
power supply current drops below 0.1 amp. When the power supply current drops below 0.02 amps the relay configuration will be as shown in figure 5. Note that slot \#10 relay 1000 is now closed (1.e. the $10 \mathrm{ohm} c \mathrm{cr}$ is in the circuit) and slot $\$ 3$ relay 300 is open to allow CVR voltage measurement on slot \#6 channel 600 .

\section{DISCHARGIKG DIC'S}

Before the start of a test, voltage on selected test channels is measured. If voltage is greater than 0.1 volts then all selected channels are discharged and shorted for 30 seconds. Figure 6 shows the relays used for discharge and shorting of tester channel \#00. 


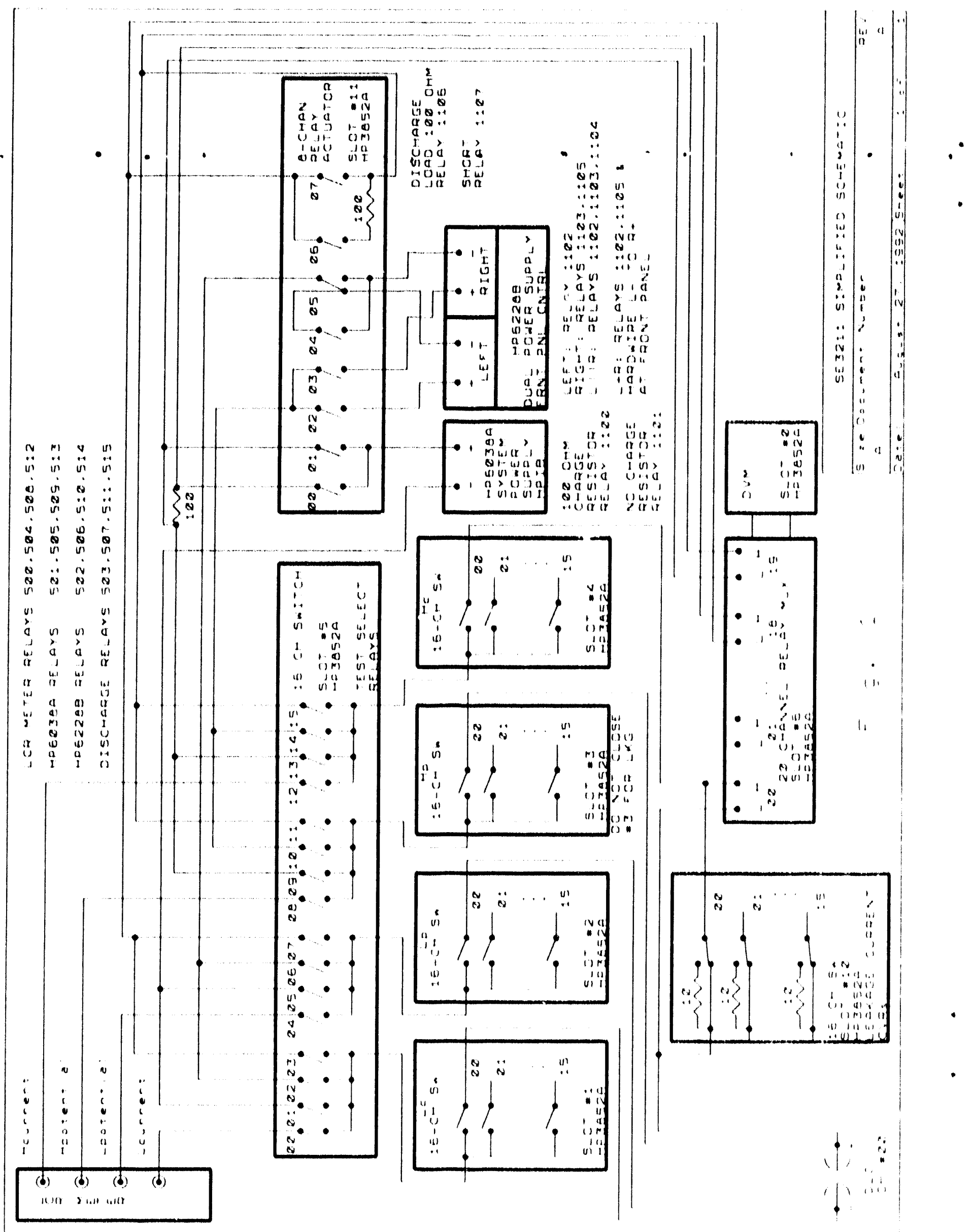




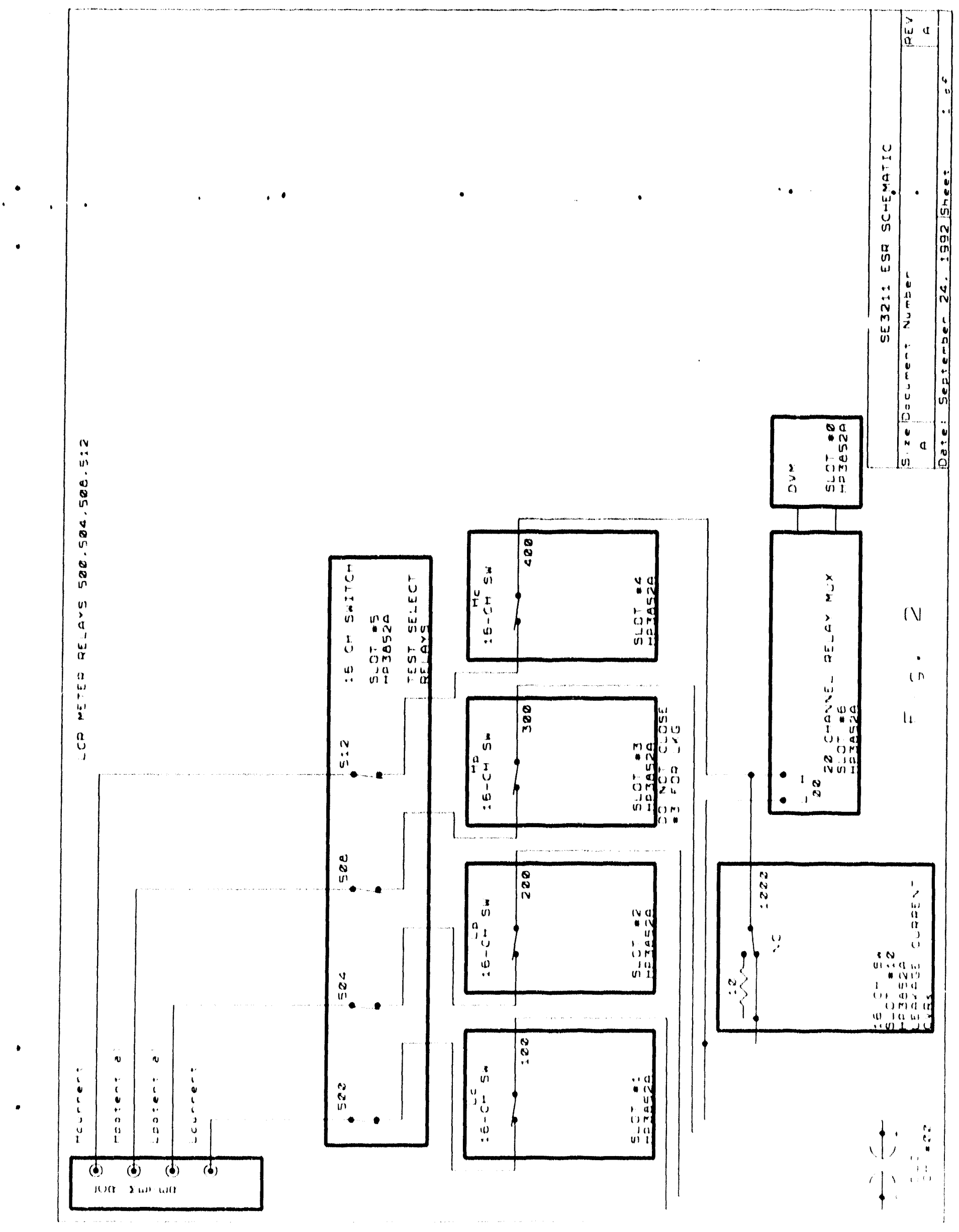




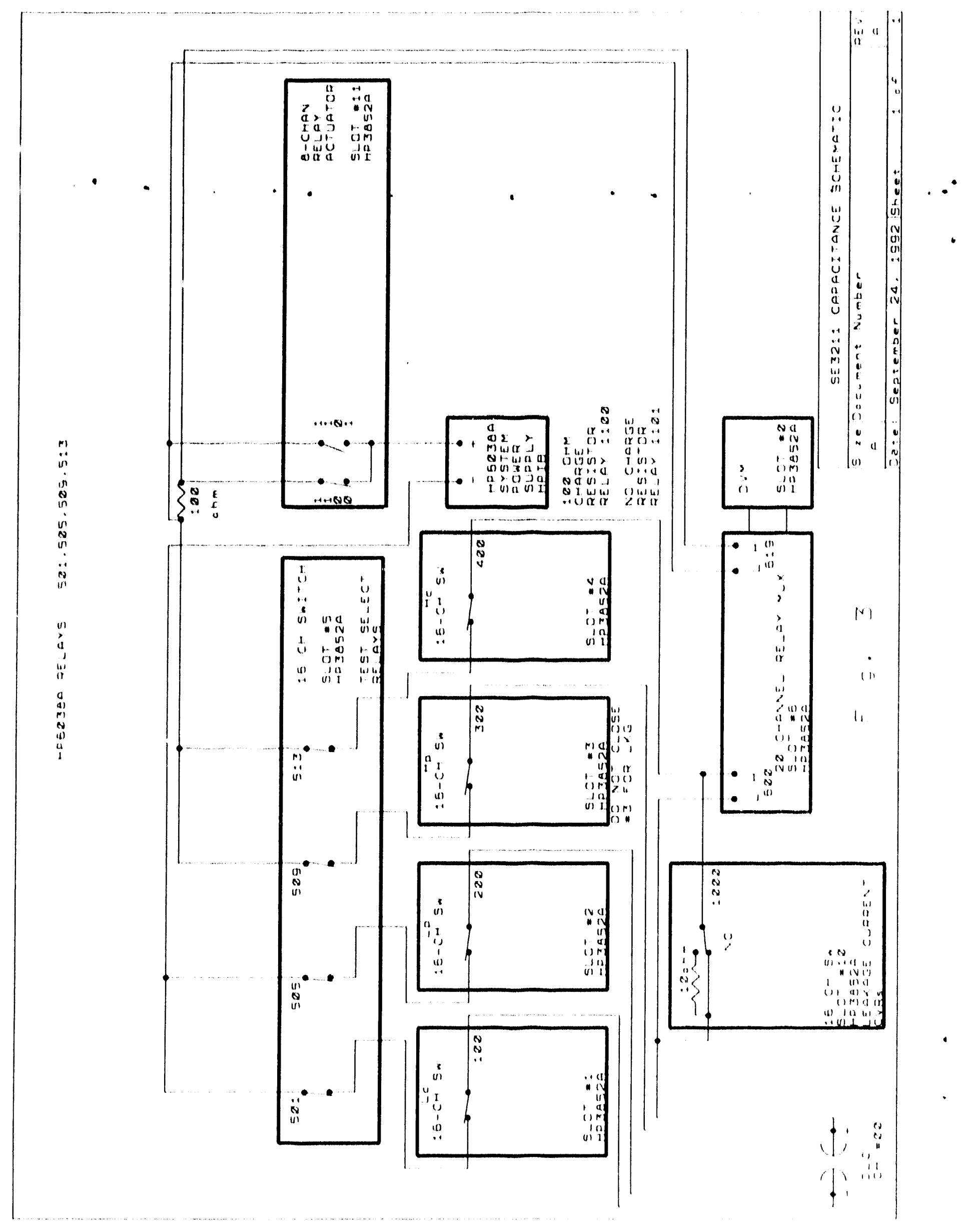




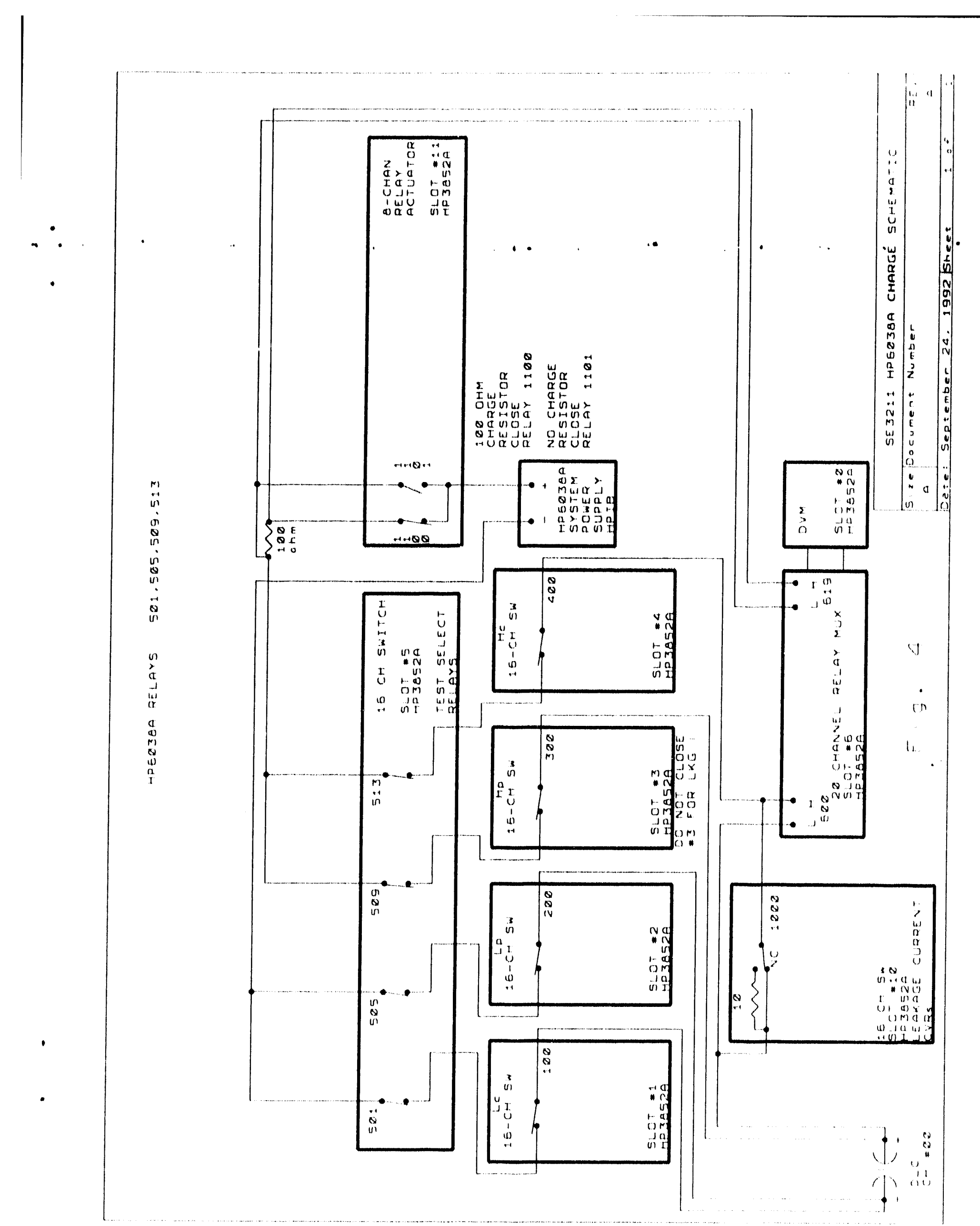




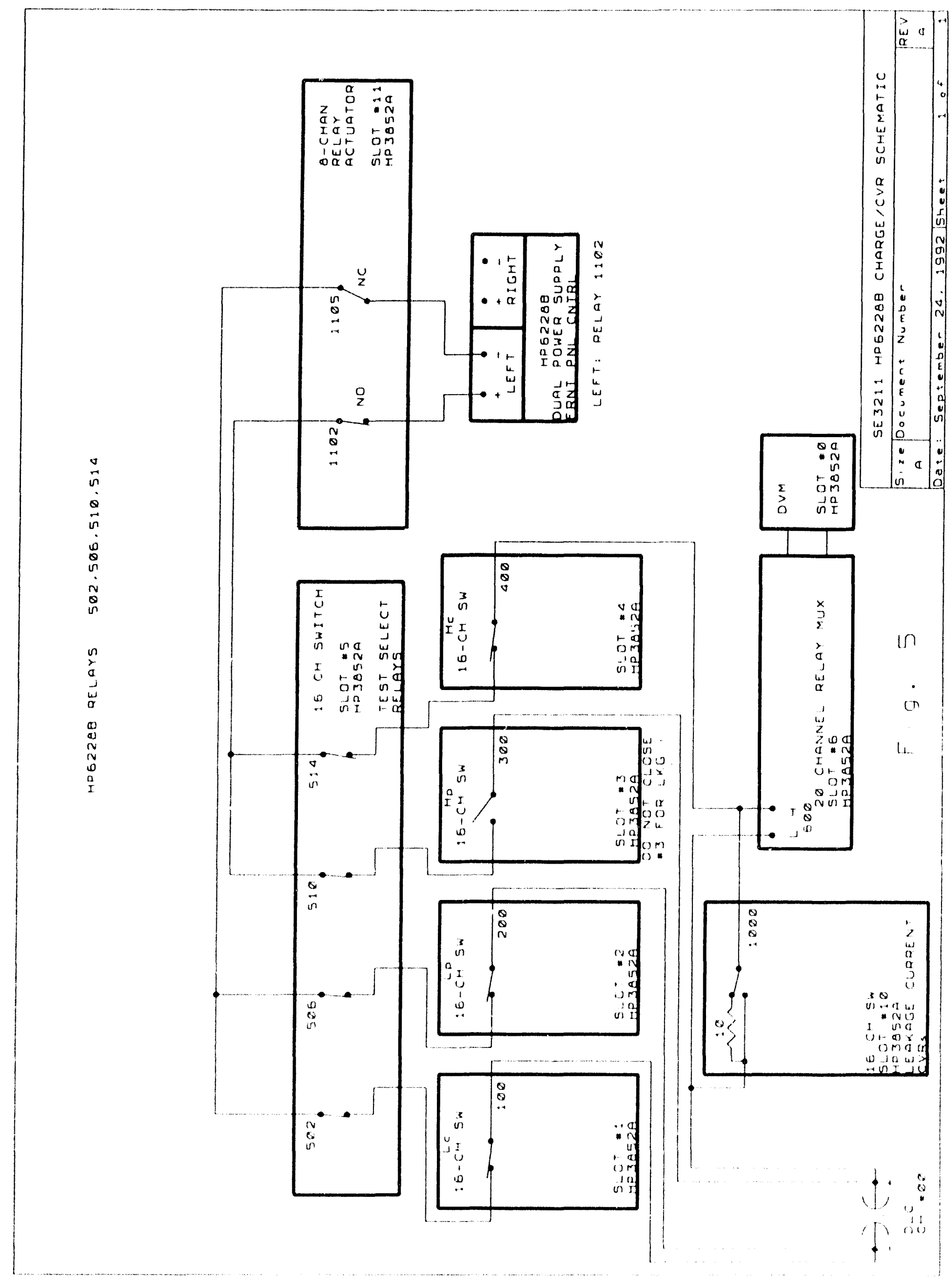




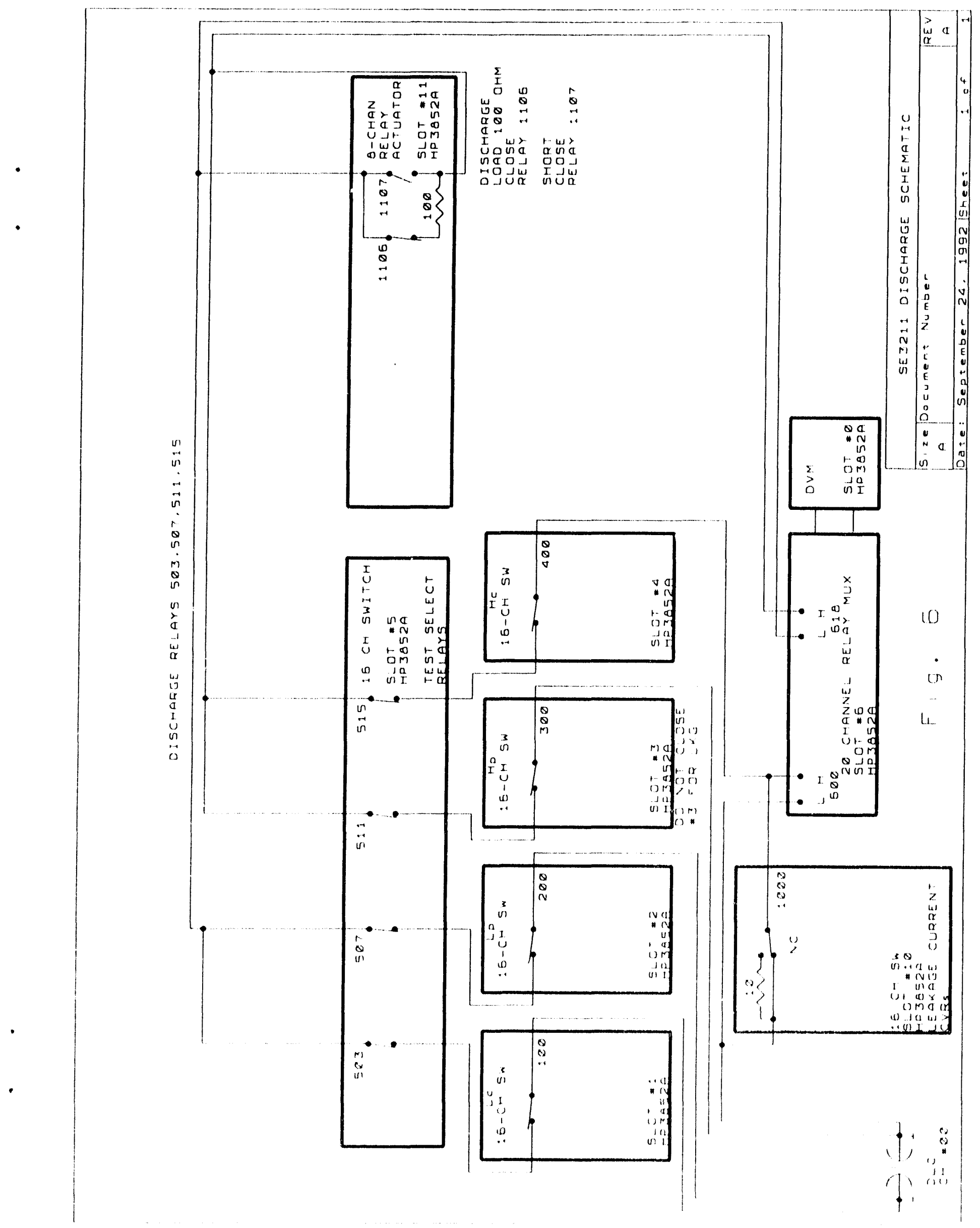




\section{APPENDIX B}

\section{Top Drawing for MC4169}




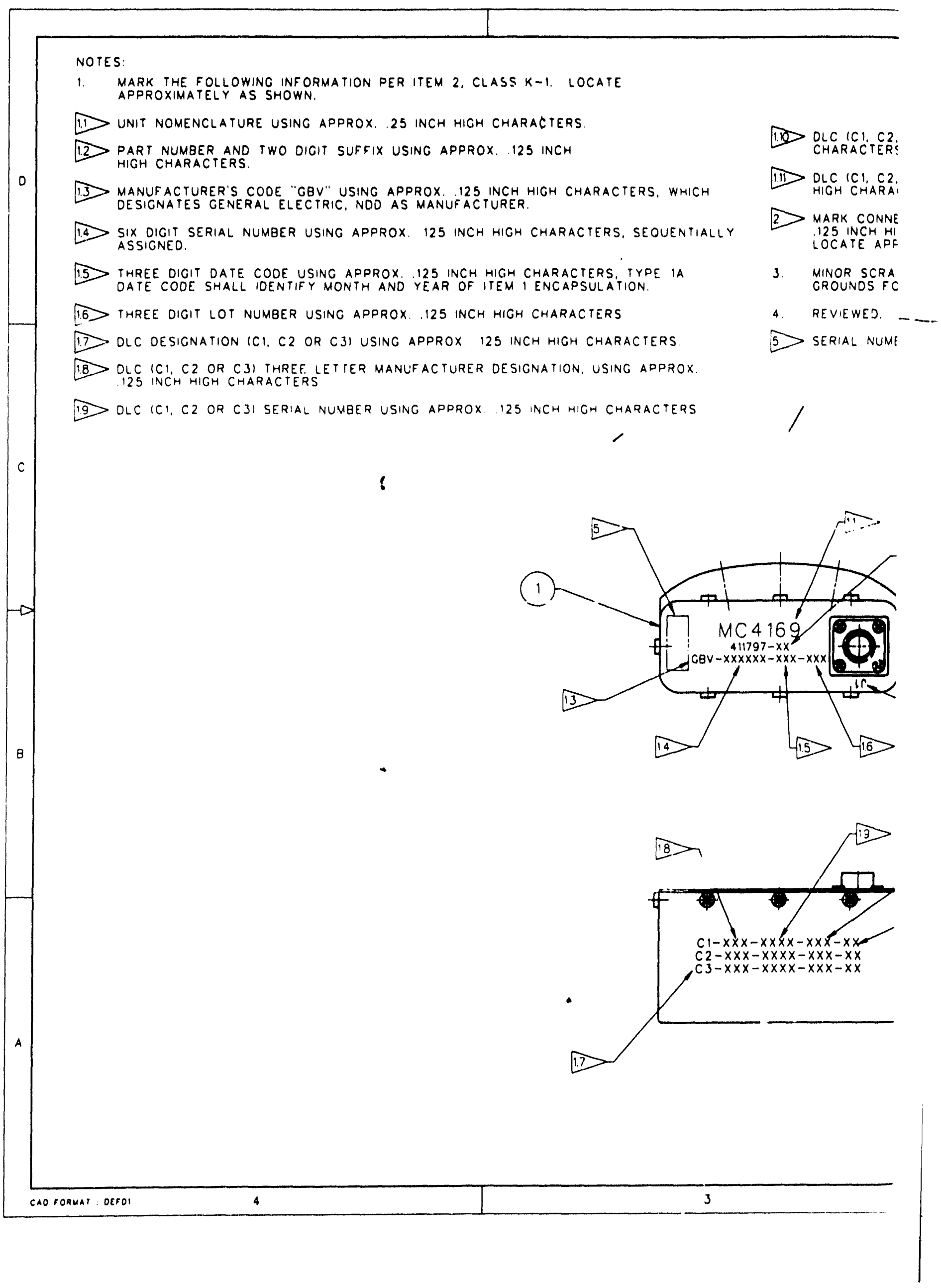




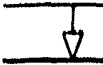

C31 THIEE DIGIT DATE CODE, USING ARPRUX, 125 INCH HIGH

\begin{tabular}{|c|c|c|c|c|c|c|c|}
\hline \multirow{2}{*}{ CONPAAR' OR NUEBCR } & \multicolumn{7}{|c|}{ Acvisions } \\
\hline & 153 & $\begin{array}{l}\text { SHECT } \\
\text { ZONE }\end{array}$ & PAEPA & descriprion & OATE & CHKA & APVO \\
\hline $411797-00$ & $k$ & & $\begin{array}{l}\text { JA GRITTON } \\
\text { JO SGRO, PP } \\
N \text { CLARK, SA }-2526\end{array}$ & 9icis $39 P P$ & $8 / 7 / 92$ & & \\
\hline
\end{tabular}

C3I TWJ DIGIT LOT NUMBER, USING APPROX. 125 INCH

:TERS.

GTOR DI SIGNATION "JI" US"MIC APPROXIMATELY

SH CHAFACTERS PER ITEM 2. CLASS A-2-A.

TCHES OR DEFECTS TO CHROMATE COATINS SHALL NOT BE R PART REJECTION.

ALL REGUIREMENTS ARE/O/ EXCEDT TiHOSE INDICATEO AS/U,

IER SCRBED IN INOICATEO AREA IS ACCEPTABLE.

\section{2)}

$\mid$
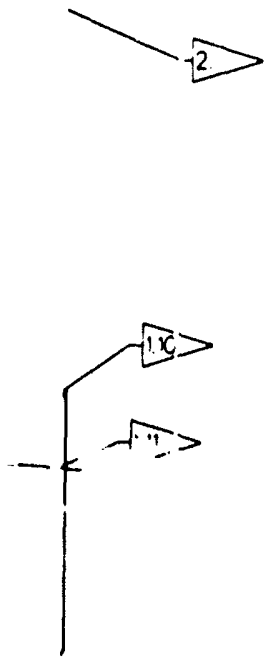

\begin{tabular}{|l|l|l|}
\hline NA & 100241886001 \\
\hline NA & \\
\hline
\end{tabular}

NA 0 T $411797-000$

VA JOR 411797.000

\begin{tabular}{|l|l|l|l|}
\hline NA & $P \subseteq 411797-000$ \\
\hline 1 & $P T 3392-04$ \\
\hline
\end{tabular}

\begin{tabular}{l|l|l}
\hline & PT $3392 \cdots 0_{4}$ \\
\hline
\end{tabular}

$\div \frac{411797-002}{50}$

- -...

NA A $1411797-001$

NA AF 392795-000

\begin{tabular}{|l|l|l}
\hline NA & AF $392592-002$ \\
\hline NA
\end{tabular}

NA AM392592-001

\begin{tabular}{l|l}
\hline NA & $50392592-001$
\end{tabular}

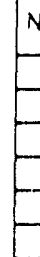

NA AM 392591-001

1 UA5743-000

1 UA5565-000

1 CB3841-000

\begin{tabular}{l|l}
1 & CB3843-000 \\
\hline 1 & $C B 3844-000$ \\
\hline
\end{tabular}

1 C83844-000

\begin{tabular}{l|l}
1 & CB3152-000 \\
\hline & CB3163-001
\end{tabular}

1 CB3163-001

\begin{tabular}{|l|l}
\hline 1 & $C B 3803-000$ \\
\hline 1 & $C B 3842-000$
\end{tabular}

1 CB3842-000

\begin{tabular}{l|l}
1 & CBOB $68-000$ \\
\hline & $391073-200$
\end{tabular}

\begin{tabular}{l|l}
1 & $391073-200$
\end{tabular}

\begin{tabular}{|l|l|}
\hline NA & 9900000 \\
\hline NA & 9919100 \\
\hline
\end{tabular}

NA 9919100

\begin{tabular}{|l|l}
\hline 1 & $391045-200$ \\
\hline
\end{tabular}

OTY PART/COMTROL NO.

OMI DARTICONTROL NO.

CAPACITOR PKC REOTS

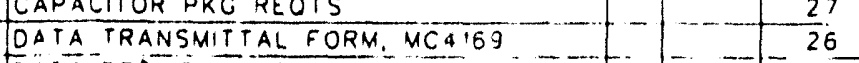

OA A AROUIREMENTS, YC4 169

P. S. MC 4169

- JTO PWR SOURCE.S TESTER

CERAT VO PRCLEDURE, PI3S92/MC 4169

DAU PROFILE DISTK. PIJ3 $\overrightarrow{92 / M C 4169}$

OPERATING PROC, UA5565/MC4169 INC

OPERATING PROC, PT3392/MC4 69

LOAD PROFILE UISK, PT $3392 / M C 4 ! 2$; VIB

LOAD PROFILE OOC. PT3392/MC4169 ENV

LOAD PROFILE DISK, PT3392/MC4169

SHOCK ANO LINEAR ACCELERATION

DLC ENVIRONMENTAL TEST BOX

OLG DEVELOPMENT TESTER

DLC TEST CABLE

DLC TEST CABLE

DLC TEST CABLE

CONNECTOR CABLE

ENVIRONMENTAL CABLE

ENVIRONMENTAL CABLE

DLC TEST CABLE

CABLE ASSEMBLY

SHORTING PLUG

GENL MFG REOTS

CENL MARKINC

UNIT ENCAPSULATION

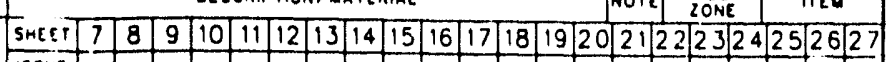

issue

\begin{tabular}{|l|}
\hline PAR! \\
COOS
\end{tabular}

\begin{tabular}{|l|l|l|l|l|l|l|}
\hline SHEE & 1 & 2 & 3 & 4 & 5 & 6 \\
\hline ISSUE
\end{tabular}

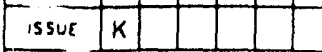

PART : LASSIFICATION

UNCLASSIFIED

oraming classiríation

UNCLASSIFIED

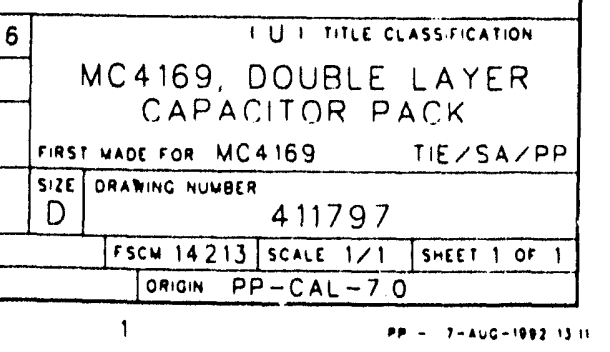




\section{APPENDIX C \\ Internal Design for MC4169}




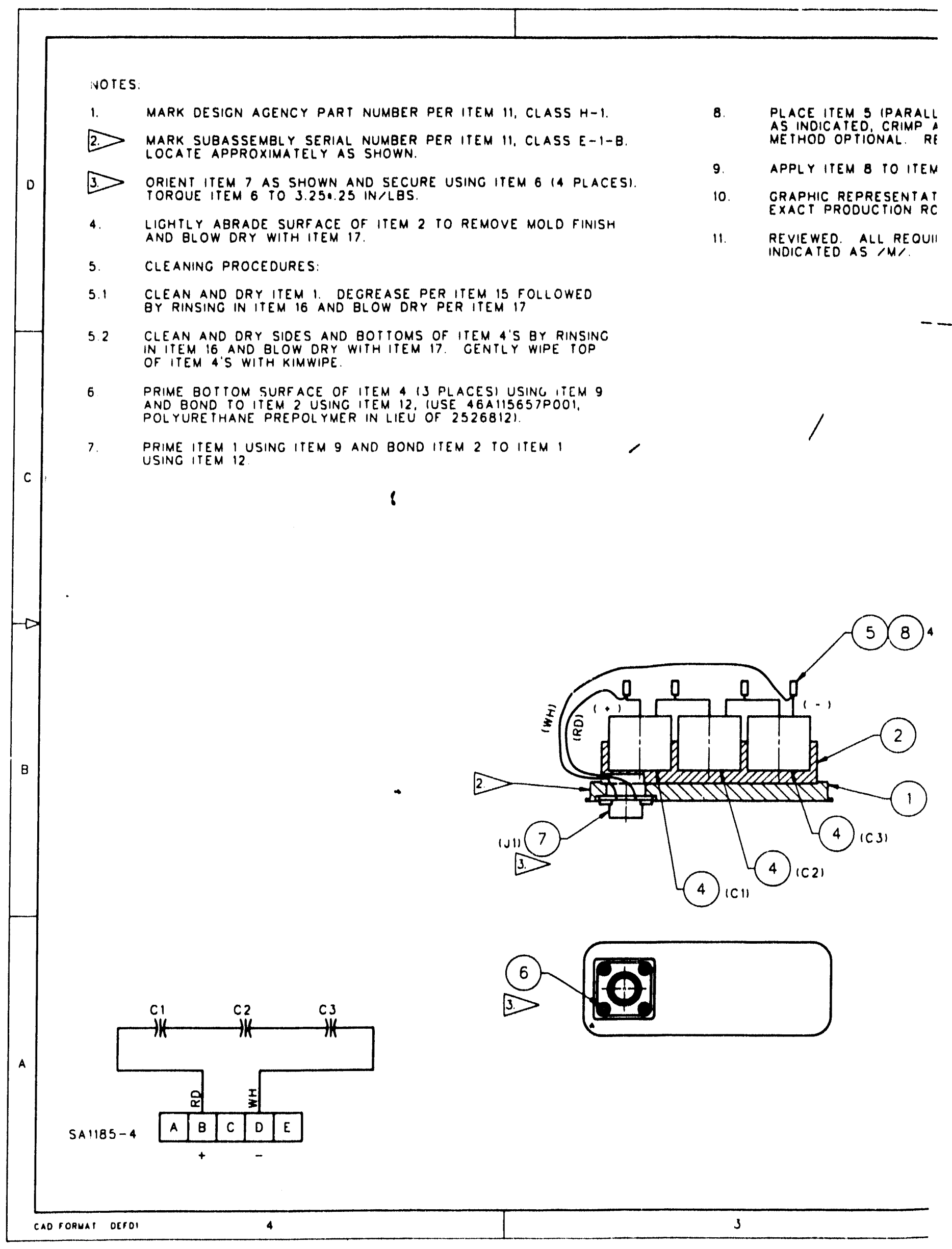




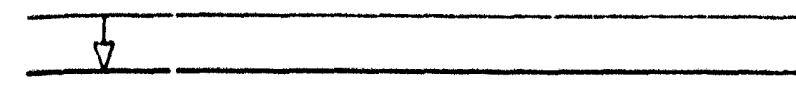

EL SPLICE) OVER WIRES TO BE JOINEO

ND SOLDE ? USINC ITEM I PER ITEM IA.

MOVE EXCESS FLUX USING ITEM 16.

\begin{tabular}{|c|c|c|c|c|c|c|c|}
\hline \multirow{2}{*}{$\begin{array}{l}\text { PARt ON } \\
\text { CONinOL nUMAE }\end{array}$} & \multicolumn{7}{|c|}{ arvisions } \\
\hline & 153 & $\begin{array}{l}9 \mathrm{MCC} \\
\mathrm{lom}\end{array}$ & OAEPAACO UY & OESCRIPIION & 0.18 & Cann & APVD \\
\hline-200 & $F$ & & $\begin{array}{l}\text { CP } 5 \text { ANNING } \\
\text { JO SGRO, PP } \\
N \text { CLARK, SA }-2526\end{array}$ & $910141 C E$ & $3,25,91$ & & \\
\hline
\end{tabular}

3. 4 PLA:ES

ION OF WIIRE ROUTINC IS NOI NECESSARILY

UTING. SIE SCHEMATIC FOR WIRINC PROCEDURE

PEMENTS \&RE /O, EXCEPT THOSE

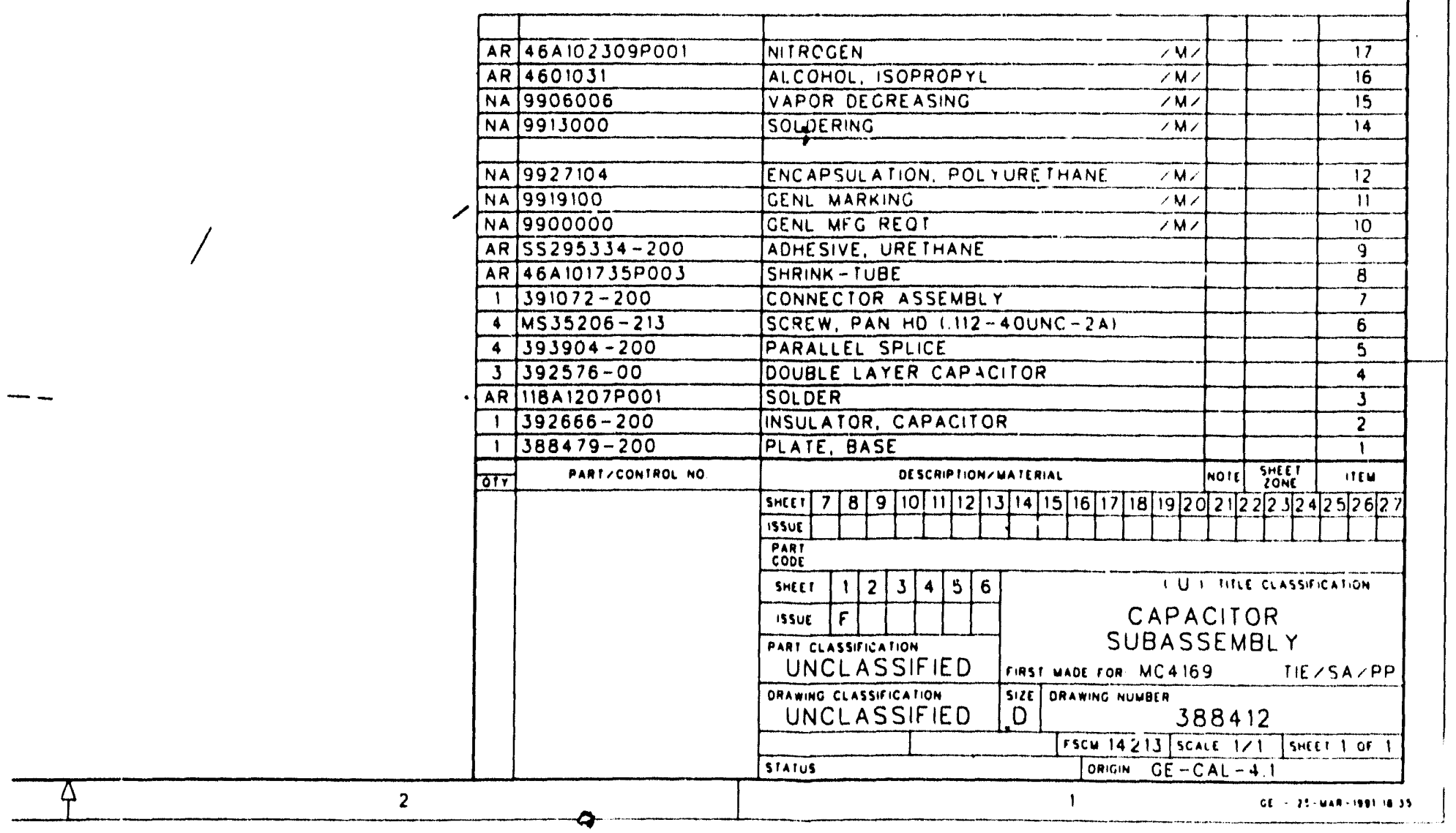




\section{APPENDIX D Safety Studles}


Mr. Cllft Wagner

GE Aorciefroce, Noutron Dovices

P. O. BOX 2908

Largo, Florldo 34649

Dear Cltef:

You aked for commente on electrlcal an faty lasues relating to the use of our Capattory double layer capacitor. Although not on expert on thls subject, I are pluased to provide you with the information I have.

We routinely handle alngle, charged, $11 \mathrm{~V}, 0.36 \mathrm{~F}$ roted

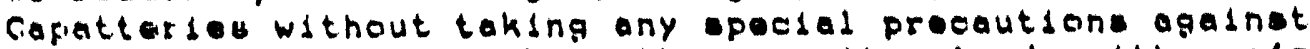
- lectrleal shock. Touching the capacitor laad with on " finger creates no fiercaptible consation, and does not meanurably discherge the capacitor. Three sorles-connected copaclter of the same rating charged to 34 volt have - inflar of foet.

From my dimlted inveatigation of edectrdeal aafaty, it opfear that de voltages balow so $\mathrm{V}$ are not consldered serlous health hazords. I reforence the followlng sectlone of the 1990 odition of the "National Eloctrical Code" (Noticinal Fir Protection Asociation, Batterymerch Park, Quiney, MA., O2z(G),

110-17 GUAROING OF LIVE PARTS (600 V, nominad, or lass)

(a) Live parta guarded agalnat accldental contact. Except as elsowhere required or pormitted by this Code, live parte of olcetric oquipment oporating at 50 volt or more hald be guarded against accidental contenet ty approved onelosuros or by any of the followling: .....

460-6 DISCHARGE OF STORED ENERGY CaPACltor $600 \mathrm{~V}$, nominal, or loses Capocitor shall be provided with a mans of discharging stored enorgy.

(a) Time of Discharga. The rasldual voltage of a cafieltur siall be raduced to se volts, nominal, or less, within 1 minute ofter the capocitor 18 disconnected from the sciurce of supply. 
480-8 BATTEKY LOCATIUNS. Battery locatione ahadd conform to (a) and (b) bolow.

(a) Vantdiatdon......

(b) Livo Parto. Guarding of livo parts shadd oompdy with section 110-17. (11sted above)

I hope these comments are adequate in addreseing the lacue. ploase phone if you noed additional information.

-

sinceraly,

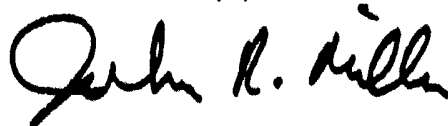

John K. Mldier

Evans Consultent

ec David A. Evana 


\section{ENVIRONMENTAL, HEALTH AND SAFETY}

\section{Double Layer Capacitor Power Source Injury Potential Analysis}

J. C. Roubik, Principal Engineer

Specialty Equipment

C. G. Wagner, Principal Engineer

Power Sources Engineering

September 1993

Martin Marietta Specialty Components, Inc., is the Management and Operating Contractor for the Pinellas Plant Under

U. S. Department of Energy Contract No. DE-AC04-92AL73000. 


\section{NOTICE}

This report wes prepered es an secount of work sponsored by en egeney of the Untred Stetes Covernment. Netther ine United States

Covernment nor any agency thereot. nor any of inair employees. nor eny of their contrectors. subcontroctors. Or their employees, makes eny worronny, exprese or implied, or sesumes any logal lin. illiry or responsibility for the sceursey. comploteness, of vectulness of any intormation. apparatus, product, or proceses dieclosed. or represente that he use would not infringe privately owned rights. Relerence nerein to any specilfic commercial product, process. or service by tradename, trademark. manutacturer, of othenwise, does not necessarily construte or imply its endorsement, recommendation, of Povoring by the United States Covernment or any agency inereot. the views and opiritions of suthors expressed herein do not neceserrily state or reflect those of ine United States Government or eny egeney thereol. 
GEPP-EV- 1261

$\cup C-707$

\section{DOUBLE LAYER CAPACITOR POWER SOURCE} INJURY POTENTIAL ANALYSIS

John C. Roubik, Principal Engineer

Specialty Equipment

C. G. Wagner, Principal Engineer

Power Sources Engineering

September 1993

Martin Marietta Specialty Components, Inc.

P. O. Box 2908 - Largo, FL 34649-29C8

Management and Operating Contractor

for the Pinellas Plant under

U. S. Department of Energy

Contract No. DE-AC04-92AL73000 


\begin{abstract}
An analysis of the Double Layer Capacitor (DLC) was performed at the Pinellas Plant to determine its potential for producing physical injury. The DLC is a low voltage energy storage device. The destructive effects produced as the result of the release of stored energy relates to both the rate at which the energy is absorbed and the energy density which occurs in the absorbent. The energy buildup in an energy-absorbing element is sensed as heat and is dissipated through heat flow and infrared radiation. Heat is represented by molecular and atomic vibrations. The level of these vibrations is, in turn, related to the absorbents temperature. Analysis for potential temperature rise in human flesh provides an indication of injury risk to humans from a low voltage electrical energy storage device.

The conclusion for the work is that the voltage and current associated with either the DLC (11 volt, 0.5 farad) or with three DLCs wired in series ( 34 volt, 0.1 farad) is too low to present a significant injury risk to individuals.
\end{abstract}




\section{TABLE OF CONTENTS}

Section

Page

$\begin{array}{ll}\text { INTRODUCTION } & 1\end{array}$

BACKGROUND 1

Burn Potential 1

EXPERIMENT

Flesh Resistance 3

DOUBLE LAYER CAPACITOR OPERATIONS

$\begin{array}{ll}\text { CONCLUSIONS AND RECOMMENDATIONS } & 6\end{array}$

$\begin{array}{lc}\text { REFERENCES } & 6\end{array}$

$\begin{array}{lc}\text { ACKNOWLEDGMENTS } & 6\end{array}$

APPENDIX A -UA6114 Double Layer Capacitor Safety Discharge Load A-1 Draft Operating Procedure

DISTRIBUTION

\section{ILLUSTRATIONS}

Number

Page

$1 \quad$ Equivalent Electrical Circuit for Electrical Energy Absorption by Flesh

2

\section{TABLES}

Number

Page

$1 \quad$ Skin Resistance of Chicken Leg at 35 Volts Applied

4 


\section{INTRODUCTION}

Minimum injury risk and safe human contact with potential injury-producing material, components, equipment, and processes is a major objective in operations at the $U$. S. Department of Energy (DOE) Pinellas Plant. A Double Layer Capacitor (DLC) electrical energy discharge injury risk analysis was performed to address this objective. To this end, an analysis was performed on the DLC to determine the risk of injury from electrical discharge.

\section{BACKGROUND}

\section{BURN POTENTIAL}

The effects produced as the result of the release of electrical energy into an energy absorbing body are related to both the rate at which the energy is absorbed and the density of energy occurring as a result within the absorbent. The energy density buildup within the absorbent is sensed as heat. Heating occurs as the result of molecular and atomic vibration and interactions. The level of these vibrations/interactions is, in turn, related to the body's temperature.

Recognizing that (by definition) it requires 1 calorie of absorbed heat energy to raise 1 gram or $1 \mathrm{~cm}^{3}$ of water $1^{\circ} \mathrm{C}$, and assuming that human flesh is essentially composed of water, $1 \mathrm{~cm}^{3}$ of flesh will increase $1^{\circ} \mathrm{C}$ in temperature for each calorie received. A Jain, by definition, 1 calorie equals 4.1868 joules, and 1 joule is the equivalent of 1 electrical watt-second. In symbolic form:

$$
J=P t=\int_{t 1}^{t 2} R^{2} R d t=\left(\frac{1}{4.1868}\right) \text { calories }
$$

Where: $J=$ Joules

$$
\begin{aligned}
& P=\text { Watts } \\
& t=\text { Time } \\
& I=\text { Current } \\
& R=\text { Resistance }
\end{aligned}
$$

To approximate the temperature variation in flesh with time, it is necessary to have an idea of the energy source's discharge current into the absorber as a function of absorption time. The current may be approximated (if it is assumed that the electrical resistance of flesh is a constant expressed in ohms) by employing the electrical circuit shown in Figure 1. 


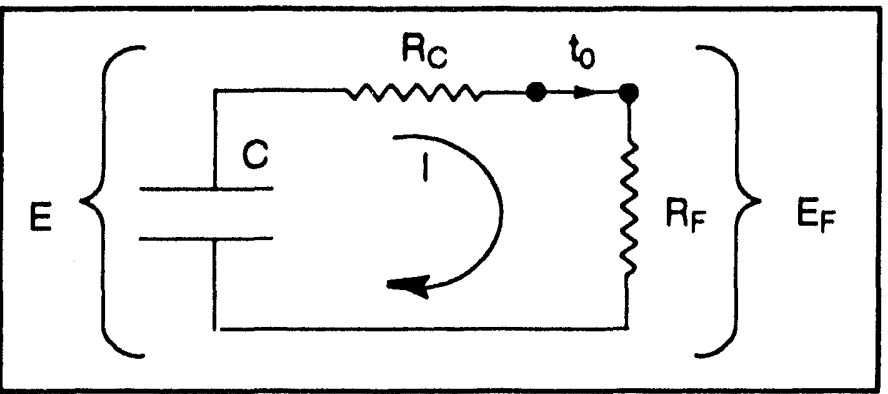
Where: $E$ = Electric Potential
$C=$ Energy Storage Capacitance
1 = Electrical Current
$R_{c}=$ Internal Resistance of Storage Device
$R_{F}=$ Resistance of Flesh
$E_{F}=$ Initial Voltage Applied to the Flesh

Figure 1. Equivalent Electrical Circuit for Electrical Energy Absorption by Flesh

Solving the Figure 1 differential equation for the current flow as a function of time, the following equation is obtained:

$$
I\left(F_{C}\right)=\frac{E}{R_{C}+R_{F}}\left(e-\frac{t}{\left(R_{C}+R_{F}\right) C}\right)
$$

Employing equation 2 in equation 1, and evaluating the integral portion of equation 1 over the interval $t_{0} \rightarrow t_{x} \cdot\left(t_{0}=\right.$ time zero $)$ :

$$
\left.\int_{t_{0}}^{t_{x}} R_{F}\right|^{2} d t=\frac{C E^{2}}{2}\left(\frac{R_{F}}{R_{C}+R_{F}}\right)\left(1-e^{\frac{2 t_{x}}{\left(R_{C}+R_{F}\right) C}}\right)
$$

Now:

$$
E_{F}=\frac{R_{F}}{R_{C}+R_{F}}
$$

And:

$$
\left.\int_{t_{0}}^{t_{x}} R_{F}\right|^{2} d t=1 / 2 C E^{2}\left(\frac{E_{F}}{E}\right)\left(1-e^{\frac{-2 t_{X}}{\left(R_{C}+R_{F}\right) C}}\right)
$$

Now, if the energy is delivered to $1 \mathrm{~cm}^{3}$ of flesh, the temperature rise $\left(\Delta \mathrm{C}^{\circ}=\right.$ temperature change) will be:

$$
\underset{4.186}{\Delta C^{\circ}}=\left(1 / 2 C E^{2}\right)\left[\frac{E_{F}}{E}\left(1-e^{\frac{-2 t_{x}}{\left(R_{C}+R_{F}\right) C}}\right)\right]
$$


To obtain temperature in degrees Fahrenheit:

$$
\frac{\Delta F^{\circ}}{\Delta C^{\circ}}=1.8
$$

Equations 6 and 7 provide a (relative) value of temperature rise under the defined conditions based on absorption into $1 \mathrm{~cm}^{3}$ (i.e., normalize to $1 \mathrm{~cm}^{3}$ ). If the volume should be other than $1 \mathrm{~cm}^{3}$, it is recognized that the temperature rise will vary inversely with the volume change:

$$
C^{\circ} @ \text { different volume }=\frac{\left(C^{\circ} @ 1 c c\right)}{(\text { new volume })}
$$

Based on this data, the temperature at a point of electrical contact with flesh can be extremely high. A charred condition would be noticeable at this point.

\section{EXPERIMENT}

\section{FLESH RESISTANCE}

In the context of this analysis, flesh is considered to consist of skin, muscle and fat. The skin is normally the first part of the flesh to make contact with an electrical energy storage system. To gain some knowledge of typical skin electrical resistance, 20 individuals were measured. Using a Fluke* Model $8020 \mathrm{~A}$ digital multimeter, skin resistance was found to vary over a range of 13 megohms to $180 \mathrm{kilohms,} \mathrm{(at} \mathrm{a} \mathrm{temperature} \mathrm{of} 75 \pm 5^{\circ} \mathrm{F}$ and relative humidity of $55 \pm$ $5 \%$ ) with a mean of 4.2 megohms. In this case, the mean has little value, as the individuals most likely to receive the worst injury are those in the 180-kilohm range; they would absorb energy at the highest rate.

The measurements were made at a spacing of approximately $1 \mathrm{~cm}$, employing the meter test leads gripped by the thumb and first finger. An additional set of measurements were made between the fingertips on the left hand and right hand. A high of 27 megohms, a low of 600 kilohms, and a mean of 5.5 megohms were obtained, not a real significant difference. For these series of measurements, the Fluke multimeter contained a 9-volt power source.

The next concern was the dependence of the skin resistance on applied voltage. Since caution has to be exercised when using higher voltages with human subjects, a substitute was employed. A fresh (never been frozen) chicken leg was obtained. Measurements made on the Fluke multimeter with the chicken skin indicated a resistance of 1 megohm, whish fell in the range of measurements performed with human subjects. The voltage level was raised to 35 volts $d c$, and the initial current flow was measured. The resistance results are given in Table 1.

\footnotetext{
*Trademark, John Fluke Mfg. Co. Inc.
} 
Table 1. Skin Resistance of Chicken Leg at 35 Volts Applied

\begin{tabular}{lll}
\hline Skin & Muscle & Fat \\
\hline $35 \mathrm{~mA}$ & $111 \mathrm{~mA}$ & $11 \mathrm{~mA}$ \\
1000 ohms & 315 ohms & 3150 ohms \\
\hline
\end{tabular}

The resistance dropped by at least three orders of magnitude, a highly significant amount, especially if these surrents are ervisioned as potentlally passing through the heart.

To determine the time effect, voltages were applied for up to 5 minutes. In each case, the resistance increased with time. The flesh in the vicinity of the electrode gradually took on a cooked appearance which spread through the flesh with time. At the test electrodes (essentially point contacts), the flesh bubbled and emitted steam.

When the above experiments were performed with a DLC at a voltage of 33 volts, equivalent results were obtained.

The cooking observed is not surprising if equation 9 is applied to the DLC situation. The equation indicates that if no heat conduction away from the contact site occurs, $1 \mathrm{~cm}$ of flesh (skin, muscle, or fat) would be raised to $615^{\circ} \mathrm{F}$ above body temperature. This temperature is unlikely, as the water in the flesh would turn to steam at $212^{\circ} \mathrm{F}$ and produce bubbles or vent as steam, limiting the temperature to approximately this level.

\section{DOUBLE LAYER CAPACITOR OPERATIONS}

The DLCs of this work are carbon/sulfuric acid based units. The case is tantalum metal which tolerates the acid well and gives a rugged, sealed unit suitable for high reliability military or space applications. The units header has a glass to metal seal around the lead. The cathode is connected to the tantalum case. The case has a welded seam to assure a completely sealed unit.

The device is essentialy non-polar. The DLCs are rated at 11 volt maximum working voltage and 0.47 farad capacitance. These units were designed to have low equivalent series resistance (ESR) values less than 2 ohms. The ESR is very temperature dependent and decreases as the temperature increases.

Assemblies consisting of three DLCs wired in series are made in the plant. The DLCs are secured in a dense polyurethane base to assure electrical isolation from each other. The subassembly is overpotted with lower density polyurethane and is encased in an aluminum case. The assemblies are rated at 34 volts and have nominal capacitance of 0.10 farads at room temperature.

Capacitors can be dangerous eiactrical shock devices and the comparatively high capacitance values associated with the DLCs was a cause for concern. In particular the joule ratings of three fully charged series connected capacitors in an assembly was fairly high at 96.33 joules. We consider charged capacitors rated at higher than 50 joules potentially dangerous and, therefore, require a injuring risk study before use. 
The guidelines and rules applicable to the elctrical shock evaluations are based on the fact that shock intensity is directly proportional to the amount of current forced through the body. Direct currents over $50 \mathrm{~mA}$ produce painful to severe shock. Investlgators have reported that alternating currents around 100 to $200 \mathrm{~mA}$, or direct currents around $500 \mathrm{~mA}$ can be lethal. The lethallity is assoclated with ventricular fibrillation of the heart. Some work indicates that the DC current takes time to produce the effect, approximately three seconds. Greater than approximately $800 \mathrm{~mA}$ shocks cause muscular contractions so severe that the heart clamps during the shock. Although severe burns, loss of consciousness, stoppage of breathing occurs, the incident is not fatal if resuscitation is quickly accomplished.

Voltage is required to force current through the body. The magnitude of the current depends on the magnitude of the voltage and the resistance of the body, $I=V / R$. Body resistance is highly variable. Literature values of resistance reported vary iiom one kilo-Ohm to 500 Kilo-Ohms. The lowest recorded dealth by electrocution is 42 volts DC Implying a resistance of 400 Ohms. The current must penetrate the skin to affect the heart. We are using a standard model for body resistance under wet conditions of $500 \mathrm{Ohms}$ for each arm and leg and 100 ohms for the trunk [1]. Thus hand to hand resistance is 1000 ohms.

The voltage of a single DI.C in tinis study is 11 volts, 19 maximum under overcharging, and the joules rating is 30.25 joules; calculated as $1 / 2 V^{2} C$ where $V$ is the DLC rated voltage and $C$ is the DLC capacitance. The voitage value is too low to cause concern. If wet hands establish a current path from DLC positive lead to negative lead, across the chest and heart, then using $1000 \mathrm{Ohm}$ body resistance, the current is $11 \mathrm{~mA}(1=11 \mathrm{~V} / 10 \mathrm{cr}$. Ohms). This current is below the painful shock level and well below the lethal current level.

The three DLC assembly is still at low voltage (34 volts) although the joule rating is substantial at 96.33 joules. However, if wet hands are brought in contact across the charged three capacitors then the current is $34 \mathrm{~mA}$. This value is also below the painful shock level and no loss of muscular control is experienced. Therefore one will react to release the assembly immediately as the shock is experienced. However the individual should experience a mild shock. Three series connected DLCs having exposed connector pins or wires should only be charged and discharged when in an electrically protected interlocked test condition.

During development it was an occasional practice to discharge the DLC pack with a 10-ohm resistor held between the first finger and thumb. The 10-ohm resistor is inserted into the DLC pack connector to cause a discharge. The discharge time constant in this case would be approximately 1 minute, provided the resistor remains connected. If the applying operator were to remain in contact with the resistor leads for the 1 minute discharge time, the energy dissipated in the skin would raise $1 \mathrm{~cm}^{3}$, approximately $6^{\circ} \mathrm{F}$ above body temperature. If a break occurred in the skin, the muscle beneath would be raised $18.45^{\circ} \mathrm{F}$ above body temperature. In actuality, these temperatures would be higher, as the energy would be concentrated at the point where the resistor leads make contact; therefore, an injury risk does exist. However, the operator is not expected to hold on to the leads, while they are heating up, and the current is below the let-go limit so that thi. consideration has a negligible probability of occurring. 


\section{CONCLUSIONS AND RECOMMENDATIONS}

Since one cannot predict with certainty that an injury would not occur, the following recommendations are made:

- Review/revise the safety policy for low voltage electrical power sources.

- Design/fabricate a DLC safety discharge load (UA6114) and provide procedures for minimized risk usage. (This design has been completed; see Appendix A.)

- A DLC safety discharge load device was constructed and its use during assembly construction is required to assure assembly discharge. The device senses the presence of a charge (LED indicator); determines the voltage on the part, if desired, using an accompanying voltmeter; gives an indication of discharge state when achieved (LEDs) and performs the act of discharging the part at the same time.

- Wear protective gloves or use other means to prevent direct contact with the DLC electrodes where practicable at engineering discretion. The subassembly is carried in a construction fixture which eliminates the need for an operator to come in contact with DLCs or wiring during processing.

- Shorting caps have been designed and are used on the finished assemblies to assure that they are stored and maintained in a shorted condition.

- Set up a safety demonstration for personnel who come in contact with the DLC, employing the experimental procedure described in this report. While video taping is a possibility, it is not as dramatic as the vision of cooked flesh in one's presence.

- Assembly workers are required to take CPR courses and to keep their certificates current. In addition a plant video tape course on capactors must be reviewed annually.

\section{REFERENCES}

1. U. S. Department of Energy Electrical Safety Manual (Draft), May 1991.

\section{ACKNOWLEDGMENTS}

Special appreciation is due to John Miller, JME Inc, for help and information on the DLCs. 


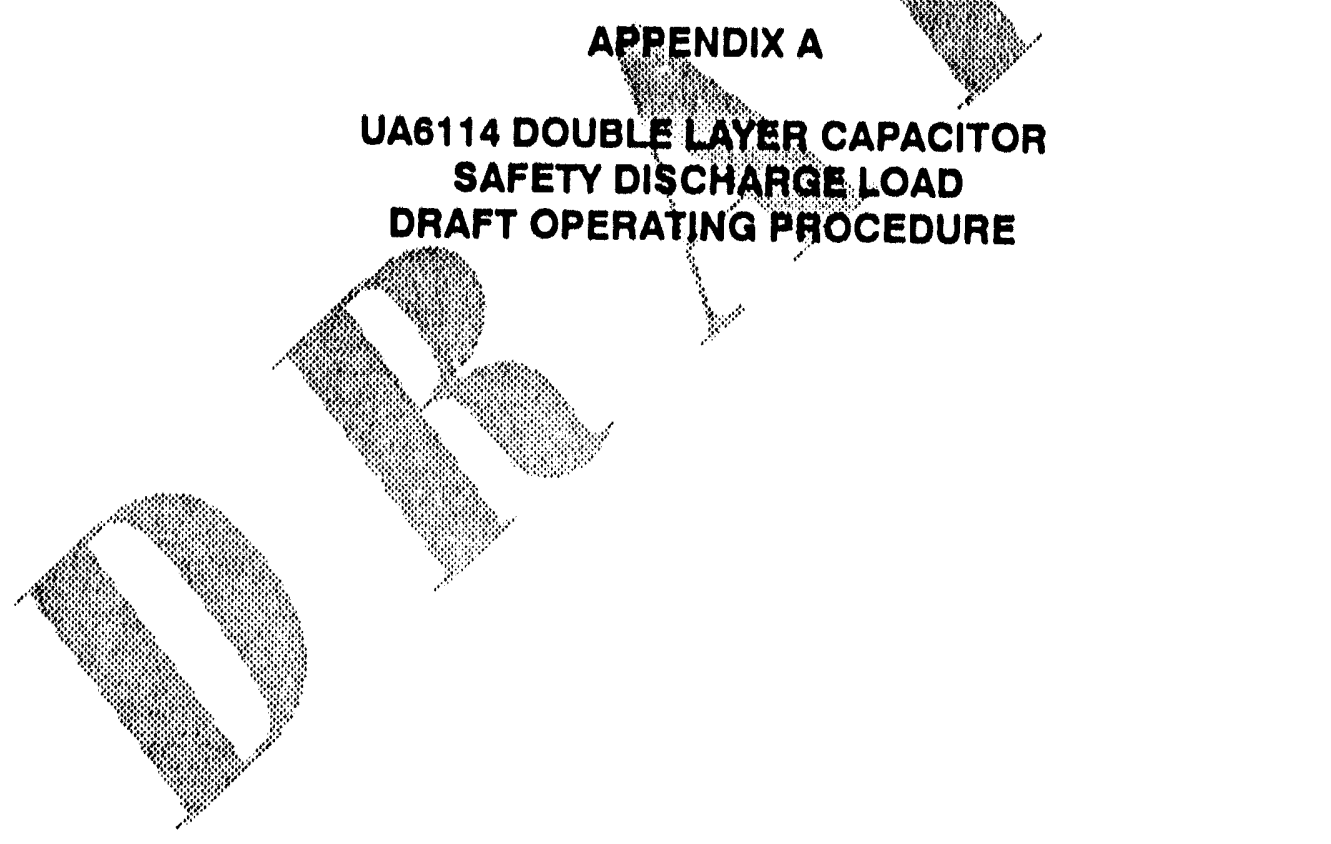


TITLE: OPERATING PROCEDURE, UAB114 DLC SAFETY DISCHARGE LOAD

TABLE OF CONTENTS

Section

Page

WARNING

$A-2$

1.0 GENERAL

1.1 Part Discharged/Tested

1.2 Safety Discharge Load Identílication

1.3 Safety Discharge Load Characteristics

2.0 DOCUMENTS AND EQUIPMENT

2.1 Required Documents

2.2 Relerence Documents

2.3 Required Equipment

2.4 Required Facillites

3.0 PROCEDURES

3.1 Preliminary procedures
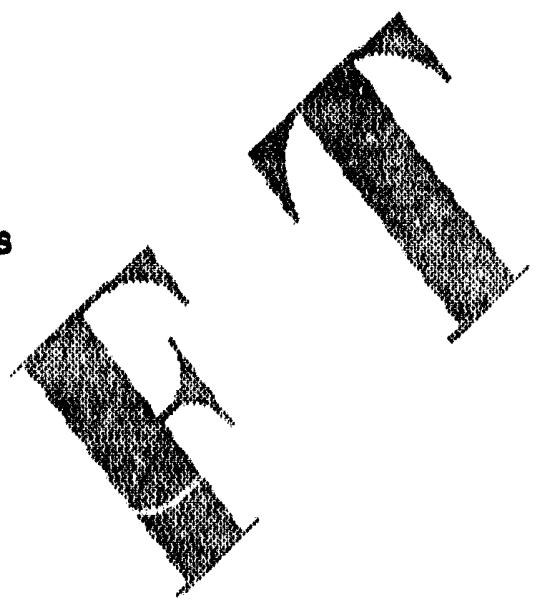

A-2

A-2

A-2

A-2

A-2

A-2

A-2

$A-3$

A-4

A-4

A-4

3.2 Part Mating

A-4

3.3 Test Operation

A-4

3.4 Equipment Storage

A-5 


\section{WARNINQ - ELECTRICAL SHOCK}

The UA6114 discharges MC4169 and MC4224 DLC assembly packs, subassemblies, and three gang DLC test setup fixtures while also ensuring simultaneous evaluation of the state of charge of these devices. The devices to be discharged have up to three series-connected DLCs in them and, If charged, are capable of giving mild electrical shocks and/or burns to individuals prior to the act of being discharged.

1.0 GENERAL

\subsection{Part Discharged/Tested}

MC4169 DLC Assembly or subassembly

MC4224 DLC Assembly or subassembly

DLC Three Gang Fixture

1.2 Safety Discharge Load Identiflcation UA6114

\subsection{Safoty Dlscharge Load Characteristics}

a. Senses the presence of Charge (LED indleator)

b. Determines the voltage din if part if desired (accompanying voltmeter)

c. Gives an indication of discharged otate when achieved (LEDS)

d. Performs act of discharging the parts

\subsection{DOCUMENTS AND EQUIPMENT}

\subsection{Required Document}

Drawing No. UA6114, DLC Safety Discharge Load (Attachment 1)

\subsection{Reterence Documents}

Environmental Health and Safety (EH\&S) Memorandum on Applicability of EH\&\& Standard Nos. 2.1 and 2.2

4. Boulbik and C. G. Wagner, "Double Layer Capacitor Power Source Injury Potentlal Analysis," GE Neutron Devices Environment, Health and Satety Report, GEPP-EV-1261, Unpublished

\subsection{Required Equlpment}
a. UA6114
b. Part to be discharged/evaluated
c. Optional voltmeter with BNC connection cable
d. Optional power supply with 10-volt capacity 


\subsection{Required Facilitios}

Power source appropriate for power supply and voltmeter if used

\subsection{PROCEDURES}

\subsection{Prollminary Procedures}

a. UA6114 Calibration Verification

Prior to operating the discharge/tester (UA4116), verify that callbration interval as shown on UAG114 calibration sticker has not expired.

b. Optional UA6114 Operation Verification

Prior to operating the UA6114 to discharge and Wrify the discharge of a pack, subassembly, or test setup, one can verify that the device is working as follows: Attach pin B on the UA6114 donnector to either the positive or negative post of the power supply and attach pin $D$ to the opposite charged post of the power supply. Set the bower supply to approximately 10 volts and verify that the appropriate light on the WA6114 is lit. One LED lights if $B$ is positive and $D$ is negatlve; the other twB $B$ ights if $B$ is negative and $D$ is positive. Quickly turn the power supply off and verity that the light on the UA6114 goes out. The Woltages can be followed by attaching a voltmeter to the BNC connector on th. UAB 114. Both lights should be tested to verify that both are working. This verffeatlon should be performed quickly to avold heating up the resistprs in the UA6114.

c. Optional Voltage Meter Use with UA6114

A voltmeter, or multimeter, may be attached to the UA6114 using the BNC connector on the UA6114. The meter will then follow the voltage of the object beling discharged.

\section{2 . Part Mating}

The llye-pin connector (SA-11909-4) on the UA6114 connects directly to the mating connector (SA-1185-4) on the unit under test. Note: The making of thls connection automatically discharges the unit under test.

\subsection{Test Operation}

a. Connect the UA6114 to the object under test.

b. The UA4166 automatically and immedlately discharges the object under test.

c. If the object under test had voltage present when the connection was made, then one of the two LEDs on the UA6114 will light up as the connection is made. If neither LED lights up, then no voltage exist on the device under test. Which LED lights depends on which pin in the connector was positive, l.e., pin $B$ or pin $D$. The LEDs are marked as $+B /-D$ or $-B /+D$. 
d. Maintain the connection until the light dims and slowly goes out as the voltage on the object under test decreases to near zero. This should happen within several seconds. Voltage status of the object under test can be confirmed with a voltmeter.

e. Disconnect the UA4114 from the object under test.

\subsection{Equipment Strorage}

a. Simple disconnection of the UA6114 is the equivalent of turning it off.

b. Store in or on a clean dry drawer or shelf.
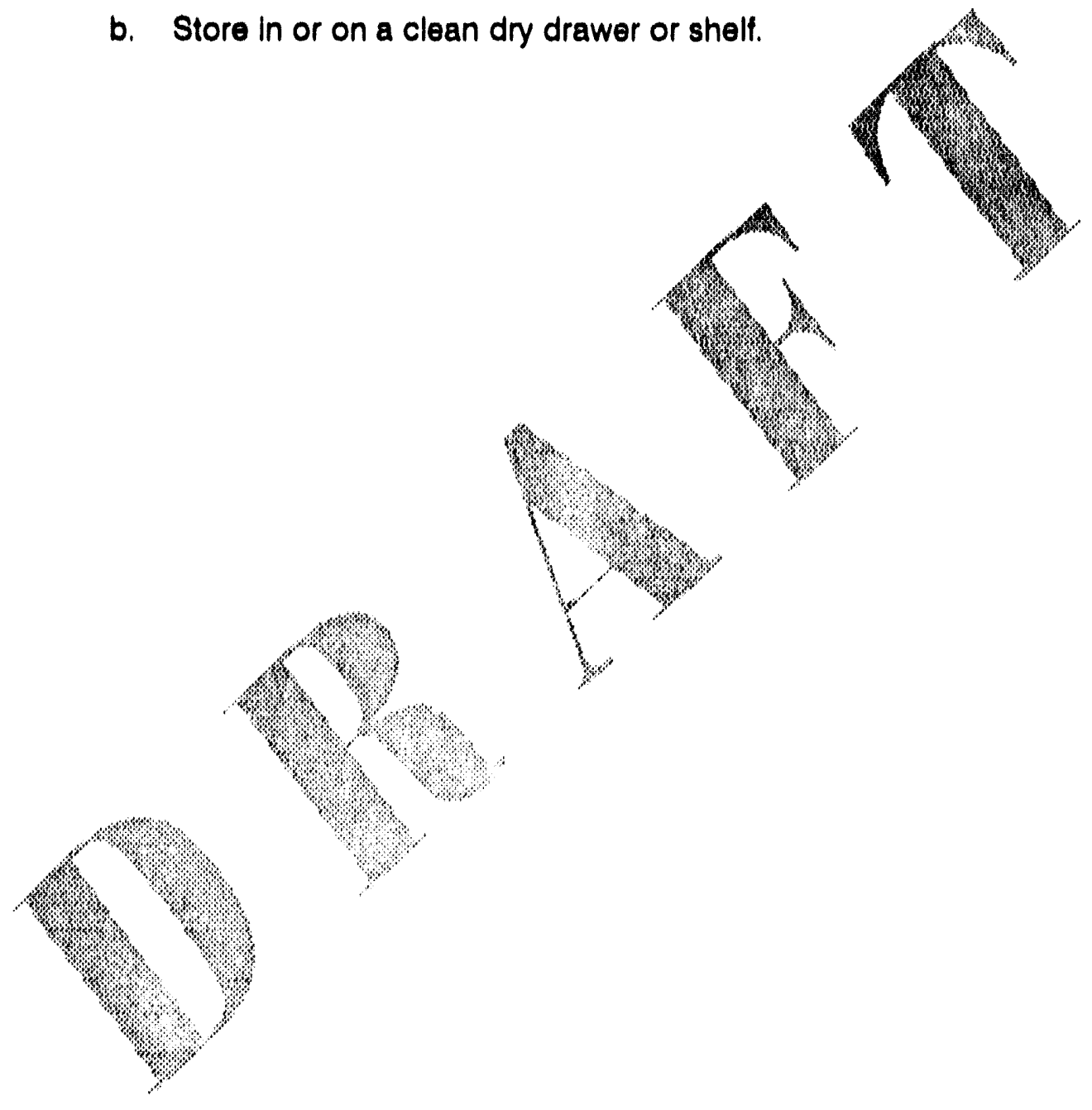
Attachment 1

Drawing No. UA6114, DLC Safety Discharge Load

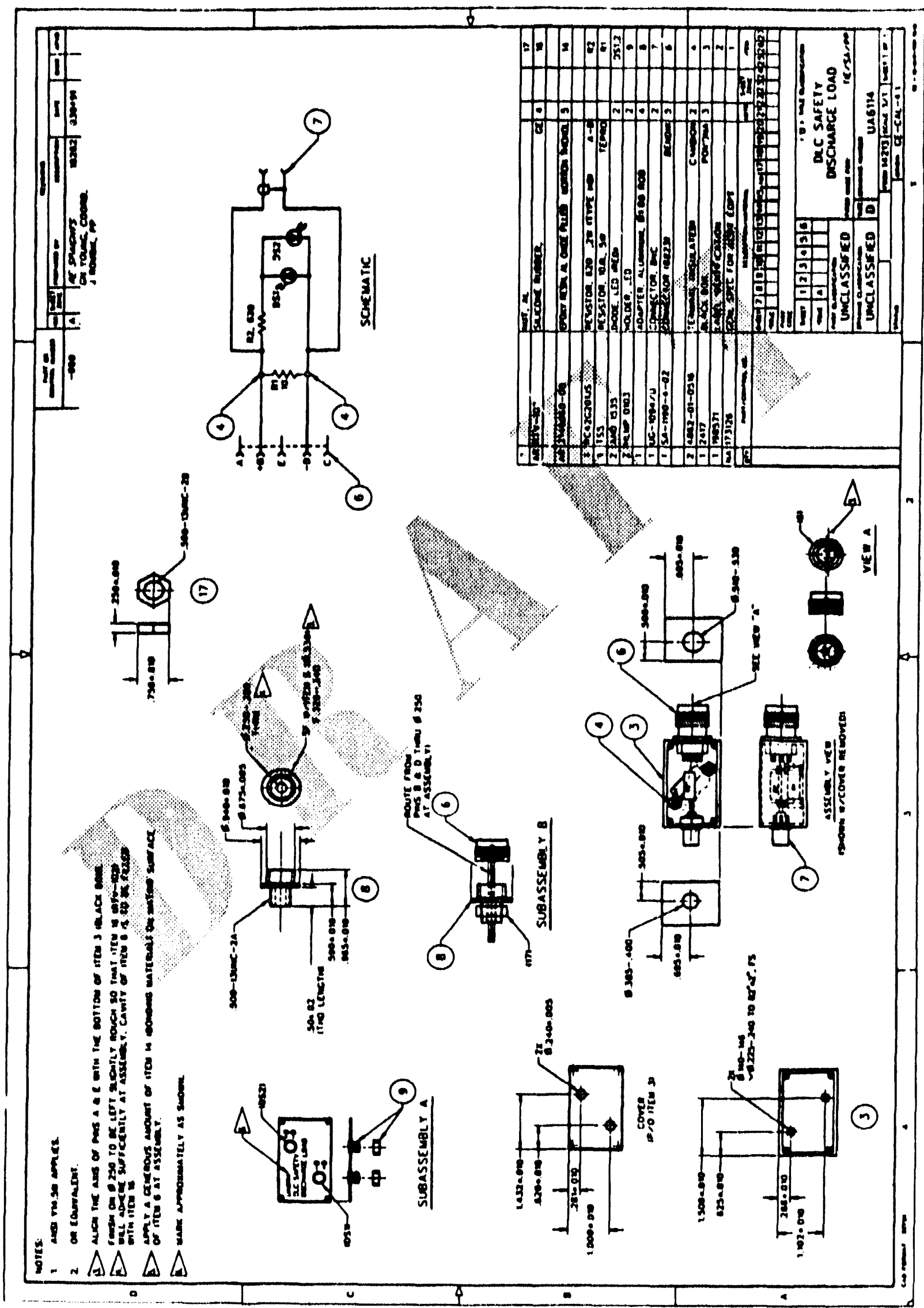


DOE

R. E. Glass, PAO

OSTI, Oak Ridge/AD-21 (2)

MMSC

B. J. Haeger 017

J. A. Judy 016

W. J. McCracken 016

N. E. Miller 016

J. C. Roubik 023

C. G. Wagner 016

Technical Information Center

Technical Support (Master)

SNL-Albuquerque

N. Clark (3) 2525 


\section{APPENDIX E}

Reliability Study 
Sandia National Laboratories

dale: March 20, 1990

Albuquerque. New Mexico 87185

10: N. H. Clark, 2526

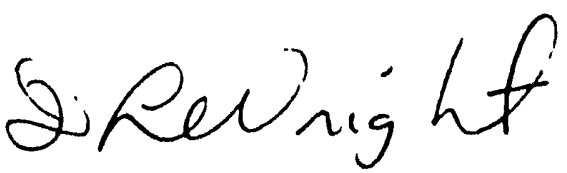

subject: MC4169 Double-Layer Capacitor (DLC) Assembly Testing

This memo is in response to your request to review the proposed testing for the MC4169 to be used in the B61 Common JTA. The MC4169 is an assembly of three DLC's functionally in series which provide initial power to the telemetry system until the thermal battery rises to voltage. The DLC's are commercial components purchased as six-digit parts. I have reviewed the current issues of the PS's for the MC4169 Assembly and the DLC with respect to test data that should be available for assessing the reliability of the MC4169. I have also reviewed ST389621 which describes the planned long-term surveillance program for both the MC4169 Assembly and the DLC. I estimate that at the end of production there will be approximately 125 MC4169 units that will have been selected for environmental sample testing or for long-term surveillance. Assuming zero failures, these units will support an assessment equal to the 0.995 reliability goal for the MC4169.

In addition to the MC4169 testing, there will be both environmental acceptance and surveillance testing of individual DLC's. It is not clear at this time whether the individual DLC testing can be combined with that of the MC4169 for assessing individual DLC reliability because of concerns about different environmental effects between the two types of testing. It is my hope that as we gain experience with the DLC's, we will be able to rely on the DLC level testing to predict the MC4169 capability. This could allow a reduction in testing required at the MC4169 level. While this is similar to the approach used with LAMB power supplies, it is not as critical because the MC4169 and DLC testing are not considered degrading.

Copy to:

2526 P. C. Butler

7222 G. C. Novotny 


\section{DISTRIBUTION:}

7 Martin Marietta Specialty Components

Attn: B. Hagger

R. Walton

N. Miller

L. Benson

L. Demo

W. McCracken

C. Wagner

PO Box 2908

Largo, FL 34294

1 D. Evans

33 Eastern Ave.

PO Box 4158

East Providence, RI 02914

$12504 \quad$ R. P. Clark

$12522 \quad$ K. R. Grothaus

$12523 \quad$ D. H. Doughty

$12525 \quad$ P. C. Butler

12525 W. E. Baca

$30 \quad 2525 \quad$ N. H. Clark

15111 A. L. Hillhouse

$\begin{array}{lll}1 & 8451 & \text { R. E. White }\end{array}$

18451 T. F. Eklund

1 8523-2 Central Technical Files

57141 Technical Library

1 715! Technical Publications

10 7613-2 Document Processing for DOE/OSTI

1 Dr. John Miller

JME, Inc.

17800 Oakland Dr.

Shaker Heights, OH 44122 


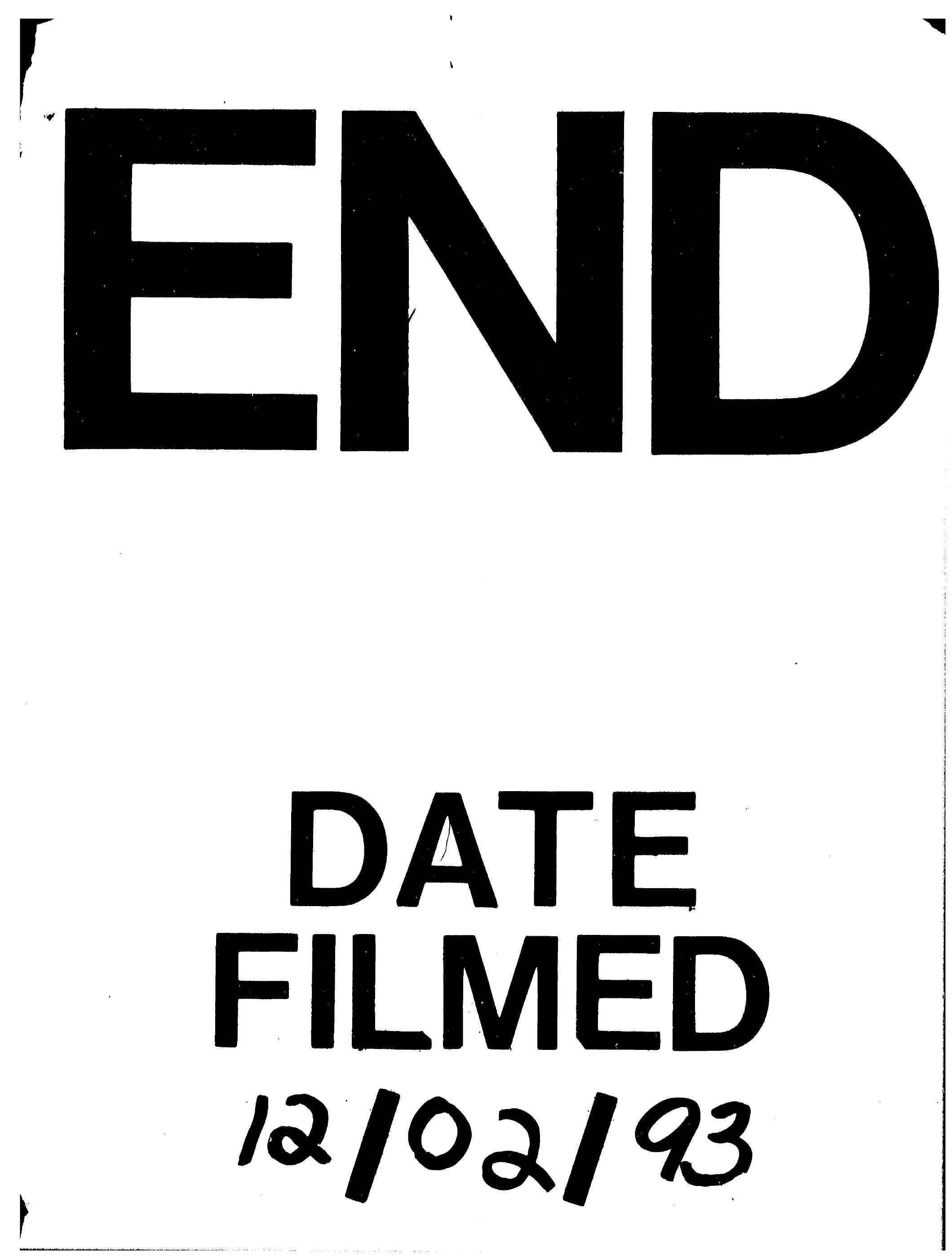


